\title{
Revista Saúde (Santa Maria)
}

Centro de Ciências da Saúde

Universidade Federal de Santa Maria

ISSN 2236-5834

Revista Saúde (Santa Maria), v. 37, n.2, p. 01 - 106, jun./dez.2011 


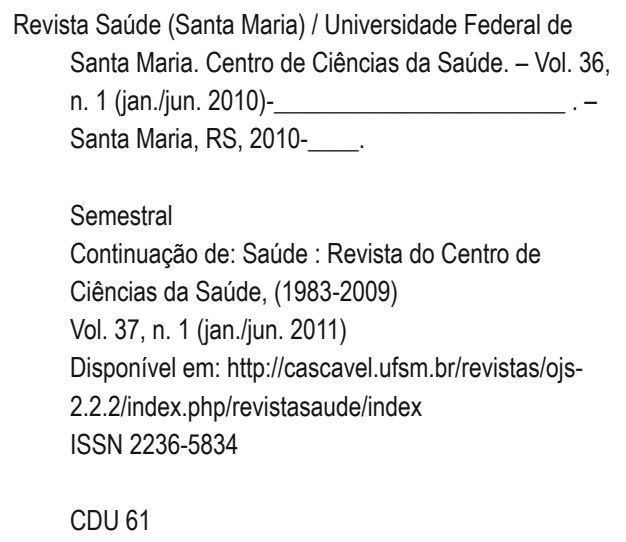

Ficha catalográfica elaborada por

Alenir Inácio Goularte CRB-10/990

Biblioteca Central da UFSM

\section{Indexadores}

Latindex - Sistema Regional de Información en Línea para Revistas Científicas de América Latina, el Caribe, España y Portugal (México), site: http://www.latindex.unam.mx

\section{Banco de Dados}

Sumários.org (Sumários de Revistas Brasileiras), site: http//www.sumarios.org

Disponível no Portal CAPES http://novo.periodicos.capes.gov.br

\section{Universidade Federal de Santa Maria}

Av Roraima, 1000, Prédio 26, sala 1205/ 1201. Departamento de Análises Clínicas e Toxicológicas. Centro de Ciências da Saúde. Cidade Universitária, Bairro Camobi. Santa Maria - RS. CEP. 97105-900 Tel: (55) 32208751 / 8464

Email: revistasaude.ufsm@gmail.com

Site: http://www.ufsm.br/revistasaude 
Presidente da República — Dilma Rousseff

Ministro da Educação - Fernando Haddad

Reitor da Universidade Federal de Santa Maria - Felipe Martins Müller

Diretora do Centro de Ciências da Saúde-Paulo Afonso Burmann

Editora- Rosmari Horner

Núcleo Editorial

Antonio Marcos Vargas da Silva

Universidade Federal de Santa Maria, Santa Maria, Rio Grande do Sul, Brasil

Jadir Lemos

Universidade Federal de Santa Maria, Santa Maria, Rio Grande do Sul, Brasil

Renato Borges Fagundes

Universidade Federal de Santa Maria, Santa Maria, Rio Grande do Sul, Brasil

Rosmari Horner

Universidade Federal de Santa Maria, Santa Maria, Rio Grande do Sul, Brasil

\section{Conselho Editorial Científico}

Alexandre Meneguello Fuentefria — Universidade Federal do Rio Grande do Sul, Porto Alegre, Brasil

Carlos Heitor Cunha Moreira - Universidade Federal de Santa Maria, Santa Maria, Rio Grande do Sul, Brasil

Carolina Lisboa Mezzomo — Universidade Federal de Santa Maria, Santa Maria, Rio Grande do Sul, Brasil

Cristiane Cademartori Danesi - Universidade Federal de Santa Maria, Santa Maria, Rio Grande do Sul, Brasil

Diogo André Pilger — Universidade Federal do Rio Grande do Sul, Porto Alegre, Brasil

Dorival Terra Martini — Universidade Federal de Santa Maria, Santa Maria, Rio Grande do Sul, Brasil

Gilmor Jose Farenzena — Universidade Federal de Santa Maria, Santa Maria, Rio Grande do Sul, Brasil

Itamar dos Santos Riesgo — Universidade Federal de Santa Maria, Santa Maria, Rio Grande do Sul, Brasil

Lissandra Dal Dal Lago — Institut Jules Bordet, Bélgica

Marcia Keske-Soares — Universidade Federal de Santa Maria, Santa Maria, Rio Grande do Sul, Brasil

Melânia Palermo Manfron — Universidade Federal de Santa Maria, Santa Maria, Rio Grande do Sul, Brasil

Miriam Cabrera Corvelo Delboni - Universidade Federal de Santa Maria, Santa Maria, Rio Grande do Sul, Brasil

Renato Borges Fagundes - Universidade Federal de Santa Maria, Santa Maria, Rio Grande do Sul, Brasil Roselei Fachinetto - Universidade Federal de Santa Maria, Santa Maria, Rio Grande do Sul, Brasil

Rosmari Horner — Universidade Federal de Santa Maria, Santa Maria, Rio Grande do Sul, Brasil

Sadja Cristina Tassinari de Souza Mostarde - Universidade Federal de Santa Maria, Santa Maria, Rio Grande do Sul, Brasil

Sérgio de Vasconcellos Baldisserotto - Universidade Federal de Santa Maria, Santa Maria, Rio Grande do Sul, Brasil

Tânia Denise Resener — Universidade Federal de Santa Maria, Santa Maria, Rio Grande do Sul, Brasil 


\section{Equipe de editoração eletrônica}

Cláudia Sitó Alves - Universidade Federal de Santa Maria, Santa Maria, Rio Grande do Sul, Brasil

Mara Eliana Graeff Dickel — Universidade Federal de Santa Maria, Santa Maria, Rio Grande do Sul, Brasil 
SUMÁRIO

EDITORIAL

SÍNDROME DE STURGE-WEBER

Nelson Barbosa Franco Neto, Fernanda Paula Franchini, Vilson Gentil Foletto Júnior, Valdeci Juarez Pomblum

INIBIDORES DA BOMBA DE PRÓTONS: REVISÃO E ANÁLISE FARMACOECONÔMICA

Muriele Picoli Braga, Cristiane de Bona da Silva, Andréa Inês Horn Adams

ESTRESSE OCUPACIONAL EM TRABALHADORES BANCÁRIOS: PREVALÊNCIA E FATORES ASSOCIADOS

Ione Teresa Altermann Pozeczek Koltermann, Elaine Tomasi, Bernardo Lessa Horta, Annie Pozeczek Koltermann.

FREQUÊNCIA DO SISTEMA RH E KELL NOS DOADORES DO HEMOCENTRO DE SANTA MARIA RS

José Edson Paz da Silva, Adriana Najai Bortolotto, Márcia M.Mikalauscas, Anelise Mulari, Samara Rubin

PHYSICO-CHEMICAL QUALITY CONTROL AND DOSAGE OF TOTAL POLYPHENOLS, FLAVONOIDS OF MORUS ALBA LEAVES (MORACEAE)

Camila B. Pereira, Aline Marin, Tiago D. T. Maki, Raquel M. M.Necchi, Melânia Palermo Manfron

ANTICORPOS DE REAÇÃO CRUZADA DURANTE INFECÇÃO AGUDA POR T. GONDII

Alison Menna Fontoura, Sandra Trevisan Beck

PARASITOS GASTROINTESTINAIS E SANGUÍNEOS EM CÃES. RISCO PARA ADOÇÃO?

Mario Luiz de la Rue, Ariéli de Andrade, Lilian Varini Ceolin, Carina de Castro Gabriel, Lis Schons Garrot, Vanessa Correa da Silva, Fernanda Flores Vogel, Luis Antônio Sangioni

PREVALÊNCIA DE CANDIDA E CRYPTOCOCCUS EM HEMOCULTURAS ORIUNDAS DE PACIENTES DO HOSPITAL UNIVERSITÁRIO DE SANTA MARIA, RS (HUSM) NO ANO 2006.

Danieli Urach Monteiro, Thiele Faccim de Brum, Charlise Bolson Noal, Roselene Alves Righi, Edileusa Rosa dos Santos, Loiva Therezinha Ottonelli de Oliveira, Mário Luiz de La Rue

81

AS CONCEPÇÕES DOS ENFERMEIROS/DOCENTES FRENTE À ATUAÇÃO DA ENFERMAGEM NA TERAPIA COM CÉLULAS TRONCO

Danusa Begnini, Silvana Bastos Cogo Bisogno, Tamires Patrícia Souza 
ANÁLISE FITOQUíMICA PRELIMINAR DAS FOLHAS DE VITEX MEGAPOTAMICA (SPRENGEL) MOLDENKE

Thiele Faccim de Brum, Marina Zadra, Amanda Luana Forbrig Froeder, Aline Augusti Boligon, Janaína Kieling Frohlich, Margareth Linde Athayde 


\section{EDITORIAL}

É com satisfação que disponibilizamos aos nossos leitores e leitoras mais um número da Revista Saúde (Santa Maria) - 2/2011 (Vol. 37, No.2, jul./dez.2011), o qual está composto por dois artigos de revisão, sete artigos originais e uma nota prévia.

A qualidade dos dois volumes publicados no ano de 2011 devemos aos autores e autoras que contribuíram com a submissão de seus trabalhos com temas fundamentais na área da saúde. Contudo, também devemos agradecimentos especiais aos revisores ad hocs que ofereceram seu tempo e dedicação à análise e avaliação dos artigos encaminhados, efetuando um trabalho sério, bem como a Comissão Editorial Executiva e a Secretaria Executiva.

Não poderíamos deixar de agradecer à Direção do Centro de Ciências da Saúde, e a todos os membros que atuam na sua Secretaria, pelo incondicional apoio e sempre jovial acolhida, fazendo jus ao "juntos CCS".

Do envolvimento das mais variadas pessoas dependem as revistas acadêmicas para publicação e divulgação.

Gostaríamos mais uma vez de lembrar que o Centro Brasileiro do ISSN (CBISSN - ISSN = Número Internacional Normalizado para Publicações Seriadas - International Standard Serial Number), em resposta à nossa solicitação, atribuiu o ISSN 2236-5834 para a publicação online da Revista Saúde (Santa Maria).

Somando os esforços de todas essas pessoas, juntamente com o nosso, apresentamos o presente volume, com imensa satisfação e esperança, de que as leitoras e os leitores que acessarem nossa Revista Saúde (Santa Maria) se beneficiem com os conteúdos expostos, e que possam neles encontrar elementos que contribuam para sua formação nas Ciências da Saúde e na sua vida.

Desejamos uma ótima leitura.

Rosmari Hörner

Editora 


\title{
Síndrome de Sturge-Weber
}

\author{
Nelson Barbosa Franco Neto*, Fernanda Paula Franchini*, Vilson \\ Gentil Foletto Júnior**, Valdeci Juarez Pomblum**
}

RESUMO: A Síndrome de Sturge-Weber é uma doença rara, caracterizada por desordens cutâneas, neurológicas e oculares como conseqüência de malformações capilares faciais, angioma leptomeníngeo e anormalidades na vasculatura ocular. Dentre os achados clínicos mais comuns, evidencia-se proeminente mancha facial de cor semelhante ao vinho do Porto, convulsões e glaucoma. A Ressonância Nuclear Magnética é o padrão ouro na identificação de anormalidades estruturais encefálicas. $O$ tratamento foca as três principais manifestações da síndrome. $O$ laser corante pulsado permanece $o$ tratamento de escolha para a maioria das crianças com malformações capilares faciais. 0 tratamento padrão para o glaucoma tem sido a medicação continuada combinada com procedimentos cirúrgicos. $\mathrm{O}$ controle das convulsões é difícil e geralmente requer o uso de fármacos associados. Este trabalho objetiva expor aos clínicos as manifestações características e o tratamento desta Síndrome. Ainda são necessários esclarecimentos acerca da fisiopatologia da Síndrome, do estabelecimento de critérios diagnósticos e do tratamento.

Descritores: Síndrome de Sturge-Weber; Hemangioma; Glaucoma; Epilepsia.

\section{Sturge-Weber syndrome}

ABSTRACT: The Sturge-Weber syndrome is a rare disease, characterized by cutaneous, neurological and ocular disorders as a consequence of facial capillary malformations, leptomeningeal angiomatosis and ocular vasculature abnormalities. Amongst the most prevalent clinical findings are a prominent facial port-wine stain, glaucoma and seizures. The Magnetic Resonance Imaging has evolved as the gold standard for the identification of structural brain abnormalities. Treatment focuses on the three main manifestations of syndrome. Pulsed-dye laser remains the treatment of choice for most children with port-wine stains. The standard treatment for glaucoma has been the lifelong medical treatment in combination with surgical procedures. Seizure control is difficult and usually requires the administration of more than one drug. This work aims at to expose for clinicians the characteristic manifestations and treatment of this syndrome. Until the present, it is necessary lights concerning the physiopathology, the establishing diagnosis criteria and the treatment of the Syndrome.

Descriptors: Sturge-Weber Syndrome; Hemangioma; Glaucoma; Epilepsy.

*Acadêmicos do Curso de Graduação em Medicina da Universidade Federal de Santa Maria (UFSM), Santa Maria, RS, Brasil.

** Residente em Clínica Médica do Hospital Universitário de Santa Maria (HUSM), Santa Maria, RS, Brasil.

*** Professor Adjunto do Departamento de Clínica Médica da Universidade Federal de Santa Maria (UFSM), Santa Maria, Rio Grande do Sul, Brasil. 


\section{Introdução}

A Síndrome de Sturge-Weber (SSW) é uma síndrome congênita neurocutânea, esporádica, caracterizada por uma malformação capilar facial, um angioma leptomeníngeo ipsilateral e anormalidades na vasculatura ocular. Diferentemente de outras síndromes, a SSW não está associada a neoplasias intracranianas. Sua incidência é atualmente estimada em 1:50.000 nascidos vivos, apesar da identificação de formas intermediárias terem levado a um aumento dessa freqüência estimada ${ }^{1}$. Não há diferenças raciais ou de gênero. Casos familiares são raros - há apenas dois casos relatados na literatura². Nessa síndrome, uma extensa malformação capilar-venosa afeta um ou, ocasionalmente, os dois hemisférios cerebrais; pode estar associada com epilepsia intratável, progressivo retardo mental e eventualmente requerer extensos procedimentos neurocirúrgicos como lobectomia ou hemisferectomia1.

\section{Metodologia}

Realizou-se um estudo do tipo exploratório descritivo com busca no banco de dados da Biblioteca Virtual de saúde do National Institute of Health - PUBMED, no mês de setembro de 2010. Os termos utilizados foram "Sturge-Weber" e "Sturge-Weber Syndrome". A pesquisa foi realizada pelo método integrado obtendo-se 950 publicações, sendo 129 artigos de revisão. A seleção das produções científicas desenvolveu-se a partir da leitura dos títulos e dos resumos. Utilizaram-se como critérios de seleção: a inclusão de artigos, textos completos, idiomas em português, espanhol e inglês Foram excluídos os trabalhos sem resumo, que não foram encontrados disponíveis na íntegra ou não se referiam especificamente ao tema.

\section{Manifestações clínicas}

As características primárias para o diagnóstico de SSW são uma malformação vascular cutânea facial e um angioma leptomeníngeo presentes desde o nascimento. Os componentes clínicos da Síndrome podem ser divididos em malformações cutâneas, neurológicas e oculares, sendo a mais proeminente uma mancha facial, usualmente unilateral, de cor semelhante ao vinho-do-porto (MVP), ipsilateral às malformações vasculares cerebrais. Todavia, nem todas as crianças com MVP possuem SSW. Esta malformação cutânea está presente em cerca de $0,3 \%$ de todos os nascidos vivos, sendo a malformação congênita vascular mais comum. Dentre as crianças com tal característica, aproximadamente $8 \%$ são portadoras da Síndrome ${ }^{3}$. Pode haver formas incompletas da SSW, de modo que algumas crianças a possuem sem, no entanto, apresentar MVP ( $5 \%$ a $15 \%$ dos casos), malformação ocular ou outros sintomas neurológicos ${ }^{1}$. Desta forma há três subdivisões clínicas da síndrome: a SSW tipo I, quando há malformações vasculares faciais e endocranianas com a possibilidade de glaucoma (forma clássica); a SSW tipo II, quando há angioma facial sem, no entanto, evidência de envolvimento intracraniano; e a SSW tipo III, apenas com envolvimento leptomenínge ${ }^{4}$. 


\section{Manifestações cutâneas}

O portador da SSW, na grande maioria dos casos, apresenta um nevus angiomatoso congênito, geralmente observado na pálpebra superior e área supra-orbital, ipsilateral ao angioma leptomeníngeo. São manchas bem demarcadas e papulares que, microscopicamente, consistem em vasos sanguíneos hipertrofiados, sem evidência de hiperplasia, na derme e epiderme com progressivo espessamento e micro-nodulação múltipla, associados a cronicidade 6 . Poucas vezes, desenvolvem-se nódulos maiores que representam granulomas piogênicos ou tumores arteriovenosos acrais ${ }^{7}$. Geralmente as MVP não ultrapassam a linha média, entretanto, alguma extensão além deste limite pode ser observada ${ }^{3,5}$. As manchas sempre envolvem o território do primeiro ramo do nervo trigêmeo V1 - osso frontal, pálpebras ${ }^{3,5,8}$. Menos freqüentemente, também há envolvimento de V2 e V3, o que está associado a menor risco de malformações oculares e intracranianas ${ }^{5}$. Ainda, pode haver bilateralidade do nevus $(10 \%$ a $30 \%$ dos casos $2,3,5)$. Acima de $20 \%$ dos pacientes apresentam envolvimento de V1 sozinho; a inclusão de V2 ou V2 e V3 está entre 2\% a $23 \% 3,5,9$. O avanço da mancha para áreas maxilares e mandibulares está associado à hipertrofia de partes moles e crescimento excessivo das regiões ósseas subjacentes. Nesses casos é freqüente hiperplasia gengival e má erupção dos dentes ${ }^{10}$. A presença, ausência ou extensão da MVP não é proporcional à presença, grau e severidade dos sintomas neurológicos, nem é sua localização um indicador confiável da presença e topografia da lesão cerebral2,3,11.

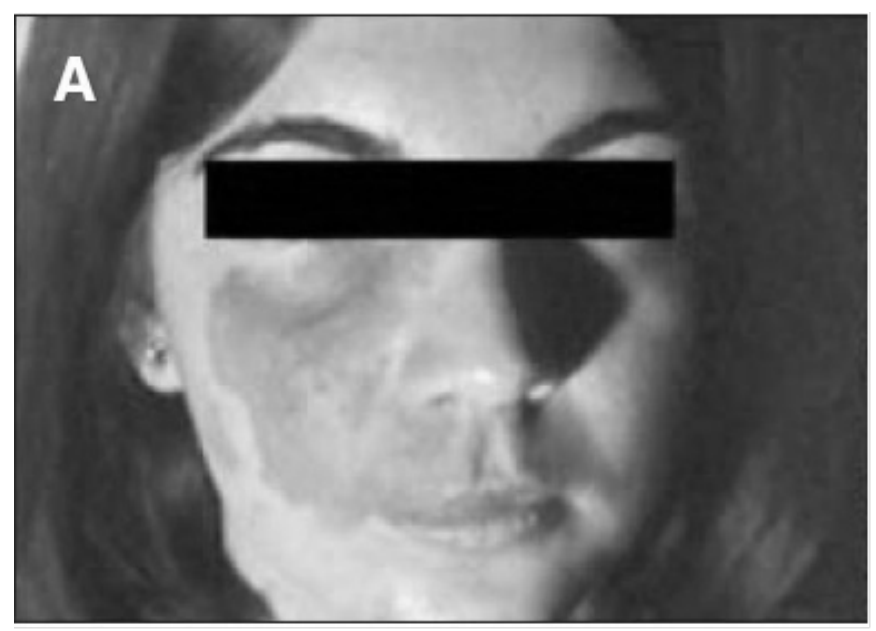

Figura 1 - Mancha de coloração vinhosa distribuída nos territórios V1 e V2. (extraído de Cronemberger et al33)

\section{Manifestações oculares}

Glaucoma é a manifestação oftalmológica mais comum na SSW, ocorrendo em $30 \%$ a $70 \%$ dos pacientes ${ }^{9,12}$. É usualmente ipsilateral a MVP. Todavia, também pode ser bilateral a despeito de uma mancha unilateral ${ }^{13}$. O glaucoma pode ocorrer tanto na infância $(60 \%)$ quanto no adulto-jovem $(40 \%)^{12}$, estando presente, em média, por volta dos cinco anos ${ }^{9}, 0$ que implica necessidade de vigilância contínua. $\mathrm{O}$ início precoce do glaucoma causa aumento dos diâmetros corneanos e miopia. $\mathrm{O}$ início tardio raramente conduzirá a tal desfecho ${ }^{12}$. A fisiopatologia do glaucoma ainda não está totalmente elucidada, embora dois mecanismos tenham sido propostos. O glaucoma infantil estaria associado a anormalidades no seio

Saúde (Santa Maria), v.37, n.2, p. 09-18, 2011. Franco Neto; Franchine; Foletto Júnior; ISSN 2236-5843 
camerular, o que aumentaria a resistência à saída do humor aquoso e, conseqüentemente, aumento da pressão intra-ocular. Em contraste, os pacientes, com início tardio do glaucoma, freqüentemente, possuem seio camerular normal ou com ligeiras anormalidades. Estes pacientes, entretanto, têm sinais clínicos de pressão venosa episcleral aumentada, causada por shunts arteriovenosos dentro do hemangioma episcleral levando a um possivel aumento da pressão intra-ocular ${ }^{14}$. A segunda manifestação mais comum é 0 angioma coroidal, o qual pode contribuir para a causa do glaucoma. O hemangioma é difuso, normalmente vermelho, plano a moderadamente elevado, produzindo uma aparência clássica de ketchup na fundoscopia. A exsudação contínua do tumor pode, cronicamente, levar a mudanças secundárias, tais como degeneração do epitélio pigmentário da retina, metaplasia fibrosa, degeneração cística e descolamento da retina, o que conduz a defeitos no campo e acuidade visual. O hemangioma coroidal sugere fortemente a presença de alterações na leptomeninge ${ }^{15}$. Outras manifestações oculares podem incluir dilatação e tortuosidade dos vasos conjuntivais e episclerais, heterocromia da íris, buftalmia, coloboma de disco óptico e catarata. Nevus de Ota pode coexistir ${ }^{16}$. Defeitos no campo visual podem ocorrer quando 0 córtex occipital está afetado.

\section{Manifestações neurológicas}

Uma das manifestações neurológicas mais comuns na SSW é a convulsão, ocorrendo em $23 \%$ a $83 \%$ dos pacientes ${ }^{2,9}$. A primeira manifestação convulsiva pode ocorrer entre 0 nascimento e 23 anos de idade, com uma média aos seis meses ${ }^{9}$. Os ataques tipicamente iniciam como episódios focais e, freqüentemente, são precipitados por febre e infecções ${ }^{17}$, podendo ser acompanhados ou seguidos pelo aparecimento de déficits focais motores tais como hemiparesia e hemiplegia ${ }^{2,17}$. Os sintomas podem ser focais, contralaterais a MVP, ou generalizados, com predomínio das formas focais. Convulsões generalizadas são, primeiramente, tônico-clônicas. Todavia, convulsões atônicas e crises de ausência também podem ocorrer ${ }^{2,11}$. Existe uma correlação direta entre a idade de início das convulsões, a extensão do envolvimento neurológico e 0 grau de deficiência intelectual ${ }^{17}$. Crianças sem epilepsia ou que iniciam os ataques depois dos quatro anos de idade têm inteligência e desenvolvimento normais ${ }^{9}$. 0 início precoce das convulsões pode estar relacionado a pior prognóstico e dificuldade no controle da epilepsia². A ocorrência de convulsões prolongadas, durando mais de 60 minutos, correlaciona-se com epilepsia severa, déficits motores e deterioração mental ${ }^{11}$. Com 0 aumento da idade, as crises tendem a se tornar mais severas, freqüentes e complexas. Os mecanismos mais aceitos na patogênese das convulsões são a diminuição do fluxo sangüíneo cerebral nas áreas corticais envolvidas pela malformação vascular, bem como, a diminuição do retorno venoso, hipóxia focal e diminuição do metabolismo neuronal. Não obstante, registros eletrocorticográficos intra-operatórios têm demonstrado que a maior parte das áreas epileptogênicas ativas podem estar localizadas além das manchas angiomatosas ${ }^{18}$. A angiomatose leptomeníngea bilateral, presente em 7\% a $26 \%$ dos pacientes, é fator de risco para convulsões mais severas, atraso no desenvolvimento e déficits focais. A malformação, usualmente, envolve os lobos occipital e parietal, mas pode afetar todo o hemisfério. Dilatação do plexo coróide é comum. Calcificações são observadas nas artérias meníngeas e veias corticais e subcorticais subjacentes ao angioma. Juntamente com a atrofia cortical, são consideradas uma 
conseqüência indireta de isquemia crônica, devido à estase vascular na área do angioma leptomenínge $0^{19}$. As anormalidades na vasculatura cerebral podem acarretar eventos hipóxicos, especialmente durante as crises convulsivas, quando a demanda de oxigênio é maior. Oclusão venosa e hipóxia podem contribuir para o declínio neurológico. Outras manifestações neurológicas incluem retardo mental, migrânea, déficits focais transitórios e déficit de atenção-hiperatividade. Cerca de $80 \%$ dos pacientes apresentam-se com problemas cognitivos $^{9}$. Clinicamente, a maioria das crianças atinge 0 marco de desenvolvimento apropriado para a idade nos primeiros meses de vida, mas aproximadamente metade dos pacientes com SSW não mantém esse padrão ${ }^{12}$. Dois terços exibem atraso psicomotor na infância ${ }^{2}$ e 50\% tem significativo retardo mental tardio na idade escolar ${ }^{2,9}$. Enxaquecas iniciam em média aos oito anos de idade, sendo mais freqüentes em pessoas com déficits focais transitórios ${ }^{20}$. A enxaqueca secundária a SSW resulta, possivelmente, de um aumento no escoamento vasogênico de plasma e neuropeptídeos no espaço subaracnóide. Os neuropeptídeos podem ativar as fibras trigêmino-vasculares periféricas e produzir disfunção neuronal e vasodilatação no córtex correspondente ${ }^{21}$. Déficits focais transitórios caracterizamse por episódios de hemiparesia ou defeito de campo visual não diretamente associados à epilepsia. Os episódios podem durar de horas a vários dias ${ }^{22}$. No caso de hemiparesia, a extremidade envolvida pode não crescer com velocidade normal, resultando em hemiatrofia. A hipótese mais aceita para essa desordem é a ocorrência de trombose recorrente ${ }^{22}$. Outro modo comum de apresentação é o déficit de atenção-hiperatividade, que deve ser tratado clinicamente da mesma forma como se faz em pacientes com essa desordem, mas sem SSW, ou seja, monitoramento e administração de medicamentos que minimizem os sintomas ${ }^{17}$. Pode haver presença de hidrocefalia devido a um aumento da pressão venosa intracraniana causada por trombose de seios venosos profundos ou anastomoses arteriovenosas extensas ${ }^{23}$.

\section{Neuroimagem e eletroencefalografia}

A tomografia computadorizada (TC) e a ressonância nuclear magnética (RM) são os exames complementares mais úteis no diagnóstico da SSW, embora a TC por emissão de fóton único (SPECT), tomografia por emissão de pósitrons (PET) e espectroscopia por RM também tenham seu valor ${ }^{17}$. A TC é útil para demonstrar calcificações intracranianas, enquanto que a RM é válida para demonstrar o angioma leptomenínge ${ }^{24,25}$. Na TC, os achados incluem atenuação difusa da matéria branca superficial e profunda, presumivelmente devido a microcalcificações; realce giriforme após uso de contraste iodado sendo esta uma expressão da angiomatose pial; atrofia cerebral, como uma conseqüência de shunts vasculares nas estruturas corticais envolvidas pelo angioma; espessamento da caixa craniana, secundário à atrofia cerebral ${ }^{26}$. A RM contrastada é o padrão-ouro para identificação de anormalidades na estrutura cerebral na SSW. A RM sem contraste pode mostrar atrofia cerebral, tanto na seqüência T1 quanto em T2, proeminência diplóica e aumento do plexo coróide. Calcificações podem ser observadas em $\mathrm{T} 2^{25}$. Após a injeção de gadolínio, há aumento pial difuso, visto nas imagens em T1. Esse é o critério isolado mais confiável para 0 diagnóstico de SSW. Aumento do plexo coróide do lado afetado e hemangioma coroidal são 
forma usual, a angiografia por RM e a angiografia convencional mostram diminuição no calibre das artérias, dilatação das veias internas, aumento no tamanho do plexo coróide e ausência de veias hemisféricas superficiais do lado afetado ${ }^{24}$. A eletroencefalografia típica na SSW é assimétrica, com o hemisfério afetado mostrando uma redução na voltagem e lentificação do background. Essa assimetria pode ser detectada desde os primeiros meses de vida, todavia torna-se mais evidente quando a atrofia cerebral progride ${ }^{27}$.

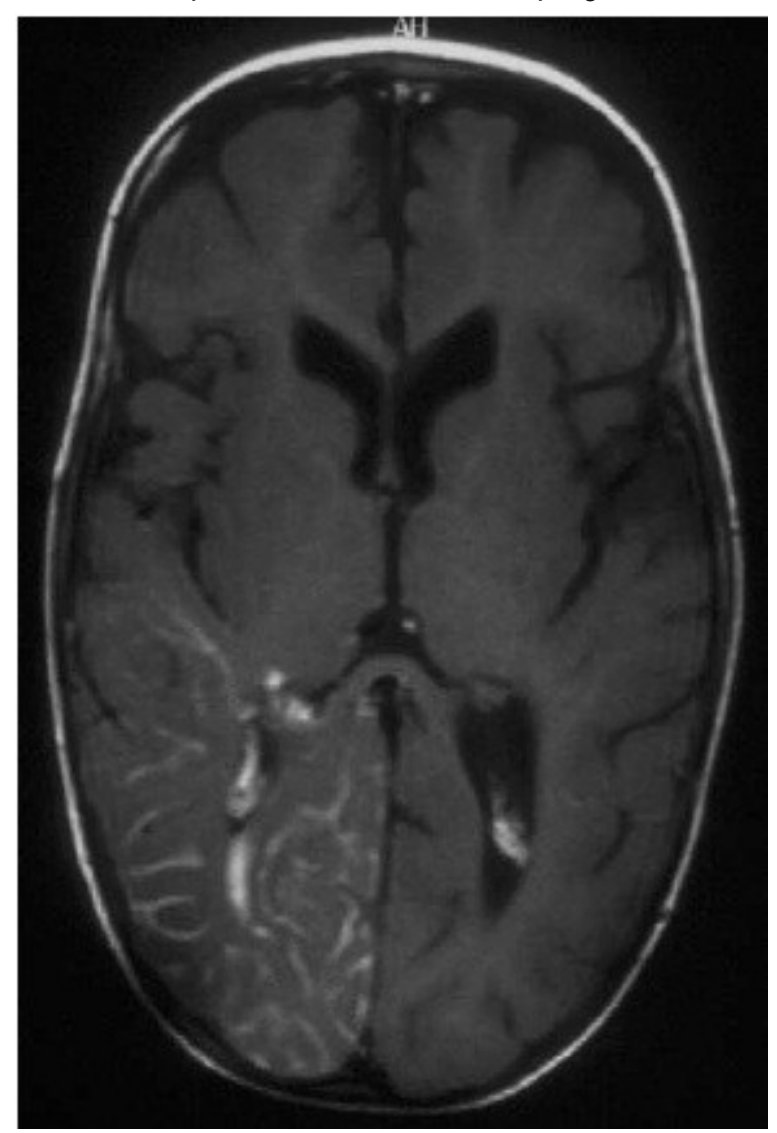

Figura 2 - Imagem por RM em T1 após injeção de gadolíneo mostrando realce do angioma leptomeníngeo no lobo occipital direito. (extraído de Baselga ${ }^{34}$ )

\section{Tratamento}

Freqüentemente, as modalidades de tratamento são focadas nas três principais manifestações da SSW: cutânea, ocular e neurológica. O laser corante pulsado permanece 0 tratamento de escolha para as MVP na maioria das crianças. A resposta no território de V1 nos pacientes com SSW é satisfatória, mas o resultado é menos exuberante quando existe concomitante envolvimento dos territórios de $\mathrm{V} 2$ e $\mathrm{V} 3^{28}$. 0 início precoce da terapia correlaciona-se com uma melhor resposta ${ }^{29}$. Fatores que influenciam na resposta ao tratamento são a profundidade e o diâmetro dos vasos sangüíneos constituintes da mancha ${ }^{30}$. Com o tempo, a lesão cresce e pode escurecer, desenvolvendo ectasias vasculares que promovem nodulações e vesículas superficiais se 0 tratamento com laser não for realizado ${ }^{31}$.

A terapia padrão para o glaucoma é o tratamento medicamentoso contínuo combinado com freqüentes cirurgias ${ }^{8}$, com o objetivo de controlar a pressão intra-ocular e prevenir danos 
realizados em pacientes que não respondem ao tratamento clínico, porém a anormalidade na vasculatura e a elevada pressão venosa episcleral reduzem as taxas de sucesso das cirurgias $^{8}$. Nos casos de grandes hemangiomas coroidais circunscritos, com fluido subretinal, o tratamento com placa de braquiterapia episcleral é freqüentemente considerado efetivo.

O tratamento da epilepsia é difícil e geralmente requer o uso de associação de fármaco. Carbamazepina ou oxcarbazepina são a primeira escolha, com fenobarbital e fenitoína como terapias de segunda linha. Se o controle não for alcançado, valproato de sódio ou topiramato são usados em associação com a carbamazepina. Reserva-se o uso de monoterapia com valproato ou topiramato como última tentativa ${ }^{17}$. Um controle ruim das crises convulsivas está relacionado à progressiva deterioração mental e déficit motor ${ }^{2}$. Uma variedade de procedimentos cirúrgicos tem sido proposta. Excisões corticais, lobectomia ou hemisferectomia são as mais freqüentes estratégias terapêuticas, devido ao caráter focal e unilateral na grande maioria dos casos. A literatura tem mostrado que quase todos os pacientes submetidos à lobectomia apresentaram diminuição da freqüência de convulsões, entretanto, poucos ficaram totalmente curados ${ }^{18}$. Em pacientes com convulsões severas, que não respondem à medicação, a hemisferectomia, pode ser uma opção, ainda que os riscos superem os benefícios ${ }^{8}$. Se a trombose for considerada uma causa da deterioração clínica, a terapia com ácido acetil-salicílico deve ser considerada. A aspirina pode ser usada também como prevenção de ataques isquêmicos transitórios, diminuindo, assim, sua freqüência²2.

\section{Conclusão}

A despeito da quantidade de informação publicada sobre a SSW, muito ainda precisa ser esclarecido acerca da fisiopatologia - especialmente do glaucoma - sugerida nos modelos teóricos, os quais necessitam expansão. Ainda, o estabelecimento de critérios diagnósticos não está bem demonstrado na literatura. Novos ensaios clínicos são necessários para firmar melhor manejo e tratamento precoce nos casos de epilepsia com evolução para a intratabilidade e/ou desenvolvimento para déficit intelectual. As MVP requerem, da mesma forma, desenvolvimento de terapêutica mais efetiva.

\section{Referências}

1. Di Rocco C, Tamburrini G. Sturge-Weber Syndrome. Childs Nerv Syst, 2006;22:909-21.

2. Pascual-Castroviejo I, Diaz-Gonzalez C, Garcia-Melian RM, et al. Sturge-Weber syndrome. Study of 40 patients. Pediatr Neurol, 1983;9:283-8.

3. Tallman B, Tan OT, Marelli JG, et al. Location of port-wine stains and the likelihood of ophthalmic and/or central nervous system complications. Pediatrics, 1991;87:323-7.

4. Roach ES. Neurocutaneous syndromes. Pediatr Clin North Am, 1992; 39: 591-620.

5.Enjolras O, Riche MC, Merland JJ. Facial port-wine stains and Sturge-Weber syndrome. Pediatrics, 1985;76:48-51.

Saúde (Santa Maria), v.37, n.2, p. 09-18, 2011 Franco Neto; Franchine; Foletto Júnior Pomblum.

6. Mulliken JB - Capillary (port-wine) and other telangiectatic stains, In: McAllister L ed. - Vascular Birthmarks. Hemangiomas and Malformations. Philadelphia, Sauders, 1988;172-81. 
7. Carrasco L, Pastor A, Farina C, et al. Acral arteriovenous tumor developed within a nevus flammeus in a patient with Sturge-Weber syndrome. Am J Dermatol, 2003;25:341-5.

8. Bodensteiner JB, Roach ES. Sturge-Weber Syndrome. Mt. Freedom, NJ: The Sturge-Weber Foundation 1999.

9. Sujanski E, Conradi S. Outcome of Sturge-Weber syndrome in 52 adults. Am J Med Genet, 1995;57:35-45.

10. Ahluwalia TP, Lata J, Kanwa P. Sturge-Weber syndrome with intraoral manifestations. A case report. Indian J Dent Res, 1998;9:140-4.

11. Ville D, Enjolras O, Chiron C, et al. Prophilatic antiepileptic treatment in Sturge-Weber disease. Seizure, 2002;11:45-50.

12. Roach ES - Congenital cutaneovascular disorders, In: Bogouslavsky J, Caplan LR, eds - Stroke syndromes. London, Cambridge University Press, 1995;481-90.

13. Amirikia A, Scott IU, Murray TG. Bilateral diffuse choroidal hemangiomas with unilateral facial nevus flammeus in Sturge-Weber syndrome. Am J Ophthalmol, 2000;130:362-4.

14. Phelps CD. The pathogenesis of glaucoma in Sturge-Weber syndrome. Ophthalmology, 1978;85:276-86.

15. Madlom MM, Hoggard N, Griffiths PD, et al. Facial naevus flammeus with choroidal haemangioma and without intracranial involvement. Dev Med Child Neurol, 2003;45:139.

16. Celebi S, Alagoz G, Aykan U. Ocular findings in Sturge-Weber syndrome. Eur J Ophthalmol, 2000;10:23943.

17. Thomas-Sohl KA, Vaslow DF, Maria BL. Sturge-Weber syndrome: a review. Pediatr Neurol, 2004;30(5):303-10.

18. Rasmussen TH, Mathieson G, Le Blanc F. Surgical therapy of typical and a forme fruste variety of SturgeWeber syndrome. Schweiz Arch Neurol Psychiatr, 1972;111:393-409.

19. Terdjman P, Aicardi J, Sainte-Rose C, et al. Neuroradiological findings in Sturge-Weber syndrome (SSW) and isolated pial angiomatosas. Neuropediatrics, 1991;22:115-20.

20. Kossoff EH, Hatfield LA, Ball KL, Comi AM. Comorbidity of epilepsy and headache in patients with SturgeWeber syndrome. J Child Neurol, 2005;20:678-82.

21. Lizuka T, Sakai F, Yamakawa K, et al. Vasogenic leakage and the mechanism of migraine with prolonged aura in Sturge-Weber syndrome. Cephalalgia, 2004;24:767-70.

22. Maria BL - Current management in child neurology. London, BC Decker, 2002;411-5.

23. Fishman MA, Baram TZ. Megalencephaly due to impaired cerebral venous return in Sturge-Weber variant syndrome. J Child Neurol, 1986; 1:115.

24. Vogl TJ, Stemmler J, Bergman C, et al. MR and MR angiography of Sturge-Weber syndrome. Am J Neuroradiol, 1993;14:417-25.

25. Vilela PF. Síndroma de Sturge Weber Revisitado: Avaliação das alterações morfológicas encefálicas por Tomografia Computadorizada e Ressonância magnética. Acta Med Port, 2003;16:141-8.

26. Griffiths PD. Sturge-Weber syndrome revisited: the role of neuroradiology. Neuropediatrics, 1996;27:28494.

27. Brenner RP, Sharbrough FW. Electencephalographic evaluation in Sturge-Weber syndrome. Neurology, 1976;26:629-32.

28. Taïeb A, Touati L, Cony M. Treatment of port-wine stains with the 585-nm flashlamp-pulsed tunable dye laser: a study of 74 patients. Dermatology, 1994;188:276-81.

Sindrome de Sturge Weber

29. Batta K. Management of large birthmarks. Semin Neonatol, 2000;5:325-32. 
30. Lanigan SW. Port-wine stains unresponsive to pulsed dye laser: explanations and solutions. $\mathrm{Br} \mathrm{J}$ Dermatol, 1998;139:173-7.

31. Geronemus RG, Ashinoff $R$. The medical necessity of evaluation and treatment of port-wine stains. J Dermatol Surg Oncol, 1991;17:76-9.

32. Van Emelen C, Goethals M, Dralands L, et al. Treatment of glaucoma in children with Sturge-Weber syndrome. J Pediatr Ophthalmol Strabismus, 2000;37:29-34.

33. Cronemberger S, Calixto N, Assunção DAM, Milhomens EG. Síndrome de Sturge-Weber: estudo ultrabiomicroscópico. Arq Bras Oftalmol, 2004; 67: 211-7.

34. Baselga E. Sturge-Weber Syndrome. Semin Cut Med Surg, 2004; 23: 87-98.

\section{Nelson Barbosa Franco Neto}

Endereço para correspondência - Rua Erly de Almeida Lima 143, ap 301, CEP 97105-120, Santa Maria, RS, Brasil.

E-mail: nefneto@gmail.com

Currículo lattes: http://lattes.cnpq.br/7385270174358253

Recebido em 21 de março de 2011.

Aprovado em 26 de setembro de 2011. 
Saúde (Santa Maria), v.37, n.2, p. 09-18, 2011.

Sindrome de Sturge Weber

| IS ISN 2236-5834 


\title{
Inibidores da bomba de prótons: Revisão e análise farmacoeconômica
}

\author{
Muriele Picoli Braga*, Cristiane de Bona da Silva**, Andréa Inês
}

Horn Adams***

RESUMO: Os inibidores da bomba de prótons (IBPs), são medicamentos que inibem a enzima $\mathrm{H}^{+}, \mathrm{K}^{+}-$ ATPase (ou bomba de prótons) realizando a supressão ácida gástrica. Atualmente, são comercializados seis representantes desta classe: omeprazol, lansoprazol, pantoprazol, rabeprazol, esomeprazol e dexlansoprazol. Um novo IBP, tenatoprazol, está ainda em fase de desenvolvimento. 0 presente estudo propõe-se a revisar os estudos disponíveis a fim de expor informações sobre os IBPs e realizar um estudo farmacoeconômico entre doses-padrão desses medicamentos para o tratamento da úlcera péptica gastroduodenal. Evidências atuais sugerem que os IBPs possuem eficácia semelhante no tratamento de várias desordens gástricas e no protocolo de erradicação do Helicobacter pylori. A partir da análise farmacoeconômica ora realizada, constatou-se que o lansoprazol apresenta perfil mais favorável.

Descritores: Inibidores da bomba de prótons; Estudo farmacoeconômico.

\section{Proton Pump Inhibitors: Review and Analysis Pharmacoeconomic}

ABSTRACT: The proton pump inhibitors (PPIs) are drugs that inhibit the enzyme $\mathrm{H}+, \mathrm{K}+-$ ATPase (or proton pump), by performing gastric acid suppression. Currently, there are five marketed drugs of this class: omeprazole, lansoprazole, pantoprazole, rabeprazole and esomeprazole. A new PPI, tenatoprazole, is still under development. This study aims to review the available studies in order to reveal information about the PPIs and to perform a pharmacoeconomic study between standard doses of these drugs, employed in the treatment of gastroduodenal peptic ulcer. Current evidence suggests that PPIs have similar efficacy in the treatment of various gastric disorders and in the eradication of Helicobacter pylori. Through the pharmacoeconomic analysis done, it was found that lansoprazole presents a more favorable profile.

Descriptors: Proton pump inhibitors; Pharmacoeconomic study.

*Mestranda no Programa de pós-graduação em Ciências Farmacêuticas pela Universidade Federal de Santa Maria (UFSM), Santa Maria, RS, Brasil.

**Pós-doutora em Ciências da Saúde (Nanotecnologia) pela Universidade Federal do Rio Grande do Sul (UFRGS), Rio Grande, RS, Brasil e professora adjunta no Departamento de Farmácia Industrial da Universidade Federal de Santa Maria (UFSM), Santa Maria, RS, Brasil.

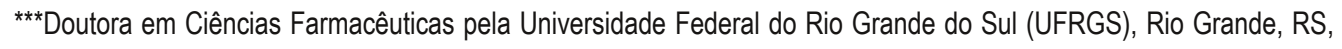
Brasil e professora adjunta no Departamento de Farmácia Industrial da Universidade Federal de Santa Maria (UFSM), Santa Maria, RS, Brasil. 


\section{Introdução}

$\mathrm{O}$ reconhecimento de que a enzima $\mathrm{H}^{+}, \mathrm{K}^{+}$- Adenosina Tri-Fosfatase $\left(\mathrm{H}^{+}, \mathrm{K}^{+}\right.$-ATPase ou bomba de prótons) constitui a etapa final da secreção ácida levou ao desenvolvimento de uma classe de fármacos, a dos inibidores da bomba de prótons (IBPs), usados no tratamento de distúrbios gastrintestinais. ${ }^{1}$

Atualmente, existem sete representantes desta classe, dos quais seis são comercializados (Figura 1): omeprazol, lansoprazol, pantoprazol, rabeprazol, esomeprazol (isômero $\mathrm{S}$ do omeprazol), dexlansoprazol (enantiômero do lansoprazol, ainda não comercializado no Brasil) e o tenatoprazol. ${ }^{2,3}$

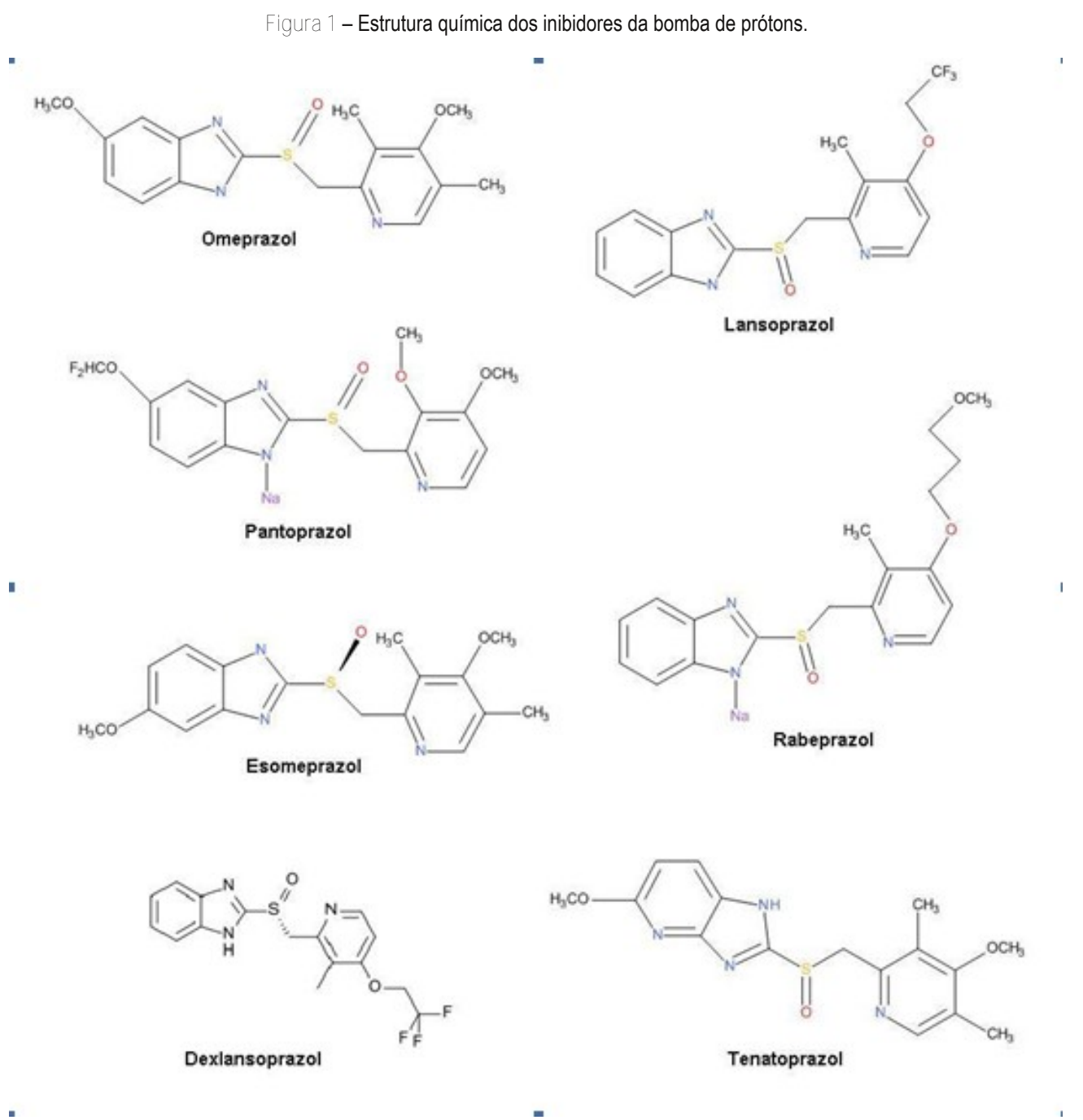

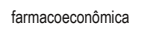

ISSN 2236-5834

O tenatoprazol está em fase de desenvolvimento e caracteriza-se por possuir um anel imidazopiridínico no lugar do anel benzimidazólico, o que aumenta seu tempo de permanência no organismo, sendo importante, principalmente, para o controle da acidez durante a noite. ${ }^{4}$ Porém, ainda se desconhece a importância clínica dessa característica farmacocinética. ${ }^{5}$ Todos compartilham da mesma estrutura, um anel a-piridilmetilsulfinil 
benzimidazol substituído, mas variam em termos de substituições nos grupos piridina ou benzimidazol. Eles também têm em comum os mecanismos inibitórios e são todos bases fracas protonáveis em $\mathrm{pK}_{\mathrm{a}}$ de cerca de 4 a 5 , o que faz com que eles se acumulem seletivamente no espaço ácido das células parietais secretoras. ${ }^{1}$

Muitos fármacos diferentes, como os antagonistas dos receptores $\mathrm{H}_{2}$, também inibem a secreção ácida. Mas os inibidores da bomba de prótons têm sido considerados mais eficazes, pois bloqueiam a etapa final da secreção ácida. ${ }^{6-8}$ Atualmente, os inibidores da bomba de prótons são a segunda classe de medicamentos mais comumente prescritos nos Estados Unidos. ${ }^{2}$

Esse trabalho propõe-se a revisar estudos disponíveis na literatura sobre os IBPs bem como, realizar um estudo farmacoeconômico entre doses-padrão utilizadas no tratamento da úlcera péptica gastroduodenal, por ser uma indicação comum dos mesmos.

\section{Fisiopatologia da úlcera péptica}

A úlcera péptica é uma das principais indicações clínicas para reduzir a secreção de suco gástrico. ${ }^{9}$ Uma úlcera péptica é uma ferida bem definida, circular ou oval, formada no revestimento do trato gastrintestinal. Os nomes das úlceras identificam a sua localização anatômica ou as circunstâncias em que se desenvolvem. A úlcera duodenal, o tipo mais comum de úlcera péptica, surge no duodeno. As úlceras gástricas normalmente situam-se na parte alta da curvatura do estômago. ${ }^{10}$

A fisiopatologia da úlcera péptica pode ser considerada um desequilíbrio entre os fatores de defesa da mucosa (bicarbonato, mucina, prostaglandina, óxido nítrico, outros peptídios e fatores de crescimento) e fatores agressivos (ácido e pepsina). ${ }^{11} \mathrm{~A}$ regulação da secreção de ácido pelas células parietais é especialmente importante na patogênese da úlcera péptica e constitui um alvo para a ação de fármacos. A secreção das células parietais é uma solução isotônica de $\mathrm{HCl}(150 \mathrm{mmol} / \mathrm{L}) \mathrm{com} \mathrm{pH}$ abaixo de 1. De modo bastante simplificado, íns cloreto $(\mathrm{Cl})$ são transportados ativamente do plasma para a célula parietal. Esta secreção de íons $\mathrm{Cl}^{-}$é acompanhada por íons $\mathrm{K}^{+}$, que são, então, trocados por íons $\mathrm{H}^{+}$pela $\mathrm{K}^{+}-\mathrm{H}^{+}-$ ATPase. Tem-se então a combinação de íons hidrogênio $\left(\mathrm{H}^{+}\right)$e cloreto $\left(\mathrm{Cl}^{-}\right)$, seguido de sua liberação pelas glândulas secretoras gástricas. ${ }^{9}$

O desenvolvimento de úlceras pépticas está relacionado à infecção da mucosa do estômago por Helicobacter pylori (bacilo gram-negativo que causa gastrite crônica), bem como ao uso de certos medicamentos (sobretudo o ácido acetilsalicílico, o ibuprofeno e outros antiinflamatórios não-esteróides), os quais provocam erosões e úlceras no estômago, especialmente nas pessoas de idade avançada. Esses efeitos, no entanto, são revertidos pela interrupção do tratamento, sendo a recidiva pouco provável, a menos que se reinicie 0 mesmo tratamento. ${ }^{10}$ As prostaglandinas (principalmente $E_{2}$ e $I_{2}$ ), sintetizadas na mucosa gástrica principalmente pela enzima ciclooxigenase-1 (COX-1), estimulam a secreção de muco e de bicarbonato, diminuem a secreção de ácido e causam vasodilatação. Todas essas ações servem para proteger o estômago contra lesões. Isto, provavelmente, explica a capacidade de muitos antiinflamatórios não-esteróides (AINEs) inespecíficos de causar sangramento e erosões gástricas, visto que são inibidores da COX-1. ${ }^{9}$

A terapia da úlcera péptica alia a redução da secreção de ácido gástrico usando

Saúde (Santa Maria), v.37, n.2, p. 19-32, 2011.

Braga, M. P.; da Silva, C. B.; Adams, A. I. 
antagonistas dos receptores $\mathrm{H}_{2}$ (cimetidina, ranitidina, nizatidina e famotidina) ou IBPs, bem como a neutralização do ácido secretado com antiácidos (hidróxido de magnésio, hidróxido de alumínio e bicarbonato de sódio) e protetores da mucosa, como o sucralfato. Embora os antiácidos tenham sido utilizados ao longo do tempo e tenham provado ser relativamente eficazes, o uso dos mesmos é inconveniente devido à necessidade de várias doses diárias e também pela associação a efeitos colaterais indesejados. ${ }^{10}$ No caso de infecção por $H$. pylori, são associados anti-secretores e antibióticos (claritromicina, amoxicilina, metronidazol, tinidazol, tetraciclina e fluorquinolonas, como levofloxaxino e moxifloxacino). 0 tratamento conhecido como terapia tríplice (combinação de um IBP, claritromicina e amoxicilina) começou a apresentar evidências de resistência microbiana por volta do ano 2000, com taxas de cura inferiores a $80 \%$. Atualmente, os estudos apontam para a eficácia de terapia concomitante (associação de amoxicilina, claritromicina, tinidazol ou metronidazol e IBP, por 10-14 dias), terapia seqüencial (amoxicilina + IBP/5 dias, seguida de claritromicina e tinidazol ou metronidazol + IBP/5 dias), terapia concomitante-combinada (combinação das duas citadas anteriormente) ou ainda, terapia com bismuto (associação de bismuto, tetraciclina, metronidazol + IBP). A terapia tríplice ainda permanece como alternativa quando há evidências de susceptibilidade à claritromicina. ${ }^{12}$

\section{Inibidores da bomba de prótons}

\section{Usos}

Em 1989 foi introduzido na terapêutica o primeiro inibidor da bomba de prótons, o omeprazol. Após surgiram outros fármacos, com propriedades físico-químicas e farmacológicas semelhantes: pantoprazol, rabeprazol, esomeprazol e mais recentemente 0 dexlansoprazol. Os fármacos desta classe são considerados muito eficazes e relativamente equivalentes durante o tratamento, reduzindo em até $95 \%$ a produção diária de ácido gástrico. ${ }^{13}$

Os IBPs produzem uma supressão ácida significativamente mais eficaz e prolongada do que os antagonistas dos receptores $\mathrm{H}_{2}$ e são capazes de manter o pH intragástrico superior a 4 por até 16 a $18 \mathrm{~h} / \mathrm{dia}$. Foi demonstrado que a cura de doenças relacionadas com o excesso de ácido está diretamente relacionada com o grau e a duração da supressão ácida e com a duração do tratamento. ${ }^{14,15}$ Dessa forma, seu uso é recomendado em diretrizes atuais para 0 tratamento da doença do refluxo gastroesofágico ${ }^{13}$, para a prevenção de úlcera péptica em pacientes recebendo agentes inflamatórios não esteróides (AINEs), em protocolos de erradicação da Helicobacter pylori, ${ }^{5}$ na síndrome de Zollinger-Ellison, gastrinomas, esofagite e gastrite. ${ }^{16}$

A Tabela 1 expõe de maneira sucinta evidências contemporâneas sobre a eficácia do tratamento com inibidores da bomba de prótons. ${ }^{5}$

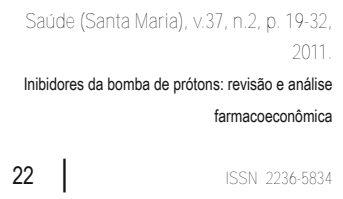




Eficácia comprovada
Tratamento sintomático e cicatrização de úlceras pépticas induzidas por uso crônico de AINEs.
Prevenção de lesões gastrintestinais induzidas pelo uso crônico de AINEs.
Coadjuvante na prevenção de recorrência de úlceras pépticas induzidas por H. pylori.
Tratamento de esofagite ou sintomas associados à doença do refluxo gastresofágico.
Provável eficácia
Tratamento da dispepsia com pirose e regurgitação.
Sugerida ineficácia
Tratamento do sangramento digestivo alto causado por úlcera péptica.
Profilaxia primária de sangramento digestivo alto causado por úlcera de estresse.

Além da atividade anti-secretora, os IBPs demonstram uma importante atividade antiHelicobacter pylori in vitro, tendo um efeito sinérgico com antibióticos..$^{18} \mathrm{O}$ mecanismo para 0 efeito sinérgico ainda não é totalmente claro, mas pode ser devido à inibição da enzima urease bacteriana, um importante fator de proteção contra o meio ácido, ou devido à ligação à enzima $\mathrm{H}^{+}, \mathrm{K}^{+}-$ATPase da bactéria, a qual auxilia na manutenção do gradiente transmembrana. ${ }^{19,20}$

\section{Farmacocinética}

Todos os inibidores da bomba de prótons são "pró-fármacos" que necessitam ativação em ambiente ácido. Os fármacos dessa classe entram na célula parietal a partir do sangue e acumulam-se nos canalículos secretores ácidos da célula parietal, onde são ativados por um processo catalisado por prótons, que resulta na formação de uma sulfenamida tiofílica ou ácido sulfênico. Essa forma ativada reage por meio de ligação covalente com o grupo sulfidril de cisteínas do domínio extracelular da $\mathrm{H}^{+}, \mathrm{K}^{+}-\mathrm{ATPase}$, as quais são essenciais para a inibição da produção ácida. ${ }^{11}$

0 resultado é a inibição irreversível da secreção ácida da bomba de prótons. ${ }^{21}$ Por causa da ligação covalente, os efeitos inibitórios dos IBPs duram muito mais tempo do que sua meia-vida plasmática. ${ }^{2}$ A meia-vida plasmática dos IBPs varia em torno de 1 a 2 horas, e o efeito sobre a secreção ácida pode durar até 24 horas, até que ocorra a síntese de nova enzima. Todo o potencial inibidor do ácido pode levar até 3 a 4 dias. ${ }^{21}$ Por exemplo, a restauração da biossíntese da enzima $\mathrm{H}^{+}, \mathrm{K}^{+}$-ATPase ocorre cerca de 96 horas após a dose oral de pantoprazol. ${ }^{22}$

De acordo com o mecanismo de ação, os anéis piridina e benzimidazol, bem como a cadeia $-\mathrm{CH}_{2}$-SO- são essenciais para a atividade dos IBPs. Os substituintes em ambos os anéis são importantes para determinar a velocidade de conversão à forma ativa e diminuir a toxicidade. ${ }^{23,24}$

São rapidamente absorvidos, altamente ligados às proteínas e geralmente bem tolerados, mas de modo semelhante a alguns bloqueadores $\mathrm{H}_{2}$, interagem com algumas enzimas microssomais do citocromo P450, podendo reduzir o catabolismo alguns fármacos, como varfarina e fenitoína. ${ }^{25,11}$ Uma vez que causam inibição profunda e duradoura da secreção ácida gástrica, teoricamente é possível que possam interferir na absorção de Saúde (Santa Maria), v.37, n.2, p. 19-32, 2011.

Braga, M. P.; da Silva, C. B.; Adams, A. I. fármacos em que o $\mathrm{pH}$ gástrico seja um fator importante para a biodisponibilidade (p. ex.: ISSN $2236-5843$ cetoconazol, ésteres da ampicilina, sais de ferro, digoxina). ${ }^{26}$ 
Apesar de pertencerem à mesma classe terapêutica, existem algumas diferenças em seus perfis farmacológicos. Ao contrário do omeprazol e do lansoprazol, o pantoprazol tem um perfil farmacocinético linear (e, portanto mais previsível), biodisponibilidade menos variável e um rápido início de ação. ${ }^{27}$

Por ser uma base mais forte, o rabeprazol converte-se mais rapidamente à forma sulfenamida, resultando em uma rápida inibição da enzima. Isto se deve ao valor de $\mathrm{pK}_{\mathrm{a}}$ do nitrogênio do seu anel piridínico $\left(\mathrm{pK}_{\mathrm{a}}=5\right)$, enquanto que o dos demais apresentam valor em torno de 4. . $^{19,28}$

Outra diferença é em relação à atividade anti-Helicobacter pylori, onde o rabeprazol mostrou ser 10 vezes mais potente que omeprazol e lansoprazol na inibição da enzima urease bacteriana. Este efeito provavelmente é devido à formação de pontes dissulfeto no sítio ativo da enzima. ${ }^{29}$ Além disso, rabeprazol e seu metabólito tioéter possuem marcada atividade inibitória sobre a motilidade de $H$. pylori, a qual é importante para colonização da mucosa gástrica. ${ }^{30}$

Seguindo nas diferenças farmacocinéticas dos IBPs, tem-se o esomeprazol (isômero $S$ do omeprazol), considerado o primeiro inibidor de bomba de prótons desenvolvido como um único isômero para 0 tratamento de doenças ácido-relacionadas. ${ }^{31} \mathrm{~A}$ justificativa para 0 desenvolvimento de isômeros únicos dos IBPs decorre do fato de que a quiralidade de fármacos pode ter um significado clínico considerável, uma vez que as enzimas e receptores geralmente têm uma preferência estereoquímica de um isômero óptico. Isso pode resultar em diferenças importantes no perfil farmacocinético e farmacodinâmico dos isômeros ópticos, e, portanto, na sua eficácia clínica. ${ }^{32} \mathrm{O}$ esomeprazol possui uma depuração mais lenta comparado com a forma racêmica e, portanto, o esperado é que se atinja um maior nível sanguíneo e melhor efeito inibitório da bomba de prótons. Em dois estudos que compararam os efeitos do pH intragástrico do esomeprazol com omeprazol, foram encontradas pequenas diferenças, mas estatisticamente significativas entre os dois. ${ }^{33,34}$

O dexlansoprazol foi aprovado em 2009 pelo FDA e ainda não é comercializado no Brasil, sendo o primeiro inibidor da bomba de prótons com uma formulação de liberação lenta que contém dois tipos de grânulos com revestimento entérico, resultando em picos de concentração em 1 a 2 horas após a administração e novamente em 4 a 5 horas. ${ }^{35}$

Estudos farmacocinéticos mostraram que o tenatoprazol exibe um longo tempo de meiavida (9 horas para a administração repetida de $40 \mathrm{mg}$, isto é, de 5 a 7 vezes maior que os outros IBPs disponíveis atualmente) e investigações farmacodinâmicas têm mostrado um aumento do $\mathrm{pH}$ intragástrico com tenatoprazol $(\mathrm{pH} \mathrm{4,6)}$ significativamente mais elevado do que o observado com o mesmo regime de esomeprazol ( $\mathrm{pH} \mathrm{4,2).} \mathrm{Evidenciou-se} \mathrm{também} \mathrm{que}$ o efeito inibitório da supressão ácida com tenatoprazol é mais duradouro, o que foi atribuído à estrutura química diferente de tenatoprazol e/ou às características resultantes da interação com o sítio da cisteína ou sítios da $\mathrm{H}^{+}, \mathrm{K}^{+}$-ATPase. ${ }^{28,36}$

Apesar de diferenças e/ou vantagens farmacocinéticas, todos os IBPs inibem fortemente a secreção de ácido gástrico, não demonstrando diferenças terapêuticas significativas entre si. $^{5}$ 


\section{Formas farmacêuticas e estabilidade}

Todos os inibidores da bomba de prótons são instáveis quando expostos a meio ácido, como o meio do estômago. Portanto, eles são formulados com revestimento entérico que protege o fármaco do ambiente ácido gástrico. ${ }^{37,38} \mathrm{As}$ formas farmacêuticas disponíveis no mercado são: injetáveis, comprimidos com revestimento entérico de liberação prolongada, comprimidos de desintegração rápida, cápsulas com grânulos com revestimento entérico de liberação normal e prolongada.

Os comprimidos com revestimento entérico ou grânulos com cobertura entérica (pellets gastrorresistentes), encapsulados em uma camada externa de gelatina, passam pelo ambiente ácido do estômago intactos. 0 revestimento entérico dissolve-se quando entra no ambiente alcalino do intestino delgado, onde o fármaco é absorvido, sendo assim evitada a degradação dos fármacos pelo ácido do esôfago e estômago. ${ }^{21}$

Desse modo, deve-se ter cuidado na administração oral quando se torna necessário uma preparação líquida, como no caso de crianças ou de pacientes hospitalizados. Muitas vezes é realizada uma preparação extemporânea a partir do conteúdo de uma cápsula (os pellets) solubilizado em solvente adequado. Porém, ao esmagar os pellets, a camada protetora é destruída, expondo o fármaco para o $\mathrm{pH}$ gástrico e, dessa forma, promovendo sua degradação. Do mesmo modo, uma formulação intravenosa não é ativa quando administrada por via oral..$^{39}$

Avaliou-se a estabilidade de omeprazol oral líquido $(2 \mathrm{mg} / \mathrm{mL})$ preparado a partir do conteúdo de cápsulas de omeprazol, o qual foi dissolvido em bicarbonato de sódio para injeção $8,4 \%$. As amostras preparadas permaneceram estáveis por 30 dias a $-20^{\circ} \mathrm{C}$ e $4^{\circ} \mathrm{C}$, apresentando menos de $3 \%$ e $5 \%$ de perda, respectivamente. Além disso, não houve alteração no aspecto do líquido armazenado nestas temperaturas. No entanto, as amostras armazenadas à temperatura ambiente apresentaram perda de $8 \%$ em 14 dias e perda de 14\% em 18 dias e a cor da preparação mudou de branco para marrom durante 0 armazenamento. ${ }^{39}$

Recentemente foi introduzido na clínica comprimido de desintegração oral, uma formulação alternativa de lansoprazol. É fácil de engolir e pode ser tomado com ou sem água. Este recurso melhora o cumprimento da terapia quando os pacientes estão fora de casa (e quando a água não está prontamente disponível), em doentes com disfagia ou odinofagia, bem como distúrbios de deglutição. A farmacocinética de lansoprazol oral após a administração do comprimido é essencialmente idêntica à observada após a dose com cápsulas de grânulos. ${ }^{40}$

\section{Doses e Posologia}

Doses-padrão de IBPs podem reduzir a secreção de ácido gástrico em até $98 \%$ por inativação irreversível da bomba de prótons da célula parietal gástrica. Recomenda-se que sejam administrados aproximadamente 1 hora antes das refeições, para aumentar a biodisponibilidade. ${ }^{21} \mathrm{~A}$ alimentação reduz 0 pico de concentração do lansoprazol e sua absorção em aproximadamente $50 \%{ }^{26}$ No entanto, a ingestão concomitante de alimento não influi significativamente na biodisponibilidade do pantoprazol em dose simples em pessoas saudáveis. ${ }^{41}$

Saúde (Santa Maria), v.37, n.2, p. 19-32, 2011.

Braga, M. P.; da Silva, C. B.; Adams, A. I. ISSN 2236-5843 
Estudos envolvendo omeprazol (20mg), pantoprazol (40 mg), lansoprazol (30 mg), rabeprazol (20 mg) e esomeprazol $(20 \mathrm{mg})$ apontam a equivalência clínica destes fármacos nestas dosagens. ${ }^{2}$ Para 0 tratamento da maior parte dos distúrbios relacionados, esses fármacos são administrados em única dose diária.

\section{Efeitos adversos}

Os IBPs são geralmente bem tolerados pelos pacientes. Dor de cabeça, dor abdominal, náusea e diarréia são os efeitos colaterais mais comuns. A incidência de diarréia aumenta com a idade e dosagem. Efeitos secundários pouco freqüentes incluem erupção cutânea, coceira e constipação. A incidência global de efeitos secundários é inferior a $5 \%$, fazendo 0 uso de IBPs ideal para a terapia de curto prazo; no entanto, continua a existir preocupações sobre 0 impacto a longo prazo. $O$ efeito de primeira passagem e a depuração renal são mínimos, portanto, a redução da dose não é necessária para pacientes com insuficiência renal. ${ }^{42}$

Na dose habitual (20 a 40 mg/dia) o omeprazol inibe acima de 90\% da secreção ácida de 24 horas na maioria dos pacientes, tornando muitos destes pacientes quase aclorídricos. Devido a esta potência, há dúvidas na segurança do seu uso em longo prazo. 0 ácido gástrico, por um mecanismo de "feedback", inibe a secreção endócrina da gastrina pelas células $\mathrm{G}$ localizadas nas glândulas antrais (pilóricas). Se a acidez gástrica é nitidamente reduzida, as células $G$ secretam quantidades aumentadas de gastrina, levando à hipergastrinemia. A gastrina é um hormônio trófico, estimula a proliferação e crescimento de certas células e tecidos. A utilização em longo prazo de omeprazol em humanos pode possivelmente produzir proliferação de células e tumores carcinóides, porém não foram ainda claramente estabelecidos como uma conseqüência do uso crônico do medicamento. ${ }^{25}$

A administração de pantoprazol em longo prazo (24 meses) em animais (ratos e camundongos) causou a inibição da secreção ácida gástrica, levando a hipergastrinemia, resultando na hiperplasia das células e observando-se tumores carcinóides do estômago e cólon nos animais testados. Estes fenômenos não foram constatados em seres humanos. ${ }^{43}$

Embora a segurança do uso dos IBPs já tenha sido comprovada, relatos recentes têm chamado a atenção para potenciais efeitos secundários ou interações medicamentosas. Estudos apontam para absorção deficiente de alguns fármacos quando administrados juntamente com os IBPs, tais como: cetoconazol, itraconazol e astranavir, bem como aumento na absorção de medicamentos como nifedipino e digoxina. ${ }^{13}$

Além disso, estudos recentes levantaram a questão de que, quando usados em terapia conjunta, os IBPs levam a uma redução na conversão de clopidogrel em sua forma ativa, reduzindo assim a eficácia do tratamento com clopidogrel, que é um importante agente antiagregante plaquetário. Dessa forma, os IBPs estariam contribuindo para a ineficácia do tratamento de cardiopatias e eventos aterotrombóticos. ${ }^{13,44}$ Por outro lado, autores citam que os estudos existentes apresentam resultados inconsistentes e discordantes. Mesmo assim, em novembro de 2009, o FDA emitiu um alerta aos profissionais de saúde sobre o potencial de interação entre clopidogrel e omeprazol ou esomeprazol, limitando o alerta apenas para 0 uso desses dois IBPs. ${ }^{44}$

Recentemente, também foi levantada a questão de que 0 uso de IBPs poderia induzir má absorção de cálcio pelos ossos e, dessa forma, levar à osteoporose e aumentar o risco da 
ocorrência de fraturas, principalmente no quadril. No entanto, os dados apresentados não são uniformes. Alguns estudos conseguem demostrar que há uma pequena, mas estatísticamente significativa, associação entre o uso de IBPs e o risco de fraturas, porém não demonstram significância clínica pelo fato do risco ser baixo. Mesmo com as limitações metodológicas dos estudos, o FDA anunciou em maio de 2010, que deveria existir uma mudança na bula dos IBPs, contendo a informação de indicar um possível risco de fratura com o uso desses medicamentos. ${ }^{44}$

\section{Análise farmacoeconômica dos inibidores da bomba de prótons}

Farmacoeconomia é um termo relativamente recente que se refere à aplicação da economia ao estudo dos medicamentos. Surgiu em países desenvolvidos no final dos anos 80 e seu corpo de conhecimento encontra-se fundamentado na economia da saúde, que visa melhorar a eficiência dos gastos nos sistemas de saúde. ${ }^{45}$

Os estudos farmacoeconômicos abrangem a identificação, o cálculo e a comparação dos custos (recursos consumidos), riscos e desfechos (clínicos, econômicos e humanísticos) de programas, serviços ou terapias e a determinação de alternativas que produzam os melhores resultados diante dos recursos utilizados. ${ }^{46}$ Esses estudos podem também ser utilizados para avaliar procedimentos, produtos médico-hospitalares e outros itens utilizados com fins terapêuticos. ${ }^{47}$

Autores clássicos categorizam quatro tipos de análises farmacoeconômicas, que têm em comum o elemento custo e diferem quanto à unidade de desfecho, sendo elas: análise de minimização de custo (AMC), análise de custo-efetividade (ACE), análise de custoutilidade (ACU) e análise de custo-benefício (ACB). ${ }^{46,48}$ Tendo em vista que o objetivo deste estudo é avaliar os custos de um certo tratamento com a aplicação dos diferentes IBPs disponíveis no mercado, foi utilizada a análise de minimização de custo.

A AMC é o tipo de análise farmacoeconômica mais simples, que utiliza como meio de comparação única e exclusivamente o custo, tendo em vista que as opções terapêuticas são igualmente efetivas. Esta abordagem é justificada quando as alternativas de programas ou terapias comparadas produzem resultados clínicos equivalentes, como em tomadas de decisões de guias terapêuticos. ${ }^{49,50}$ Assim, o primeiro passo crítico antes de conduzir a AMC é determinar a equivalência terapêutica das intervenções. ${ }^{50}$

Dessa forma, analisou-se a posologia habitualmente recomendada para obtenção da cicatrização da úlcera péptica gastroduodenal. Foram utilizados os custos relativos aos medicamentos de referência, pois rabeprazol e esomeprazol ainda não possuem o seu medicamento genérico correspondente, e, ainda, foram selecionadas as embalagens que continham o maior número de formas farmacêuticas disponíveis no mercado, visando uma maior redução dos custos e padronização da análise. Analisaram-se somente os dados relativos aos medicamentos comercializados no Brasil.

Para comparar o custo da terapia é necessário considerar a quantidade de cápsulas ou comprimidos utilizados por dia, a duração média da terapia, e a aquisição desse material. ${ }^{49}$

A Tabela 2 ilustra a comparação das opções terapêuticas. Os dados relacionados às estratégias terapêuticas foram retirados das bulas dos medicamentos de referência.

Saúde (Santa Maria), v.37, n.2, p. 19-32, 2011.

Braga, M. P.; da Silva, C. B.; Adams, A. I. 
Tabela 2 - Análise de minimização de custo dos IBPS.

\begin{tabular}{|c|c|c|c|c|c|c|}
\hline & $\begin{array}{c}\text { Preço } \\
\text { da } \\
\text { embalagem* }^{*}\end{array}$ & $\begin{array}{c}\text { Unidades } \\
\text { por } \\
\text { embalagem }\end{array}$ & $\begin{array}{l}\text { Preço } \\
\text { unitário }\end{array}$ & $\begin{array}{l}\text { Tempo de } \\
\text { tratamento }\end{array}$ & $\begin{array}{c}\text { Custo do tratamento } \\
\text { (se houver } \\
\text { fracionamento) }\end{array}$ & $\begin{array}{r}\text { Custo do } \\
\text { tratamento } \\
\text { (embalagem } \\
\text { fechada) }\end{array}$ \\
\hline $\begin{array}{l}\text { Omeprazol } \\
\text { (20 mg) }\end{array}$ & $\mathrm{R} \$ 57,54$ & 28 cáps. & $\mathrm{R} \$ 2,05$ & 6 semanas $\dagger$ & $\mathrm{R} \$ 86,10$ & $\mathrm{R} \$ 115,08$ \\
\hline $\begin{array}{c}\text { Lansoprazol } \\
(30 \mathrm{mg})\end{array}$ & $\mathrm{R} \$ 22,01$ & 14 cáps. & $\mathrm{R} \$ 1,57$ & 6 semanas $\dagger$ & $\mathrm{R} \$ 66,04$ & $\mathrm{R} \$ 66,04$ \\
\hline $\begin{array}{c}\text { Pantoprazol } \\
\text { (40 mg) }\end{array}$ & $\mathrm{R} \$ 182,55$ & 28 comp. & $\mathrm{R} \$ 6,52$ & 4 semanas & $\mathrm{R} \$ 182,56$ & $\mathrm{R} \$ 182,56$ \\
\hline $\begin{array}{l}\text { Rabeprazol } \\
\text { (20 mg) }\end{array}$ & $\mathrm{R} \$ 183,68$ & 28 comp. & $\mathrm{R} \$ 6,56$ & 6 semanas & $R \$ 275,52$ & $\mathrm{R} \$ 367,36$ \\
\hline $\begin{array}{c}\text { Esomeprazol } \\
\qquad(20 \mathrm{mg})\end{array}$ & $\mathrm{R} \$ 148,01$ & 28 comp. & $\mathrm{R} \$ 5,28$ & 6 semanas $\dagger$ & $\mathrm{R} \$ 221,76$ & $\mathrm{R} \$ 296,02$ \\
\hline
\end{tabular}

* Preços referentes à pesquisa de mercado realizada em farmácias locais † média do tempo total de tratamento ( 4 a 8 semanas)

‡ estimado de acordo com a posologia diária recomendada (1 comp. ou 1 cáp. por dia, para todos os IBPs)

A análise da Tabela 2 aponta que o preço unitário e o custo diário da terapia são mais caros com a utilização do rabeprazol e, além disso, o custo do tratamento por embalagem é cerca de 6 vezes mais caro com o emprego do rabeprazol comparado ao tratamento de menor custo, o lansoprazol. Ainda, neste caso, o paciente necessita comprar duas embalagens fechadas para a realização do tratamento por completo e há sobra de comprimidos, o que tornaria a terapia com lansoprazol novamente mais vantajosa onde, ao adquirir três embalagens fechadas para o cumprimento da terapia, o paciente conta com 0 número exato de cápsulas utilizadas em todo o tratamento, sem sobra de medicamento e sem gastos desnecessários.

\section{Considerações finais}

Os inibidores da bomba de prótons consistem em medicamentos usados muitas vezes empiricamente (por prescrição ou automedicação) para tratamento das manifestações digestivas que lembram as das doenças já referidas ou na prevenção do surgimento de tais sintomas. São considerados o maior avanço no tratamento de doenças gástricas. Quando usados corretamente, os IBPs são sem dúvida os mais potentes inibidores da secreção ácida gástrica disponíveis e, portanto, tornaram-se essenciais na terapia de várias doenças ácidorelacionadas.

Evidências atuais sugerem que os IBPs possuem eficácia semelhante. Estudos realizados com o tenatoprazol (fase pré-clínica) sugerem maior eficácia no controle da supressão da secreção gástrica noturna. Porém, estudos clínicos ainda são necessários para confirmar esta hipótese e torná-lo disponível para uso. 
Com base na análise farmacoeconômica realizada, comparando os custos dos IBPs disponíveis aplicados no tratamento da úlcera péptica gastroduodenal, o lansoprazol fornece um perfil mais favorável de farmacoeconomia. Portanto, a substituição de fármacos mais antigos por representantes mais novos acarreta, no mínimo, em custo desnecessário.

O levantamento bibliográfico realizado apontou a baixa incidência de efeitos adversos do tratamento a curto prazo; no entanto, a segurança e ausência de toxicidade a longo prazo ainda não está devidamente documentada. Sendo assim, o uso indiscriminado dessa classe de fármacos deve ser evitado.

\section{Referências}

1. Wolfe MM. Pharmacological principles governing the use of proton pump inhibitors: tailoring therapy to improve GERD outcomes. Gastroenterol Clin. 2003:32:vii-ix.

2. James MM, Gabello M, Murray LJ, Farrell CP, Bellows J, Wolov KR et al. Proton pump inhibitors: actions and Reactions. Drug Discov Today. 2009:14:13-14.

3. Peura D. Dexlansoprazole: a new PPI formulation for treatment of GERD. Nat Rev Gastroenterol Hepatol. 2009:5(5):321-323.

4. Shin JM, Homerin M, Domagala F, Ficheux H, Sachs G. Characterization of the inhibitory activity of tenatoprazole on the gastric $\mathrm{H}+, \mathrm{K}+-\mathrm{ATP}$ ase in vitro and in vivo. Biochem Pharmacol. 2006:71:837-849.

5. Wannmacher, L. Inibidores da bomba de prótons: indicações racionais. Uso Racion. Medicam. 2004:2(1):16.

6. Lanzon-Miller S, Pounder RE, Hamilton RRE, Ball S, Chronos NAF, Raymond F, Olausson M, Cederberg C. Twenty-four hour intragastric acidity and plasma gastrin concentration before and during treatment with either ranitidine and omeprazole. Aliment Pharmacol Ther. 1987:1.

7. Burget DW, Stephen G, Chiverton SG, Hunt RH. Is there an optimal degree of acid suppression for healing of duodenal ulcer? A model of the relationship between ulcer healing and acid suppression. Gastroenterol. 1990:99:345-351.

8. Bell NJ, Burget D, Howden CW, Hunt RH. Appropriate acid suppression for the management of gastrooesophageal reflux disease. Digestion. 1993: 51(1):59-67.

9. Rang HP, Dale MM, Ritter JM. Farmacologia. 6ª ed. Rio de Janeiro: Elsevier, 2007.

10. Marmo MC, Neto UF. Úlcera Péptica Gastroduodenal. J Ped Gastroenterol, Nutrition Liver Diseases. 2005:9:1-13.

11. Hoogerwerf WA, Pasricha PJ. Agentes usados para o controle da acidez gástrica e no tratamento de úlceras pépticas e da doença do refluxo gastresofágico. In: Goodman, Gilman. As bases farmacológicas da terapêutica. 10ª ed. Rio de Janeiro: McGraw-Hill, 2005.

12. Rimbara E, Fischbach LA, Graham DY. Optimal therapy for Helicobacter pylori infections. Gastroenterol. Hepatol. 2011:8:79-88.

13. Varannes SB, Coron E, Galmiche JP. Short and long-term PPI treatment for GERD. Do we need morepotent anti-secretory drugs? Best Pract Res Cl Ga. 2010:24:905-921.

14. Jones DB, Howden CW, Burget DW et al. Acid suppression in duodenal ulcer: a meta-analysis to define optimal dosing with antisecretory drugs. Gut. 1987:28:1120-7.

Saúde (Santa Maria), v.37, n.2, p. 19-32, 2011.

15. Bell NJ, Hunt RH. Role of gastric acid suppression in the treatment of gastrooesophageal reflux disease. Gut. 1992:33: 118-24.

Braga, M. P.; da Silva, C. B.; Adams, A. I. 
16. Robinson M. Proton pump inhibitors: update on their role in acid-related gastrointestinal diseases. Int $\mathrm{J}$ Clin Pract. 2005:59:709-715.

17. Grube RR, May DB. Stress ulcer prophylaxis in hospitalized patients not in intensive care units. Am J Health Syst Pharm. 2007:64:1396-400.

18. Richardson P, Hawkey C, Stack W. Proton pump inhibitors - pharmacology and rationale for use in gastrointestinal disorders. Drugs. 1998:56(3):307-335.

19. Horn J. The proton pump inhibitors: similarities and differences. Clin Ther. 2000:22(3):266-280.

20. Galmiche JP et al. Tenatoprazole, a novel proton pump inhibitor with a prolonged plasma half-life: effects on intragastric $\mathrm{pH}$ and comparison with esomeprazole in healthy volunteers. Aliment Pharmacol Ther. 2004:19:655-662.

21. Katzung BG. Basic and clinical pharmacology. New York: Lange Medical Books/McGraw-Hill, 2004. p. $1037-8,1040-1$

22. Kromer W. Similarities and differences in the properties of substituted benzimidazoles: a comparison between pantoprazole and related compounds. Digestion. 1995:56:443-54.

23. Miner PBJR, Katz PO, Chen Y, Sostek M. Gastric acid control with esomeprazole, lansoprazole, omeprazole, pantoprazole, and rabeprazole: a five-way crossover study. Am J Gastroenterol. 2003:98:26162620.

24. Pedregal $C$, Avedaño $C$. Fármacos que alteran el transporte através de las menbranas celulares. In: Lopez MCA. Introduccion a la química farmacêutica. Madrid: Interamericana McGraw Hill, 1993. p. 360-362.

25. De Giacomo $\mathrm{C}$ et al. Omeprazole treatment of severe peptic disease associated with antal $\mathrm{G}$ cell hyperfunction and hyperpepsinogenemia I in an infant. J Pediatr. 1990:177:989.

26. Andersson T. Pharmacokinetics, metabolism and interactions of acid pump inhibitors. Focus on omeprazole, lansoprazole and pantoprazole. Clin Pharmacokinet. 1996:31:9-28.

27. Hartmann $M$, Theiss $U$, Huber $\mathrm{R}$ et al. Twenty-four-hour intragastric pH profiles and pharmacokinetics following single and repeated oral administration of the próton pump inhibitor pantoprazole in comparison to omeprazole. Aliment Pharmacol Ther. 1996:10:359-366.

28. Stedman CAM, Barclay ML. Review article: comparison of the pharmacokinetics, acid suppression and eficacy of proton pump inhibitors. Aliment Pharmacol Ther. 2000:14:963-978.

29. Barth J, Hahne W. Review article: rabeprazole-based therapy in Helicobacter pylori eradication. Aliment Pharmacol Ther. 2002:16(1):31-33.

30. Tsutsui N, Taneike I, Ohara T, Goshi et al. A novel action of the proton pump inhibitor rabeprazole and its thioether derivative against the motility of Helicobacter pylori. Antimicrob Agents Chemother. 2000: 44(11):3069-3073

31. Andersson $T$ et al. Pharmacokinetics and pharmacodynamics of esomeprazole, the S-isomer of omeprazole. Aliment Pharmacol Ther. 2001:15:1563-1569.

32. Creutzfeldt W. Chiral switch, a successful way for developing drugs: example of esomeprazole. Z Gastroenterol. 2000:38:893-7.

33. Lind T, Rydberg L, Kyleback A et al. Esomeprazole provides improved acid control vs. omeprazole in patients with symptoms of gastroesophageal reflux disease. Aliment Pharmacol Ther. 2000:14:861-867.

Saúde (Santa Maria), v.37, n.2, p. 19-32, farmacoeconômica ISSN 2236-5834

34. Rohss K, Hasselgren G, Hedenstrom H. Effect of esomeprazole 40mg vs omeprazole 40mg on 24-hour intragastric $\mathrm{pH}$ in patients with symptoms of gastroesophageal reflux disease. Dig Dis Sci. 2002:47:954-958.

35. Fass $R$, et al. The effect of dexlansoprazole MR on nocturnal heartburn and GERD-related sleep disturbances in patients with symptomatic GERD. Am J Gastroenterol. 2011:106:421-431. 
36. Hunt RH, Armstrong D, James C, Chowdhury SK, Yuan Y, Fiorentini P, Taccoen A, Cohen P. Effect on intragastric $\mathrm{pH}$ of a PPI with a prolonged plasma half-life: comparison between tenatoprazole and esomeprazole on the duration of acid suppression in healthy male volunteers. Am J Gastroenterol. 2005: 100:1949-1956.

37. Larson C, Cavuto NJ, Flockhart DA, Weinberg RB. Bioavailability and efficacy of omeprazole given orally and by nasogastric tube. Dig Dis Sci. 1996:41:475-479.

38. Chun AH, Erdman K, Zhang Y, Achari R, Cavanaugh JH. Effect on bioavailability of admixing the contents of lansoprazole capsules with selected soft foods. Clin Ther. 2000:22:231-236.

39. Trissel LA. Trissel's: Stability of Compounded Formulation. $2^{\mathrm{a}}$ ed. Washington: American Pharmaceutical Association, 2000.

40. Baldi F, Malfertheiner P. Lansoprazole fast disintegrating tablet: a new formulation for an established proton pump inhibitor. Digestion. 2003:67:1-5.

41. Huber R, Hartmann M, Bliesath $\mathrm{H}$ et al. Pharmacokinetics of pantoprazole in man. Int $\mathrm{J}$ Clin Pharmacol Ther. 1996:34:185-94.

42. Fitton A, Wiseman L. Pantoprazole. A review of its pharmacological properties and therapeutic use in acidrelated disorders. Drugs. 1996:51:460-82.

43. Vanderhoff MD, Tahboub RM. Proton pump inhibitors: an update. Clin Pharmacol. 2002:66:273-80.

44. Madanick RD. Proton pump inhibitor side effects and drug interactions: much ado about nothing? Clev Clin J Med. 2011:78(1):39-49.

45. Sacristán Del Castilho JA, Llach XB. Farmacoeconomia: evalución económica de medicamentos. Madrid: Ed. Medica; 1995.

46. Secoli SR. Farmacoeconomia da terapia analgésica utilizada na dor pós-operatória. São Paulo:[s.n.], 2002. Tese (Doutorado) - Universidade de São Paulo. Escola de Enfermagem, 2002.

47. Baskin LE. What is the difference between pharmacoeconomics and outcomes research? In: Baskin LE. Practical pharmaeconomics: how to design, perform and analyze outcomes research. Indianapolis (OH/USA): Advanstar Communications. 1998:1-4.

48. Drummond MF. The use of health economic information by reimbursement authorities. Rheumatol. 2003: 42(3):60-3.

49. Eisenberg JM. Clinical economics: a guide to economic analysis of clinical practices. JAMA. 1989:262(20):2879-86.

50. Robertson J, Lang D, Hill S. Use of pharmacoeconomics in prescribing research. Part 1: costs-moving beyond the acquisition price for drugs. J Clin Pharm Ther. 2003:28:73-79.

\section{Andréa Inês Horn Adams}

Endereço para correspondência - Departamento de Farmácia Industrial, Prédio 26, Centro de Ciências da Saúde - Campus UFSM.

Santa Maria, RS, Brasil - CEP: 97110-970

E-mail: andrea.ih.adams@gmail.com

Currículo lattes: http://lattes.cnpq.br/6872246935204149

Recebido em 30 de abril de 2011.

Saúde (Santa Maria), v.37, n.2, p. 19-32,

Aprovado em 26 de novembro de 2011. 
Saúde (Santa Maria), v.37, n.2, p. 19-32,

$$
2011 .
$$

Inibidores da bomba de prótons: revisão e análise

32 | ISSN 2236-5834 


\title{
Estresse ocupacional em trabalhadores bancários: prevalência e fatores associados
}

\author{
Ione Teresa Altermann Pozeczek Koltermann*, Elaine Tomasi*, \\ Bernardo Lessa Horta**, Annie Pozeczek Koltermann***
}

\begin{abstract}
RESUMO: 0 estudo objetivou avaliar a prevalência de estresse ocupacional em trabalhadores bancários e investigar fontes estressoras do ambiente de trabalho. Estudo transversal, realizado em 2004, incluiu bancos estatais e privados de Pelotas e das cidades da região de cobertura do Sindicato dos Trabalhadores em Estabelecimentos Bancários (SEEB-Pel), com 650 bancários sindicalizados. Os dados foram coletados através do Inventário de Sintomas de Stress-Teste de Lipp (ISS), além de informações sócio-demográficas e das características do processo de trabalho. Foi possível entrevistar $502(77 \%)$ bancários. No tocante ao estresse, $14,7 \%$ dos bancários encontravam-se na fase de alerta, $45,6 \%$ na fase de resistência e 18,1\% na fase de exaustão. Os eventos estressores das categorias moderado e alto demonstraram associação significativa com todas as fases de estresse $(p=0,00)$. Maiores níveis de estresse foram registrados para as mulheres, para os bancários com dependência de bebida de álcool, tabagistas e com maior carga horária de trabalho.
\end{abstract}

Descritores: Estresse ocupacional; Saúde dos trabalhadores; Riscos ocupacionais.

\section{Occupational stress in bank workers: prevalenve and related factors}

\begin{abstract}
The objective of this article is to assess the predominance of occupational stress in bank workers and to determine sources of stress in their work environment. A cross-sectional study, realized in 2004, included state and private banks from Pelotas and from cities that belong to the area covered by the Bank Establishments Workers Union (SEEB-Pel), totaling 650 unionized bank workers. The data were collected through the Lipp Stress Test Symptoms Inventory (SSI), besides social demographic information and work process characteristics. In total, $502(77 \%)$ people were interviewed. The answers to the questionnaires showed that, in regard to stress, $14.7 \%$ of the bank workers are in the alert phase, $45.6 \%$ are in the resistance phase and $18.1 \%$ are in the exhaustion phase. The moderate and high stress causing events demonstrated a significant association with all stress phases $(p=0.00)$. Higher levels of stress were identified in women, workers with alcohol dependence, smokers and the ones with longer working hours.
\end{abstract}

Descriptors: Occupational stress; Workers health; Occupational risks.

\footnotetext{
* Mestre em Saúde e Comportamento pela Universidade Católica de Pelotas (UCPel), Pelotas, RS, Brasil.

** Programa de Pós-Graduação em Epidemiologia, Universidade Federal de Pelotas (UFPel), Pelotas, RS, Brasil.

*** Mestre em Saúde Coletiva pela Universidade do Vale do Rio dos Sinos (UNISINOS), docente do Curso de Odontologia do Centro Universitário Franciscano (UNIFRA), Santa Maria, RS, Brasil.
} 


\section{Introdução}

Sabe-se da importância que o trabalho ocupa na vida das pessoas como fator relevante na formação da identidade e na inserção social. Considera-se que o bem-estar adquirido pelo equilíbrio entre as expectativas em relação à atividade profissional e sua concretização é um dos fatores que constituem a qualidade de vida ${ }^{1,2}$.

O trabalho é essencial para a vida humana, mas é também fonte de múltiplos riscos à saúde dos trabalhadores entre eles o estresse ocupacional é um dos riscos que compromete o bem-estar do indivíduo.

Suportes afetivos e sociais que os indivíduos recebem durante seu percurso profissional e uma relação satisfatória e harmoniosa com a atividade de trabalho é fundamental para 0 desenvolvimento nas diferentes áreas da vida humana ${ }^{2}$. A fragilidade emocional provocada pela falta de tais suportes pode trazer grande sofrimento, e esse reflexo atua tanto na vida privada como no campo das relações de trabalho ${ }^{3}$. 0 trabalhador, ao sentir-se sem alternativa de compartilhar suas dificuldades, tende a aumentar sua tensão emocional, o que consequentemente pode levar ao surgimento do estresse ocupacional ${ }^{1,2}$.

Selye, citado por Lipp, em 1936 identificou o estresse como uma síndrome que apresentava profundas correlações com o estado de saúde física e mental, bem como 0 adoecimento dos indivíduos, a qual chamou de "síndrome geral de adaptação". Foi o primeiro autor a conceituar 0 estresse distinguindo suas formas positivas e negativas. 0 mesmo autor refere que o processo de estresse desencadeia-se em três fases: alerta, resistência e exaustão. ${ }^{4}$

$\mathrm{Na}$ fase de alerta, o organismo prepara-se para a reação de luta ou fuga, ajustando o corpo e a mente à autopreservação; na fase de resistência, o organismo tenta se adaptar, mas se o estressor é de longa duração, após um tempo sem efeitos positivos, entram em cena sintomas como o desgaste e o cansaço. Já, na fase de exaustão, caracterizada pelo estresse contínuo e pela incapacidade da pessoa em lidar com a situação, ocorre esgotamento das energias disponíveis e do próprio organismo, culminando no aparecimento de doenças mais sérias, resultando na interrupção das atividades da pessoa. ${ }^{4,5}$

\section{Estresse no trabalho}

O estresse ocupacional entendido como estresse no trabalho representa risco para 0 bem estar físico e emocional e tem sido motivo de vários estudos nos mais diferentes setores produtivos, tais como profissionais de saúde ${ }^{6,7}$, estudantes ${ }^{8}$, trabalhadores do transporte

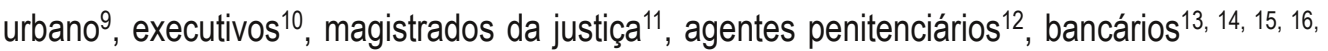
17 e outros.

Para atender a demanda e atingir metas por exigência de um mercado competitivo, as organizações necessitam cada vez mais administrar mudanças em seu ambiente organizacional. Estudos têm relatado que eventos como carga horária excessiva, ambiente

prevalência e fatores associados psicologicamente insatisfatório ${ }^{12}$, sobre carga de trabalho doméstico, velocidade rápida no trabalho e descontentamento no trabalho ${ }^{14}$, diferenças de caixa e agressões dos clientes ${ }^{15}$, pressão e cobranças por resultados, quadro de funcionários aquém das necessidades da 
instituição que leva ao acúmulo de funções ${ }^{18}$, representam situações de sofrimento e consequentemente pode levar ao estresse. Segundo Xavier ${ }^{19}$, o processo de trabalho bancário pode levar à depressão, manifestada através de tristeza, baixa auto-estima, ansiedade, comprometimento do humor, do pensamento, da conduta e comportamento suicida.

O estresse é importante para a realização de qualquer atividade e a sua total ausência, assim como seu excesso, podem ser prejudiciais à saúde 2 . 0 prolongamento de situações de estresse pode determinar um quadro patológico, originando distúrbios com sintomas físicos e emocionais como esquecimento, irritação, ansiedade ${ }^{3}$, perda de apetite, dificuldade de desligar-se ${ }^{16}$, tensão muscular, sensação de desgaste físico, cansaço constante ${ }^{6}$, sensibilidade excessiva e pensamento recorrente ${ }^{8}$.

Também pode contribuir para a etiologia como ação desencadeadora ou agravante de várias outras doenças como hipertensão arterial essencial, úlceras gastroduodenais, psoríase, vitiligo, retração de gengivas ${ }^{4}$. Levi20 cita que o estresse relacionado ao trabalho seja um fator determinante da síndrome metabólica representado por uma combinação de acúmulo de gordura abdominal, diminuição na sensibilidade celular à insulina, dislipidemia e aumento na pressão sangüínea.

Na I Conferência Internacional sobre Promoção da Saúde, 1986, no Canadá, houve consenso em torno de uma nova concepção de saúde, que pudesse responder à emergente complexidade dos problemas de saúde da atualidade; a doença não é mais vinculada apenas a um determinado agente ou grupo de agentes, mas produto de um conjunto multifatorial de elementos, dentre os quais se destacam as condições e modos de vida e trabalho. Neste contexto, a Vigilância em Saúde do Trabalhador aponta para a necessidade de se integrar de forma mais efetiva às ações de promoção da saúde, a fim de se afirmar a essa nova concepção de atuação em Saúde Pública ${ }^{21}$.

Assim, tentando contribuir para este debate, o presente estudo sobre o trabalho bancário teve como objetivo estimar a prevalência de estresse ocupacional em trabalhadores bancários e investigar sua associação com as características do processo do trabalho, as características demográficas e comportamentais, além de caracterizar e quantificar o efeito dos eventos estressores na atividade bancária sobre 0 estresse.

\section{Metodologia}

Realizou-se estudo transversal, entre maio e dezembro de 2004, em instituições bancárias (estatais e privadas) das cidades de cobertura do sindicato dos Trabalhadores em Estabelecimentos Bancários de Pelotas (SEEB- Pel), constituído por: Pelotas, Piratini, Pedro Osório, Canguçu, Jaguarão, Arroio Grande, Capão do Leão, Herval, Santana da Boa Vista e Morro Redondo. De acordo com o Sindicato, existiam 650 bancários em atividade na região, por ocasião da coleta de dados.

A coleta de dados nas agências bancárias foi realizada em horários previamente estipulados pela administração. Após o esclarecimento e informações sobre os objetivos do estudo, os questionários foram distribuídos aos bancários. Foi destacada a não obrigatoriedade da participação no estudo, além de garantir o sigilo das informações. A devolução dos questionários foi feita aos pesquisadores no período médio de uma semana, em envelopes lacrados.

Saúde (Santa Maria), v.37, n.2, p. 33-48, 2011. 
Além das informações sociodemográficas - idade, sexo, escolaridade - foram estudadas características comportamentais - tabagismo, dependência de bebida alcoólica, medida pelo teste CAGE $^{22}$ e as características do processo do trabalho - tipo de banco, cargo, horas de trabalho e atividade.

Para a caracterização das fontes e/ou eventos estressores na atividade e no ambiente organizacional, utilizaram-se um inventário com 24 itens construído para tal propósito, a partir de outros estudos (Sindicato dos Bancários de Porto Alegre ${ }^{23}$, Xavier ${ }^{19}$, Margis ${ }^{24}$, Mompó ${ }^{25}$ ). Para a análise, uma nova variável foi criada agrupando-se as fontes/eventos em três grupos, de acordo com sua distribuição de freqüência: considerou-se categoria baixa quem assinalou até sete itens, categoria moderada quem assinalou entre oito e quinze itens e categoria alta quem assinalou 16 itens ou mais.

Para a avaliação de estresse, utilizou-se o Inventário de Sintomas de Stress (ISS), validado por Lipp ${ }^{26,4}$. O ISS permite diagnosticar se a pessoa tem estresse, em que fase do processo se encontra (alerta, resistência e exaustão) e se sua sintomatologia é mais típica da área somática ou cognitiva ${ }^{8}$. Ele tem sido utilizado em outros estudos (Nacarato27, Girardello ${ }^{28}$, CASSI $^{29}$, Nunes ${ }^{17}$ ), é de fácil aplicação e é composto por três quadros, cada um se referindo a uma das fases do processo de estresse, de acordo com o modelo trifásico de Selye. $O$ respondente é solicitado a indicar se tem tido o sintoma especificado em cada quadro e a classificação de seu nível de estresse ocorre da seguinte forma: sete itens ou mais no Quadro I significam que se encontra em fase de alerta; quatro itens ou mais no Quadro II significam que se encontra na fase de resistência e nove itens ou mais no Quadro III correspondem à fase de exaustão.

O estudo piloto foi realizado com 11 bancários que faziam parte da diretoria do Sindicato dos Bancários. A digitação dos dados foi feita utilizando-se o programa EPI-INFO 6.04, em estrutura para a entrada de dados com limites tanto para as variáveis quantitativas quanto qualitativas, para evitar erros na amplitude e consistência dos dados. Todos os questionários foram duplamente digitados e os arquivos foram comparados para detecção de erros. 0 arquivo final foi convertido para o programa SPSS 8.0 for Windows.

Uma primeira análise tomou como desfecho o estresse se o bancário pontuou alguma fase das três acima referidas, visto que o mesmo sujeito poderia pontuar em mais de uma fase. Uma segunda análise foi realizada tomando-se como variáveis dependentes as três fases do Inventário de Sintomas de Stress, separadamente.

A associação entre as variáveis foi verificada através do teste do qui-quadrado e foram calculadas as razões de prevalência (RP), com seus respectivos intervalos de confiança de 95\% (IC95\%).

\section{Resultados}

Foram entrevistados $502(77 \%)$ bancários. As perdas foram principalmente devidas a recusas da totalidade de bancários de três agências e os demais motivos foram férias e por prevalência e fatores associaa falta de devolução dos questionários preenchidos no prazo estipulado. A taxa de não resposta foi maior nos estabelecimentos públicos $(26 \%)$ do que nos privados (11\%). Do total dos 
entrevistados, quase $80 \%$ trabalhavam em Pelotas. Nos demais municípios, observaram-se uma concentração de bancários em instituições públicas (96\% contra 70\% em Pelotas).

Com relação ao sexo, $58 \%$ da amostra eram do sexo masculino e $29 \%$ estavam na faixa entre 42 a 46 anos. Quanto à escolaridade $37 \%$ possuíam $3^{\circ}$ grau e $8 \%$ possuía pósgraduação. Dos entrevistados, $22 \%$ faziam uso de tabaco e $6 \%$ apresentou CAGE positivo (Tabela 1).

Dos bancários entrevistados, $68 \%$ eram escriturários e menos de 10\% referiu desempenhar outra atividade profissional. No banco em que trabalhavam $86 \%$ realizavam atividades de atendimento ao público. Praticamente 40\% da amostra era bancário há 20 anos ou mais e $63 \%$ trabalhavam mais de seis horas por dia (Tabela 1).

Tabela 1 - Distribuição da amostra de acordo com características demográficas, comportamentais e do processo de trabalho em bancários da zona sul do RS, 2004 ( $n=502)$.

\begin{tabular}{|c|c|c|}
\hline Variável & $n$ & $\%$ \\
\hline \multicolumn{3}{|l|}{ Sexo } \\
\hline Masculino & n291 & 58,0 \\
\hline Feminino & 211 & 42,0 \\
\hline \multicolumn{3}{|l|}{ Idade (anos) } \\
\hline 20 a 34 & 135 & 26,9 \\
\hline 35 a 41 & 117 & 23,3 \\
\hline 42 a 46 & 144 & 28,7 \\
\hline 47 a 59 & 106 & 21,1 \\
\hline \multicolumn{3}{|l|}{ Escolaridade } \\
\hline $1^{\circ} \mathrm{grau}$ & 14 & 2,8 \\
\hline $2^{\circ}$ grau & 265 & 52,8 \\
\hline $3^{\circ}$ grau & 183 & 36,5 \\
\hline Pós-graduação & 40 & 8,0 \\
\hline \multicolumn{3}{|l|}{ Tabagismo } \\
\hline Sim & 109 & 22,1 \\
\hline Não & 384 & 77,9 \\
\hline \multicolumn{3}{|l|}{ CAGE + } \\
\hline Sim & 30 & 6,0 \\
\hline Não & 472 & 94,0 \\
\hline \multicolumn{3}{|l|}{ Cidade } \\
\hline Pelotas & 392 & 78,0 \\
\hline Outra & 110 & 22,0 \\
\hline
\end{tabular}




\begin{tabular}{|c|c|c|}
\hline \multicolumn{3}{|l|}{ Tempo de bancário } \\
\hline Até 9 & 126 & 25,0 \\
\hline 10 a 19 & 176 & 35,0 \\
\hline 20 ou mais & 200 & 40,0 \\
\hline \multicolumn{3}{|c|}{ Outra atividade profissional } \\
\hline $\operatorname{Sim}$ & 42 & 8,0 \\
\hline Não & 460 & 92,0 \\
\hline \multicolumn{3}{|l|}{ Horas de trabalho / dia } \\
\hline 6 & 183 & 37,0 \\
\hline 7-8 & 265 & 53,0 \\
\hline Mais de 8 & 45 & 10,0 \\
\hline \multicolumn{3}{|l|}{ Atividade } \\
\hline Só atende público & 396 & 79,0 \\
\hline Só interna & 71 & 14,0 \\
\hline Ambas & 35 & 7,0 \\
\hline \multicolumn{3}{|l|}{ Cargo } \\
\hline Escriturário & 339 & 68,0 \\
\hline Comissionado & 163 & 32,0 \\
\hline \multicolumn{3}{|c|}{ Escore de eventos estressores } \\
\hline Baixo (até 7) & 249 & 49,6 \\
\hline Moderado (8 a 15) & 189 & 37,6 \\
\hline Alto (16 ou mais) & 64 & 12,7 \\
\hline
\end{tabular}

De acordo com o relato de eventos estressores, a amostra ficou assim distribuída: $49 \%$ na categoria baixa, $38 \%$ na categoria moderada e $13 \%$ na categoria alta.

Entre os eventos mais relatados como estressores na atividade e ambiente organizacional do bancário pode-se destacar: pressão ou cobrança da chefia / exigência de metas (65\%); possibilidade de ser responsabilizado por perda de valores (58\%); insuficiência de pessoal (53\%); preocupação com a avaliação do desempenho e ascensão (50\%); acúmulo de funções e de responsabilidade (49\%); necessidade de seguir ordens do banco contrárias a interesse próprio ou de clientes (47\%); pressão do cliente (45\%); risco de assaltos (44\%).

$\mathrm{Na}$ avaliação do estresse, verificou-se que $47 \%$ da amostra apresentavam alguma sintomatologia típica de estresse. Quando examinados separadamente, obteve-se $15 \%$ na

Saúde (Santa Maria), v.37, n.2, p. 33-48,

prevalência e fatores associados fase de alerta, $46 \%$ na fase de resistência e $18 \%$ na fase de exaustão, uma vez que a mesma pessoa poderia pontuar em mais de uma fase.

A Tabela 2 apresenta as prevalências de sintomas característicos da fase de resistência. Quase metade dos bancários queixou-se de desgaste físico e problemas de memória e cerca de um terço referiu cansaço, irritabilidade e sensibilidade emotiva em excesso. 
Tabela 2 - Prevalência de sintomas de estresse característicos da fase de resistência em bancários. Pelotas, RS, 2004 (n=502).

\begin{tabular}{cc}
\hline Sintoma & $\%$ \\
\hline Sensação de desgaste físico constante & 43,4 \\
Problemas com a memória, esquecimentos & 41,4 \\
Cansaço constante & 37,6 \\
Irritabilidade excessiva & 31,2 \\
Sensibilidade emotiva excessiva & 28,0 \\
Mal-estar generalizado, sem causa específica & 27,4 \\
Pensamento constante sobre um só assunto & 26,0 \\
Formigamento nas extremidades & 24,0 \\
Mudança de apetite & 23,4 \\
Gastrite prolongada & 22,4 \\
Dúvidas quanto a si próprio & 21,4 \\
Tontura, sensação de estar flutuando & 20,6 \\
Diminuição da libido & 20,0 \\
Aparecimento de problemas dermatológicos & 19,0 \\
\hline
\end{tabular}

A Tabela 3 apresenta as análises do estresse como um todo. Destacaram-se associações significativas com sexo feminino, tabagismo, CAGE positivo, maior jornada de trabalho, cargo ocupado no banco e eventos estressores.

Tabela 3 - Prevalência de estresse de acordo com características demográficas, comportamentais e do processo de trabalho em bancários da zona sul do RS, 2004 (n=502).

\begin{tabular}{cccc}
\hline Variável & Prevalência de Estresse (\%) & RP (IC95\%) & p-valor \\
\hline Sexo & 41,6 & & \\
Masculino & 54,0 & $1,30(1,08-1,56)$ & \\
Feminino & & & \\
Idade (anos) & 43,0 & Referêência & $0,308^{*}$ \\
20 a 34 & 46,2 & $1,07(0,82-1,42)$ & \\
35 a 41 & 50,0 & $1,16(0,90-1,50)$ & \\
42 a 46 & 48,1 & $1,12(0,85-1,48)$ & \\
47 a 59 & &
\end{tabular}

Saúde (Santa Maria), v.37, n.2, p. 33-48, 2011.

Koltermann, I.T.A.P., et al. 


\begin{tabular}{|c|c|c|c|}
\hline \multicolumn{4}{|l|}{ Escolaridade } \\
\hline $2^{\circ} \mathrm{grau}$ & 48,7 & $1,10(0,91-1,33)$ & 0,378 \\
\hline $3^{\circ}$ grau ou Pós-graduação & 44,4 & Referência & \\
\hline Tabagismo & z & & \\
\hline Sim & 56,0 & $1,29(1,05-1,57)$ & 0,028 \\
\hline Não & 43,5 & Referência & \\
\hline \multicolumn{4}{|l|}{ CAGE + } \\
\hline Sim & 73,3 & $1,63(1,28-2,06)$ & 0,005 \\
\hline Não & 45,1 & Referência & \\
\hline \multicolumn{4}{|l|}{ Cidade } \\
\hline Pelotas & 45,2 & Referência & 0,194 \\
\hline Outra & 52,7 & $1,17(0,95-1,44)$ & \\
\hline \multicolumn{4}{|l|}{ Tempo de bancário (anos) } \\
\hline Até 9 & 42,1 & Referência & $0,291^{*}$ \\
\hline 10 a 19 & 48,3 & $1,15(0,89-1,48)$ & \\
\hline 20 ou mais & 48,5 & $1,15(0,90-1,48)$ & \\
\hline \multicolumn{4}{|l|}{ Outra atividade profissional } \\
\hline Sim & 35,7 & Referência & 0,179 \\
\hline Não & 47,8 & $1,34(0,88-2,03)$ & \\
\hline \multicolumn{4}{|l|}{ Horas de trabalho dia } \\
\hline 6 & 43,7 & Referência & $0,044^{*}$ \\
\hline $7-8$ & 44,5 & $1,02(0,82-1,26)$ & \\
\hline Mais de 8 & 66,7 & $1,52(1,17-1,99)$ & \\
\hline \multicolumn{4}{|l|}{ Atividade } \\
\hline Só interna ao banco & 38,0 & Referência & 0,257 \\
\hline Só atende público & 48,0 & $1,26(0,92-1,73)$ & \\
\hline Ambas & 51,4 & $1,35(0,87-2,10)$ & \\
\hline \multicolumn{4}{|l|}{ Cargo } \\
\hline Escriturário & 50,7 & $1,31(1,05-1,64)$ & 0,014 \\
\hline Comissionado & 38,7 & Referência & \\
\hline
\end{tabular}

Saúde (Santa Maria), v.37, n.2, p. 33-48,

Escore de eventos estressores 


\begin{tabular}{|c|c|c|c|}
\hline Baixo (até 7) & 29,7 & Referência & $0,000^{*}$ \\
\hline Moderado (8 a 15) & 58,2 & $1,96(1,56-2,46)$ & \\
\hline Alto (16 ou mais) & 79,7 & $2,68(2,14-3,37)$ & \\
\hline Total & 46,8 & -- & -- \\
\hline
\end{tabular}

${ }^{*} \mathrm{p}$-valor para tendência linear

As Tabelas 4 e 5 apresentam as análises das três fases do estresse separadamente. As variáveis que se associaram significativamente com a fase de alerta foram: trabalhar mais de oito horas por dia $(p=0,04)$, relato de categoria de eventos estressores moderada e alta, ambas com $p=0,00$, tabagismo com $58 \%$ e bancários que faziam ambos atendimento, interno e ao público, com 2,5 vezes mais de ter sintomas de estresse comparados com atividade somente interna.

Quem apresentou significativamente mais sintomas de resistência foram as mulheres ( $37 \%$ a mais do que os homens), os fumantes ( $28 \%$ a mais do que os não fumantes), os dependentes de bebidas alcoólicas - CAGE positivo (59\% a mais do que os não dependentes). Da mesma forma, quem trabalhava mais de oito horas por dia teve $46 \%$ a mais de sintomas de resistência comparado com os de menor jornada de trabalho $(p=0,03)$. Comparados com os funcionários comissionados, os escriturários apresentaram quase $40 \%$ mais de sintomas - $\mathrm{RP}=1,39(\mathrm{IC} 95 \%=1,10-1,75)$. Também os bancários que referenciaram categorias de fontes / eventos estressores alta e moderada apresentaram significativamente cerca de duas vezes mais sintomas nesta fase do estresse.

As variáveis significativamente associadas com os sintomas da fase de exaustão foram: CAGE positivo, jornada diária de mais de 8 horas, desempenho de atividades internas e de atendimento ao público, além das categorias moderada e alta de fontes/eventos estressores. Todas estas associações foram significativas ao nível de $p=0,00$. 
Tabela 4 - Prevalência (\%) da Fase de Alerta, Resistência e Exaustão de acordo com características demográficas e comportamentais em bancários da zona sul do RS, 2004 (n=502).

\begin{tabular}{|c|c|c|c|c|c|c|c|c|c|}
\hline \multirow[t]{2}{*}{ Variável } & \multicolumn{3}{|c|}{ Alerta } & \multicolumn{3}{|c|}{ Resistência } & \multicolumn{3}{|c|}{ Exaustão } \\
\hline & Prevalência & RP (IC95\%) & p-valor & Prevalência & RP (IC95\%) & p-valor & Prevalência & RP (IC95\%) & $p$-valor \\
\hline \multicolumn{10}{|l|}{ Sexo } \\
\hline Masculino & 13,7 & Referência & & 39,5 & Referência & & 15,1 & Referência & \\
\hline Feminino & 16,1 & $1,17(0,77-1,79)$ & 0,54 & 54,0 & $1,37(1,23-1,65)$ & 0,00 & 22,3 & $1,47(1,02-2,13)$ & 0,05 \\
\hline \multicolumn{10}{|l|}{ Idade (anos) } \\
\hline 20 a 34 & 14,1 & Referência & & 40,7 & Referência & & 12,6 & Referência & \\
\hline 35 a 41 & 15,4 & $1,09(0,60-1,98)$ & 0,91 & 45,3 & $1,11(0,84-1,48)$ & 0,55 & 21,4 & $1,70(0,97-2,98)$ & 0,09 \\
\hline 42 a 46 & 13,9 & $0,99(0,55-1,77)$ & 0,96 & 50,0 & $1,23(0,95-1,59)$ & 0,15 & 18,8 & $1,49(0,85-2,61)$ & 0,21 \\
\hline 47 a 59 & 16,0 & $1,14(0,62-2,08)$ & 0,81 & 46,2 & $1,13(0,85-1,51)$ & 0,47 & 20,8 & $1,65(0,92-2,94)$ & 0,13 \\
\hline \multicolumn{10}{|l|}{ Escolaridade } \\
\hline $1^{\circ} \mathrm{grau}$ & 28,6 & $1,99(0,82-4,84)$ & 0,29 & 57,1 & $1,33(0,82-2,14)$ & 0,45 & 21,4 & $1.17(0,41-3,30)$ & 0,94 \\
\hline $2^{\circ} \mathrm{grau}$ & 14,3 & $1,00(0,65-1,54)$ & 0,90 & 47,2 & $1,10(0,90-1,34)$ & 0,41 & 17,7 & $0,96(0,66-1,41)$ & 0,95 \\
\hline $3^{\circ}$ grau ou & 14,3 & Referência & & 43,0 & Referência & & 18,4 & Referência & \\
\hline \multicolumn{10}{|c|}{ Pós-graduação } \\
\hline Tabagismo & & & & & $1,28(1,04-1,57)$ & 0,04 & & & \\
\hline Sim & 20,2 & $1,58(1,00-2,50)$ & 0,07 & 54,1 & Referência & & 22,0 & $1,34(0,88-2,04)$ & 0,23 \\
\hline Não & 12,8 & Referência & & 42,4 & & & 16,4 & Referência & \\
\hline CAGE + & & & & & $1,59(1,23-2,05)$ & 0,01 & & & \\
\hline Sim & 26,7 & $1,91(1,01-3,60)$ & 0,10 & 70,0 & Referência & & 40,0 & $2,39(1,48-3,87)$ & 0,00 \\
\hline Não & 14,0 & Referência & & 44,1 & & & 16,7 & Referência & \\
\hline
\end{tabular}

42 ISSN 2236-5834 
Tabela 5 - Prevalência (\%) da Fase de Alerta, Resistência e Exaustão de acordo com características do processo de trabalho e eventos estressores em bancários da zona sul do RS, 2004 (n=502).

\begin{tabular}{|c|c|c|c|c|c|c|c|c|c|}
\hline \multirow[t]{2}{*}{ Variável } & \multicolumn{3}{|c|}{ Alerta } & \multicolumn{3}{|c|}{ Resistência } & \multicolumn{3}{|c|}{ Exaustão } \\
\hline & Prevalência & RP (IC95\%) & p-valor & Prevalência & RP (IC95\%) & p-valor & Prevalência & RP (IC95\%) & p-valor \\
\hline \multicolumn{10}{|l|}{ Horas trabalho / dia } \\
\hline 6 & 9,8 & Referência & & 42,6 & Referência & & 13,1 & Referência & \\
\hline $7-8$ & 16,2 & $1,65(0,98-2,77)$ & 0,07 & 43,8 & $1,03(0,83-1,28)$ & 0,89 & 18,1 & $1,38(0,88-2,17)$ & 0,20 \\
\hline Mais de 8 & 22,2 & $2,26(1,12-4,55)$ & 0,04 & 62,2 & $1,46(1,10-1,94)$ & 0,03 & 33,3 & $2,54(1,46-4,43)$ & 0,00 \\
\hline \multicolumn{10}{|l|}{ Atividade } \\
\hline Só interna & 9,9 & Referência & & 38,0 & Referência & & 15,5 & Referência & \\
\hline Só público & 14,6 & $1,49(0,71-3,12)$ & 0,38 & 46,5 & $1,22(0,89-1,67)$ & 0,24 & 16,4 & $1,06(0,59-1,91)$ & 0,98 \\
\hline Ambas & 25,7 & $2,61(1,06-6,42)$ & 0,06 & 51,4 & $1,11(0,79-1,55)$ & 0,69 & 42,9 & $2,61(1,68-4,06)$ & 0,00 \\
\hline \multicolumn{10}{|l|}{ Cargo } \\
\hline Escriturário & 14,7 & $1,00(0,64-1,57)$ & 0,90 & 50,1 & $1,39(1,10-1,74)$ & 0,00 & 17,7 & $0,93(0,63-1,38)$ & 0,81 \\
\hline Comissionado & 14,7 & Referência & & 36,2 & Referência & & 19,0 & Referência & \\
\hline \multicolumn{10}{|c|}{ Escore de eventos estressores } \\
\hline Baixo (até 7) & 4,4 & Referência & & 28,9 & Referência & & 8,4 & Referência & \\
\hline Moderado (8 a 15) & 19,6 & $4,43(2,32-8,45)$ & 0,00 & 57,1 & $1,98(1,57-2,49)$ & 0,00 & 20,1 & $2,38(1,45-3,92)$ & 0,00 \\
\hline Alto (16 ou mais) & 40,6 & $9,20(4,80-17,60)$ & 0,00 & 76,6 & $2,65(2,09-3,36)$ & 0,00 & 50,0 & $5,95(3,68-9,55)$ & 0,00 \\
\hline
\end{tabular}

RP= Razão de prevalências e Intervalo de Confiança de 95\%

Saúde (Santa Maria), Ahead of Print v.37, n.2, p. 33-48, 2011 . Koltermann, I.T.A.P., et al

ISSN 2236-5843 


\section{Discussão}

Uma vez que o percentual de não-respondentes foi elevado (23\%), pode ter ocorrido um viés de seleção. Bancários que não responderam o questionário poderiam apresentar outros resultados, com relação ao estresse, do que aqueles que participaram do estudo.

A prevalência de sintomas de estresse neste estudo foi de $47 \%$, inferior à encontrada por Donato e cols. ${ }^{16}$ na mesma categoria de trabalhadores (57\%), e por Lipp \& Tanganelli ${ }^{11}$, entre magistrados (71\%), e similar por Morais e cols. ${ }^{6}$, entre profissionais de saúde $(47 \%)$.

As mulheres apresentaram mais sintomas de estresse nas fases de resistência e de exaustão, o que está de acordo com os achados de Fernandes e cols. ${ }^{12}$, Calais e cols. ${ }^{8} \mathrm{e}$ Nunes ${ }^{17}$. Além das tarefas e exigências que as mulheres enfrentam no seu cotidiano, relativas a aspectos pessoais, biológicos, papéis sociais na família, o trabalho bancário parece também implicar em maiores cargas estressoras.

0 achado de $6 \%$ de positividade no teste CAGE entre os bancários entrevistados foi cerca do dobro do que encontrado por Primo \& $\operatorname{Stein}^{30}$ (2,5\%) e Almeida \& Coutinho ${ }^{31}$ (3\%), ambos em estudos de base populacional. A positividade no CAGE em nossa amostra associou-se significativamente com as fases de resistência e exaustão, o que pode ser relacionado às características da atividade laboral. De acordo com Camargo e cols. ${ }^{32}$, alguns tipos de trabalho são considerados fatores psicossociais de risco para o alcoolismo crônico. Entre eles, os que envolvem atividades em que a tensão resulta de altas exigências cognitivas, havendo grande densidade da atividade mental, como em repartições públicas, estabelecimentos bancários e comerciais.

Os bancários fumantes representaram $22 \%$ da amostra, proporção inferior à relatada por Griep e cols. ${ }^{33}$, de $29 \%$ entre bancários, e similar à referida por Barros \& Nahas ${ }^{34}$ entre trabalhadores da indústria em Santa Catarina (21\%), apesar de ainda menor do que a encontrada em estudos de base populacional, em torno de 35\% por Moreira e cols. ${ }^{35}$. Ainda assim, o tabagismo esteve significativamente associado ao estresse entre os bancários, principalmente nas fases de alerta e resistência.

Tanto os hábitos de fumar quanto a dependência de bebida alcoólica foram mais prevalentes nos homens, o que está de acordo com Barros \& Nahas ${ }^{34}$, que definiram um perfil bidimensional: nos homens, os comportamentos de risco mais prevalentes tomam a forma de risco direto ou ativo (fumar, abuso de bebidas alcoólicas) e, nas mulheres, tomam a forma de risco indireto ou passivo (inatividade física, estresse).

Apesar de a jornada de trabalho bancário ser constituída de seis horas diárias, em nossa amostra ela foi referida somente por $37 \%$ dos trabalhadores e trabalhar mais de oito horas por dia esteve positivamente associado com todas as fases do estresse. Da mesma forma, quem trabalhava em ambas as atividades, de atendimento ao público e expediente interno, apresentou mais sintomas de estresse, tanto na fase de alerta, quanto na fase de exaustão. A jornada e a atividade se comportaram como importantes marcadores de estresse no trabalho bancário, a exemplo do que foi destacado em outras atividades laborais como Fernandes e cols. ${ }^{12}$ e Seifert e cols. ${ }^{13}$.

Como esperado, a maior percepção dos bancários sobre eventos estressores no ambiente de trabalho, associou-se muito significativamente ao estresse, em todas as suas fases. Quanto maior o número de eventos citados, maior a prevalência de estresse. Tais achados podem ser corroborados por Seifert e cols..$^{13}$ e Sousa e cols. ${ }^{14}$. 
Rossi ${ }^{36}$, investigando diferenças de gênero em fatores estressores entre diferentes profissionais, identificou proporções relevantes de referência em 18 fatores, o que the permitiu inferir que o estresse é uma realidade presente na saúde ocupacional.

\section{Considerações finais}

Neste estudo detectou-se uma alta prevalência de estresse ocupacional entre os trabalhadores bancários, e estes achados poderão sugerir mudanças no ambiente organizacional com possibilidades de uma atividade bancária com significado importante, com reconhecimento profissional, valorizando as competências, pois trabalhadores atuando em locais que Ihes são interessantes agregam valores produtivos tanto na esfera pessoal como organizacional.

As organizações em todo o mundo estão vivenciando níveis de incerteza ocasionados por fatores como inquietações política, manipulação governamental com relação à dinâmica comercial e terrorismo. Como conseqüência em se operar em ambientes imprevisiveis ocasionou 0 aumento do uso de modificações da força de trabalho, como terceirização e as demissões. Mudanças estas que ocorrem em uma velocidade cada vez maior e as organizações em competição buscam um trabalho em menor tempo com mais eficiência. Essa incerteza no mundo do trabalho faz com que ocorra a insuficiência de pessoal e com isso os trabalhadores acumulam funções e aumentam sua carga de horas de trabalho em função da pressão dos clientes e da chefia em atingir cada vez mais metas e tende a se manifestar 0 estresse ocupacional.

Através de um gerenciamento sistemático do ambiente do trabalho realizado entre as partes envolvidas e coordenado por um serviço de saúde ocupacional vinculado à empresa representado por profissionais da área de saúde, defende-se um ambiente organizacional assertivo, com resolução de problemas, com incentivos, trabalho permanente, relações interpessoais com objetividade e cooperação, encaminhando para a humanização do trabalho e assim minimizando a lacuna causada pelo o estresse uma vez que este determina um alto preço em termos psicológicos, físicos e organizacionais.

\section{Colaboração}

Koltermann ITAP, Tomasi E, Horta BL, trabalharam na pesquisa, coleta de dados, delineamento, análise e interpretação dos dados e redação do artigo. Koltermann AP colaborou na sua revisão crítica e aprovação da versão a ser publicada.

Apoio: Sindicato dos Trabalhadores em Estabelecimentos Bancários de Pelotas (SEEB-Pel) 


\section{Referências}

1. Lennart LMD. $O$ guia da comissão européia sobre stress relacionado ao trabalho e iniciativas relacionadas: das palavras à ação. Em Rossi NA: Stress e Qualidade de Vida no Trabalho. Perspectivas Atuais da Saúde Ocupacional. São Paulo: Atlas; 2005. p.167-81.

2. Abreu KL, Ramos ISL, Baumgardt R A, Kristensen $\mathrm{CH}$. Estresse ocupacional e síndrome de burnout no exercício profissional da Psicologia. Psicol Cienc e Prof 2002; 22(2):22-29.

3. Gazzotti AA, Vasques-Menezes I. Suporte afetivo e o sofrimento psíquico em Burnout. Em: Codo W. Educação: Carinho e trabalho. 3a ed. Rio de Janeiro: Vozes; 1999. p.261-66.

4. Lipp MEN. Pesquisas sobre stress no Brasil: saúde, ocupações e grupos de risco. 2a ed. Campinas, SP: Papirus; 2001. p.304.

5. Malagris LEN. Qualidade de vida e estresse. Cad Psicol da SBP 2000; 1(1):19-26.

6. Morais PC, Costa RSC, Araújo MRGL, Donato BY. Incidência de stress em profissionais da área da saúde. Anais I Congresso Norte-Nordeste de Psicologia. V Semana Baiana de Psicologia. Salvador. Bahia. 27- 30 de Maio de 1999. Acesso: 9/9/2004. Disponível em: http://www.ufba.br/conpsi/conpsi1999/painéis

7. Weinberg A, Creed F. Stress and psychiatric disorder in healthcare professionals and hospital staff. The Lancet 2000 feb 12; 355(9203):533-37.

8. Calais SL, Andrade LM, Lipp MEN. Diferenças de sexo e escolaridade na manifestação de stress em adulto jovem. Psico Reflex Crít. 2003;16(2):257-63.

9. Sampaio RF, Coelho CM, Barbosa FB, Mancini MC,Parreira VF.Work adility and stress in a bus transportation company in Belo Horizonte, Brazil. Cienc Saúde Colet 2009:14(1):287-96.

10. Guic E, Bilbao M A, Bertin C. Estrés laboral y salud em una muestra de ejecutivos chilenos. Rev Médica de Chile. 2002; 130(10):1101-12.

11. Lipp MEN, Tanganelli MS. Stress e qualidade de vida em magistrados da Justiça do Trabalho: diferenças entre homens e mulheres. Psicol Reflex Crít. 2002;15(3):537-48.

12. Fernandes RCP, Neto AMS, Sena GM et. al. Trabalho e cárcere: um estudo com agentes penitenciários da Região Metropolitana de Salvador, Brasil. Cad Saúde Pública. 2002;18(3):807-16.

13. Seifert AM, Messing K, Dumais L. Star wars and strategic defense initiatives: work activity and healty symptoms of unionized bank tellers during work reorganization. International Journal of Health Services 1997;27(3):455-77.

14. Sousa FM, Messing K, Menezes PR, Cho HJ. Chronic fatigue among bank workers in Brazil. Occupation Medicine (Lond). 2002;52(4):187-94.

15. Palacios M, Duarte F, Câmara VM. Trabalho e sofrimento psíquico de caixas de agências bancárias na cidade do Rio de Janeiro. Cad Saúde Pública. 2002;18(3):843-51.

16. Donato YB, Almeida EM, Diniz EM et.al. Caracterização dos níveis de stress em bancários da cidade de João Pessoa - PB. Anais I Congresso Norte-Nordeste de Psicologia. V Semana Baiana de Psicologia Salvador. Bahia. 27- 30 de Maio de 1999. Acesso: 5/11/2003. Disponível em: http://www.ufba.br/conpsi/conpsi1999/paineis.

17. Nunes NA, Molina FB, Zola TRP, Lauris JRP, Nunes OBC. Avaliação do nível de estresse emocional em bancários de Cafelândia/SP e percepção de sintomas bucais. Rev. Fac. Odontol. Lins, Piracicab.

Saúde (Santa Maria), v.37, n.2, p. 33-48,

2011. 2005;17(1): 23-32

18. Pereira LZ, Braga CD, Marques AL. Estresse no trabalho: estudo de caso com gerentes que atuam em uma instituição financeira nacional de grande porte. Rev Ciências da Administração. 2008:10(21)175-96.

19. Xavier EP. Um minuto de silêncio. Réquiem aos bancários mortos no trabalho. Edição do Sindicato dos Bancários de Porto Alegre. 1998. p.110. 
20. Levi L. O guia da comissão ao trabalho européia sobre stress relacionado ao trabalho e iniciativas relacionadas: das palavras à ação. Em: Stress e qualidade de vida no trabalho. Perspectivas atuais da saúde ocupacional. São Paulo: Atlas; 2005. p. 167-181.

21. Alves RB. Vigilância em saúde do trabalhador e promoção da saúde: aproximações possíveis e desafios. Cad Saúde Pública. 2003;19(1):319-22.

22. Masur $\mathrm{J} \&$ Monteiro MG. Validation of the "cage" alcoholism screening test in a Brasilian psychiatric inpatient hospital setting. Braz J Med Biol Res. 1983;16:215-18.

23. Sindicato dos Bancários de Porto Alegre; Sindicato do Interior do Estado através do Coletivo de Saúde da Federação dos Bancários do Rio Grande do Sul; Departamento de Medicina Social da Faculdade de Medicina da UFRGS. Censo Bancário - Avaliação de Saúde dos Bancários do Rio Grande do Sul. Porto Alegre. 1997. p.95.

24. Margis R, Picon P, Coiner AF et. al. Relação entre estressores, estresse e ansiedade. Rev Psiquiatr Rio Gd Sul. 2003;25( 1):65-74.

25. Monpó GL, Vilas LA, Sotolongo PC, Carrillo PC, Carrillo CC, Gutiérrez EG. Influencia del estrés ocupacional el processo salud-enfermedad. Rev Cub Med Mil. 2003;32(2):149-54.

26. Lipp MEN, Guevara AJH. Validação empírica do inventário de sintomas de stress. Estud Psicol. 1994;11(3):43-49.

27. Nacarato AECB. Stress no Idoso: Efeitos diferenciais da ocupação profissional. Pesquisas sobre Stress no Brasil: Saúde, Ocupações e grupos de Risco. Papirus. 2001: 275-96.

28. Girardello JR. A Relação entre o cortisol sanguíneo e o estresse pré-competitivo e lutadores de caratê de alto rendimento. 2004. (dissertação), Curitiba (Pr): Universidade Federal do Paraná; 2004.

29. Caixa de assistência dos funcionários do Banco do Brasil. Manual de preenchimento dos formulários do exame periódico de saúde - EPS/2002. Acesso em: 05/01/2004. Disponível em: http://www.cassi.com.br.

30. Primo NLN, Stein AT. Prevalência do abuso e da dependência de álcool em Rio Grande (RS): um estudo transversal de base populacional. Rev Psiquiatr Rio Gd Sul. 2004;26(3):280-86.

31. Almeida LM, Coutinho ESF. Prevalência de consumo de bebidas alcoólicas e de alcoolismo em uma região metropolitana do Brasil. Rev Saúde Pública. 1993; 27(1):23-9.

32. Camargo DA, Caetano D, Guimarães LAM. Psiquiatria ocupacional II: síndromes psiquiátricas orgânicas relacionadas ao trabalho. J Bras Psiquiatr. 2005;54(1):21-33.

33. Griep RH, Chor D, Camacho LAB. Tabagismo entre trabalhadores de empresa bancária. Rev Saúde Pública. 1998;32(6):533-40.

34. Barros MVG, Nahas MV. Comportamentos de risco, auto-avaliação do nível de saúde e percepção de estresse entre trabalhadores da indústria. Rev Saúde Pública. 2001;35(6):554-63.

35. Moreira LB, Fuchs FD, Moraes RS et. al. Prevalência de tabagismo e fatores associados em área metropolitana da região sul do Brasil. Rev Saúde Pública 1995;29(1):46-51.

36. Rossi AM. Estressores ocupacionais e diferenças de gênero. Em: Stress e qualidade de vida no trabalho. Perspectivas atuais da saúde ocupacional. São Paulo: Atlas; 2005. p.9-18.

\section{Ione Teresa A. P. Koltermann}

Endereço para correspondência - Rua Daudt, 576/401, CEP: 97010-150, Santa Maria, Rio Grande do Sul, Brasil.

E-mail: ionepk@terra.com.br

Saúde (Santa Maria), v.37, n.2, p. 33-48, 2011. Koltermann, I.T.A.P., et al.

Aprovado em 26 de outubro de 2011 
Saúde (Santa Maria), v.37, n.2, p. 33-48,

$$
2011 .
$$

Estresse ocupacional em trabalhadores bancários: prevalência e fatores associados
$48 \mid$
ISSN 2236-5834 


\title{
Estudo e Frequência do sistema Rh e Kell nos doadores do hemocentro de Santa \\ Maria - RS
}

\author{
Adriana Najai Bortolotto, Márcia M. Mikalauscas, Anelise L. Murari, \\ Samara Rubin, José Edson Paz da Silva
}

\begin{abstract}
RESUMO: O trabalho teve como objetivo avaliar a frequência dos fenótipos do sistema Rh e Kell em doadores do Hemocentro de Santa Maria. A frequência destes sistemas depende da etnia de cada região. Os principais antígenos do sistema $\mathrm{Rh}$ incluem: $\mathrm{D}, \mathrm{C} / \mathrm{c} / \mathrm{C}$ w e E/e. Das 1832 amostras fenotipadas, quanto ao sistema Rh, 870 amostras (48 \%) foram fenotipadas como Rh positivo e 962 amostras $(52,0 \%)$ fenotipadas como Rh negativo . A frequência dos antígenos encontrados foi : cc 59,20 \%;CC 27,67 \%; CC 12,55 \%; Cw 0,87 \% ; ee 83,62 \%; Ee 15,30\%; EE 1,08 \% e 7,36 \% Kell positivo. Das fenotipadas como Rh negativo, 78 amostras $(8,1 \%)$ foram positivas para 0 antígeno "C" e/ou "E" e 8,2 \% Kell positivo. Uma vez que, estes antígenos são capazes de causar Doença Hemolítica Grave e Aloimunizações é necessária a pesquisa destes no doador Rh negativo

Descritores: Doadores de Sangue, Sistema do Grupo Sanguíneo de Kell, Sistema do Grupo Sanguíneo Rh-Hr.
\end{abstract}

\section{Study and Frequency of $R h$ and Kell system in blood donors of blood center in Santa Maria - RS}

ABSTRACT: The study was aimed at evaluating the frequency of Rh and Kell system phenotypes in donors at the Blood Center of Santa Maria. Frequency of such systems depends on each regions ethnicity. The main antigens of the Rh system include: D, C/c/Cw and E/e. From the 1832 phenotyped samples, regarding the Rh system, $870(48 \%)$ were Rh positive and $962(52 \%)$ were Rh negative. Frequency of the antigens was: cc $59.20 \%$; Cc $27.67 \%$; CC $12.55 \%$; CW $0.87 \%$; ee $83.62 \%$; Ee $15.30 \%$; EE 1.08\%; and $7.36 \%$ kell positive. From the samples phenotyped as Rh negative, 78 (8.1\%) were positive for the "C" and/or "E" antigen and $8.2 \%$ were kell positive. Since these antigens may cause Severe hemolytic disease and Alloimmunization, it is required to search for them in the Rh negative donors.

Descriptors: Blood Donors, Kell Blood-Group System, Rh-Hr Blood-Group System.

\footnotetext{
* Professor de Hematologia do Departamento de Análises Clínicas e Toxicológicas do Centro de Ciências da Saúde, pela Universidade Federal de Santa Maria (UFSM), Santa Maria, RS, Brasil.

** Mestranda no Programa de Ciências Farmacêuticaspela Universidade Federal de Santa Maria (UFSM), Santa Maria, RS, Brasil.

*** Funcionária do Hospital Universitário de Santa Maria (HUSM), Santa Maria, RS, Brasil.

${ }^{* * * \star}$ Graduanda no Curso de Farmácia pela Universidade Federal de Santa Maria (UFSM), Santa Maria, RS, Brasil.
} 


\section{Introdução}

Os sistemas de grupos sanguíneos são caracterizados pela presença de antígenos eritrocitários, com características funcionais e polimórficas definidas. ${ }^{1}$

Conforme Beiguelman² (2006), a frequência do sistema Rh e Kell varia entre as diversas populações no mundo,pois dependem da etnia de cada região. 0 conhecimento da freqüência fenotípica dos vários grupos sangüíneos é essencial para estimar a disponibilidade de sangue compatível para pacientes que apresentem anticorpos antieritrocitários, segundo Novaretti et al. ${ }^{3}(2000)$

O sistema Rh é o maior e mais complexo sistema de grupos sanguíneos, compreendendo atualmente 49 antígenos. E também o sistema com maior grau de polimorfismo entre os marcadores conhecidos da membrana eritrocitária. ${ }^{4,5}$

Segundo Castilho ${ }^{6}$ (2007) os antígenos Rh são codificados por dois genes, altamente homólogos, localizados no braço curto do cromossomo 1: o gene RHD, produzindo 0 antígeno $\mathrm{D}$ e o gene RHCE, produzindo dois pares de antígenos antitéticos, C/c e E/e. A proximidade entre os genes RHD e RHCE facilita a ocorrência de conversão gênica durante os rearranjos gênicos entre eles, levando, assim, à formação de híbridos (partes do gene RHD em RHCE e vice-versa), responsáveis por algumas variantes do antígeno $\mathrm{Rh} D$.

Os principais antígenos do sistema $\mathrm{Rh}$ incluem: $\mathrm{D}, \mathrm{C} / \mathrm{c} / \mathrm{Cw}$ e E/e, sendo, o antígeno $\mathrm{Rh}$ D considerado o mais imunogênico, seguido dos antígenos $c, E, C, e^{6,7,8}$

Segundo Fischer e Race citado por Harmening ${ }^{7}$ a frequência genética com que os antígenos do sistema Rh encontra-se descrita no quadro 1.

Quadro 1-Frequência dos antigenos do Sistema Rh

\begin{tabular}{|c|c|}
\hline ANTIGENOS & FREQUÊNCIA (\%) \\
\hline D & 85 \\
\hline C & 70 \\
\hline E & 30 \\
\hline$d$ & 15 \\
\hline c & 80 \\
\hline e & 98 \\
\hline
\end{tabular}

Fonte: Harmening $2006^{7}$

Os antígenos Rh são polipeptideos transmembranares. Os produtos genéticos de RHD e RHCE são notavelmente similares porque ambos codificam para proteínas compostas por 417 aminoácidos que atravessam a membrana celular 12 vezes e porque diferem apenas no par de bases 44 , segundo Harmening. Os produtos genéticos de RHCE, RHCe, RHce, RHcE são ainda mais similares. ${ }^{7}$

Os antigenos "C" e "c" diferem entre si em quatro posições de aminoácidos, e um aminoácido distingue os antigenos "E" e "e". Somente pequenas alças de proteínas Rh estão expostas na superfície da hemácia e conferem os pré-requisitos conformacionais para as diferenças sorológicas observadas entre os tipos de sangue $\mathrm{Rh}^{7}{ }^{7}$ 
$\mathrm{O}$ antígeno $\mathrm{D}$ (presente em indivíduos Rh positivo) difere da proteína CcEe em 35 aminoácidos, fato que o torna imunogênico para os indivíduos que não o possuem. Isto pode explicar porquê o sistema Rh frequentemente induz uma resposta imune muito forte. ${ }^{9}$

Os antígenos Rh são exclusivamente eritrocitários, não são encontrados em leucócitos ou plaquetas e surgem precocemente em torno da décima semana de vida intra-uterina. ${ }^{8}$

$\mathrm{O}$ antígeno Rh D é o mais importante do sistema Rh devido ao seu envolvimento na Doença Hemolítica Perinatal e nas Reações Hemolíticas Auto- imunes. ${ }^{6,8}$

A presença ou ausência do antígeno Rh $D$ nas hemácias determina o fenótipo conhecido. Portanto, o indivíduo considerado Rh positivo possui os dois genes (RHD e $R H C E$ ), enquanto no indivíduo Rh negativo, quase em sua totalidade, o gene RHD está deletado. ${ }^{4}$ Segundo Girello e Kuhn8 (2007), em torno de 85 \% da população mundial e constituída de indivíduos Rh positivos e aproximadamente $55 \%$ destes indivíduos Rh D positivo são heterozigotos em seu lócus $\mathrm{Rh} D{ }^{10}$

$\mathrm{O}$ antígeno $\mathrm{Cw}$ é produzido por um gene variante de RHCE. Não se trata de um antígeno "C" fraco, mas de um novo antígeno que pode estar presente independentemente dos fenótipos C/c. É um antígeno de baixa frequência, estimada em menos de $2 \%$ em brancos e muito raro em negros. ${ }^{4,7,8}$ Este antígeno foi descoberto em 1946, por Callender e Race, em um paciente de genótipo Cde/CDe, que tinha recebido varias transfusões. Demonstrou-se, posteriormente, que este antígeno, encontrado em indivíduos $\mathrm{Rh}$ (D) positivo, estava ligado ao fator $\mathrm{C}\left(\mathrm{rh}^{\prime}\right)$, sendo um terceiro alelo da série $\mathrm{C}-\mathrm{c}$ ao qual seus descobridores denominaram $\mathrm{Cw}$, sendo o símbolo $\mathrm{W}$ a inicial do doador (Willis), cujos glóbulos continham o referido antígeno que estimularam a formação do anticorpo anti-CW. ${ }^{11}$

De acordo com Harmening ${ }^{7}$ (2006) o sistema de grupo sanguíneo Kell é uma interessante mescla de antígenos de frequências altas e baixas. O antígeno K1 (Kell) está presente em apenas uma pequena parte da população, enquanto o antígeno k (cellano) está presente em $99 \%$, sendo considerado um antígeno de alta frequencia. Os 24 antígenos conhecidos fazem do sistema de grupo sanguíneo Kell o terceiro sistema de antígenos eritrocitários mais polimórficos. ${ }^{12}$ Sendo que estão bem desenvolvidos ao nascimento e são expressos, principalmente, na superfície da membrana dos eritrócitos e também, em órgãos linfóides, cérebro, coração e músculo esquelético, entre outros. ${ }^{4,12}$

Conforme Beiguelman² 2003, o antígeno K (Kell, K1) foi o primeiro a ser descrito (1946) seguido do antígeno $\mathrm{k}$ (Cellano, $\mathrm{K} 2$ ) três anos mais tarde. Com o emprego do anti-soro anti$\mathrm{K}$ foi constatado que cerca de $9 \%$ dos indivíduos caucasóides possuem 0 antígeno Kell, porcentagem menor em negros de 1 a $3 \%$, e nas populações do extremo oriente e praticamente nula. Os anticorpos do sistema Kell podem causar Doença Hemolítica Neonatal. A presença do anticorpo anti-Kell no feto e posteriormente no recém-nascido, pode levá-lo à anemia grave devido ao efeito inibitório da eritropoiese, independente da concentração do anticorpo. ${ }^{2,8}$

A fenotipagem sanguínea é a determinação da presença ou ausência de antígenos eritrocitários na membrana da hemácia. Atualmente, a hemoterapia, no Brasil e no mundo, tem se caracterizado pelo desenvolvimento e adoção de novas tecnologias, como a fenotipagem eritrocitária, com o objetivo de minimizar os riscos transfusionais, tornando-se uma prática mais segura. ${ }^{13}$

Saúde (Santa Maria), v.37, n.2, p. 49-55, 2011.

Neste trabalho foi avaliada a frequência dos antígenos do grupo sanguíneo $\mathrm{Rh}$ (D,C,Cw,C,E,e) e do antígeno K1 do sistema Kell em uma amostra de doadores de sangue 
da cidade de Santa Maria - RS. Com a perspectiva de conhecer a populacão em foco, uma vez que pouco se conhece a respeito da mesma. A não deteccão destes antigenos em doadores de sangue pode causar aloimunizacães nos receptores, que receberem hemácias com fenótipos diferentes.

\section{Metodologia}

Foram analisadas amostras de 1832 doadores, de um total de 7281, no período entre setembro de 2009 e setembro de 2010, no Hemocentro Regional de Santa Maria. Foram incluídos todos os doadores Rh negativos e alguns positivos, residentes na cidade de Santa Maria/RS, Brasil.

As amostras foram testadas para a determinação da fenotipagem dos principais antígenos eritrocitários dos sistemas $\mathrm{Rh}(\mathrm{D}, \mathrm{C}, \mathrm{Cw}, \mathrm{C}, \mathrm{E}, \mathrm{e})$ e Kell (K1), através da metodologia de aglutinação em coluna gel teste (Diamed Ag, Morat, Switzerland) utilizando cartões com anticorpos policlonais . ${ }^{14,15}$

Para o teste foi preparada uma suspensão de hemácias a $5 \%$ em bromelina. Incubada por dez minutos à temperatura ambiente. $\mathrm{O}$ cartão utilizado foi o cartão Rh-subgrupo + $\mathrm{Cw}+$ $\mathrm{K}$ contendo anticorpos anti-C, anti-Cw, anti-C, anti-E, anti-K e anti-e de origem humana, suspenso em gel. Foi pipetado $10 \mu \mathrm{l}$ da suspensão nos microtubos. A seguir, os cartões foram centrifugados a $910 \mathrm{rpm}$ por dez minutos. A leitura das reações foi realizada em função dos padrões de aglutinação em gel teste.

O trabalho foi aprovado pelo Comitê de Ética em Pesquisa, da Universidade Federal de Santa Maria (CONEP/MS - 23081.013622/2008-14). e o CAAE (Certificado de apresentação para Apreciação Ética): 0183.0.243.000-08.

\section{Resultados e discussão}

Quando analisados para o sistema Rh, os 1832 doadores foram fenotipados para os antígenos C, Cw, c, E, e foram encontrados 23 (12,55 \%) CC; 507 (27,67 \%) Cc; 1090 (59,20 \%) cc (Tabela 1); 20 (1,08 \%) EE; 280 (15,30\%) Ee; 1532 (83,62 \%) ee (Tabela 2); e 16 $(0,87 \%) C^{w}$ (Tabela 3$)$.

Tabela 1 - Freqüência dos antígenos C e c

\begin{tabular}{cccc}
\hline Fenótipo & Antígeno & Quantidade & Percentual \\
\hline CC & C+ c- & 230 & $12,55 \%$ \\
Cc & C+ c+ & 507 & $27,67 \%$ \\
Cc & C- c+ & 1090 & $59,20 \%$ \\
\hline
\end{tabular}


Tabela 2 - Freqüência dos antígenos $E$, e

\begin{tabular}{cccc}
\hline Fenótipo & Antígenos & Quantidade & Percentual \\
\hline EE & E+ e- & 20 & $1,08 \%$ \\
Ee & E+ e+ & 280 & $15,30 \%$ \\
ee & E - e+ & 1532 & $83,62 \%$
\end{tabular}

Tabela 3 - Freqüência do antígeno $\mathrm{C}^{\mathrm{w}}$

\begin{tabular}{ccc}
\hline Antígeno & Quantidade & Percentual \\
\hline $\mathrm{C}^{\mathrm{w}+}$ & 16 & $0.87 \%$ \\
$\mathrm{C}^{\mathrm{w}}-$ & 1816 & $99,13 \%$ \\
\hline
\end{tabular}

Quanto ao sistema Rh, das 1832 amostras fenotipadas, 962 amostras (52 \%) demonstraram-se como Rh negativo e 870 (48 \%) doadores Rh positivo. Das amostras consideradas como Rh negativo, 78 (8,1\%) foram positivas para o antígeno "C" e/ou "E" (Figura 1). Nestes resultados observamos que o fenótipo para doador Rh negativo desejado, ou seja, dccee, sofreu uma alteracão com a presença dos antigenos "C" e "E" sendo este resultado de grande importância clínica transfusional.

A frequência encontrada do antígeno $\mathrm{Cw}$, na Tabela 3, esta dentro dos valores encontrados na literatura estimada em menos de $2 \%$ em brancos. ${ }^{4}$

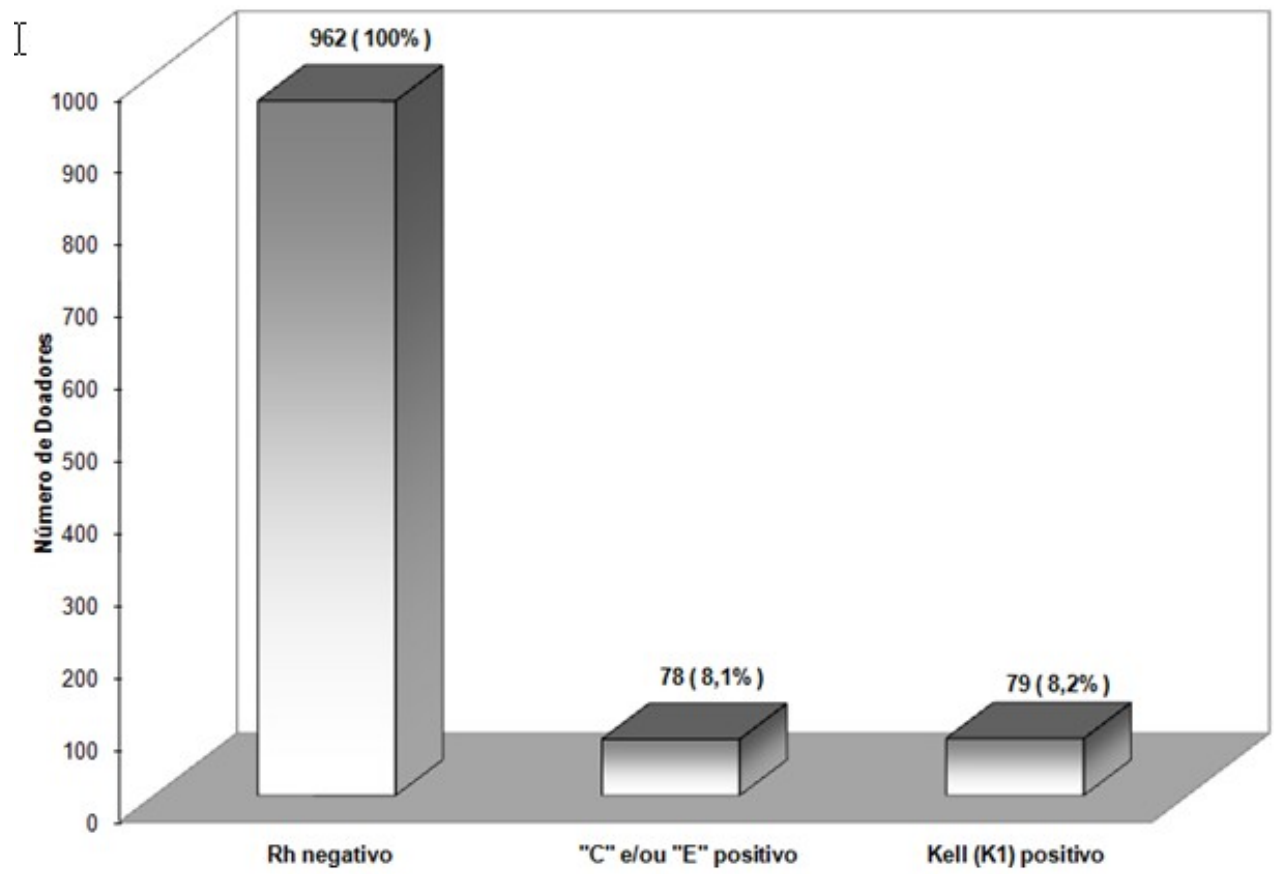

Figura 1 - Total de doadores Rh negativo com "C" e/ou "E" e (K1) Kell positivo

Na Tabela 4, encontramos os resultados referentes ao sistema Kell, onde do total de doadores fenotipados 135 (7,36 \%) são Kell positivos e 1697 (92,63 \%) são Kell negativos.

2011.

Bortolotto, A. N., et al. 
Tabela 4 - Freqüência do antígeno Kell (K1)

\begin{tabular}{ccc}
\hline Antígeno & Quantidade & Percentual \\
\hline Kell + & 135 & $7,36 \%$ \\
Kell - & 1697 & $92,63 \%$ \\
\hline
\end{tabular}

Em relação ao sistema Kell, a fenotipagem foi realizada apenas para K1. O. número de doadores Kell positivo esta dentro do esperado e semelhante ao descrito por Beiguelman ${ }^{2}$ (2003) e Harmening ${ }^{5}$ (2006). Porém ao relacionar ao sistema Rh encontramos um alto percentual deste antígeno $(8,2 \%)$ em doadores Rh negativo. ${ }^{4} \mathrm{~A}$ região é colonizada por descendentes italianos e alemães, caracterizando uma população predominante caucasoide. ${ }^{16}$

O doador sendo Rh $D$ negativo ao apresentar os antígenos $E, C$ ou $K$, em suas hemácias, seu sangue deve ser utilizado somente em pessoas que também possuam 0 mesmo fenótipo devido ao poder imunogênico e envolvimento com a Doença Hemolítica do Recém-Nascido, pois podem sensibilizar pessoas com fenótipos diferentes. ${ }^{17}$

\section{Considerações finais}

Este trabalho demonstra a importância da fenotipagem para os antígenos D, C, C, E, e, $K$, devido ao seu poder imunogênico e para conhecer a frequência destes antígenos na população.

$\mathrm{O}$ doador Rh negativo deve ser analisado para os demais antígenos do sistema que, mesmo sendo menos imunogênicos, quando presentes,são capazes de causar DHRN e sensibilizar os receptores que não os possuem.

$O$ doador sendo Rh $D$ negativo ao apresentar os antígenos $E, C$ ou $K$, em suas hemácias deve possuir um protocolo de conduta diferenciada para estes fenótipos conforme a legislação, devido ao poder imunogênico e envolvimento com a Doença Hemolítica do Recém-Nascido podendo sensibilizar pessoas com fenótipos diferentes. ${ }^{17}$ Assim como observamos a necessidade da análise conjunta destes sisitemas. Este estudo, demostra a necessidade da introdução da fenotipagem eritrocitária em todos os doadores, de forma gradativa e em todos os bancos de sangue pois esse procedimento reduziria 0 índice de aloimunizações e aumentaria a segurança tranfusional, como também reduziria custos para as instituições.

\section{Referências}

1. Storry JR, Castilho L, Daniels G, Flegel WA, Garraty G, Francis CL et al. International Society of Blood

Saúde (Santa Maria), v.37, n.2, p.49-56, Estudo e Frequência do sistema RH e Kell nos doadores do hemocentro de Santa Maria - RS $54 \mid$ Transfusion Working Party on red cell immunogenetics and blood group terminology: Berlin report. Vox Sang. 2011; 101 (1): 77-82.

2. Beiguelman B. Os Sistemas Sanguíneos Eritrocitários. $3^{\mathrm{a}}$ ed. Ribeirão Preto (SP): FUNPEC; 2003.

3. Novaretti MCZ, Dorhia CLPE, Chamone DAF. Estudo de grupos sanguíneos em doadores de sangue caucasóides e negróides na cidade de São Paulo. Rev Bras Hematol Hemoter. 2000, 22(1):23-32. 
4. Girello AL; Kuhn TIBB. - Fundamentos da imuno-hematologia eritrocitária. São Paulo: Senac; 2002.

5. Flegel, W.A. The genetics of the Rhesus blood group system. Blood Transfusion, v.5, p. 50-7, 2007

6. Castilho L. Sistema de grupo sangüineo Rh. In: Bordin JO, Langhi JR DM, Covas DT (Eds.). Hemoterapia fundamentos e práticas. São Paulo: Atheneu; 2007. 137-146.

7. Harmening DM - Técnicas Modernas em Bancos de Sangue e Transfusão. $4^{\circ}$ ed. Rio de Janeiro:Revinter; 2006.

8.Girello, A.L.; Kuhn, TII.B.B. Fundamentos da imuno-hematologia eritrocitária. São Paulo: Senac, 2007

9. Westhoff CM. Review: the Rh blood group D antigen dominant, diverse, and difficult. Immunohematology. 2005; 21:155-163.

10. Moise KJ Jr. Management of rhesus alloimmunization in pregnancy. Obstet Gynecol. 2002;100(3):60011.

11. Lima AO, Soares JB, Greco JB, Galizzi J, Cançado JR. Métodos de Laboratório Aplicados à Clínica $8^{\circ}$.ed. Rio de janeiro:Guanabara; 2001.

12. Bordin JO, Junior DML, Covas DT. Hemoterapia fundamentos e Práticas. São Paulo: Atheneu; 2007.

13. Castilho, L. Sistema Rh. In: SIMPÓSIO HEMOPASSO, 2008. Passo Fundo. Anais ... Passo Fundo: Hemocentro Regional, 2008. Disponível em: <www.pmpf.rs.gov.br/servicos/geral/files/portal/sgs.ppt>. Acesso 2m 16 dez. 2010.

14. DIAMED. Disponível em: http://www.diamed.com.br/Cmi/Pagina.aspx?379. Acesso em: dez. 2010.

15. TECHNICAL MANUAL OF AABB (USA): Bethesda, Maryland,1993.

$16 . \quad$ IBGE. Disponível em: http://www.ibge.gov.br/home/estatistica/populacao/condicaodevida/indicadoresminimos/tabela1.shtm\#a112. Acesso em: jun. 2011.

17. Brasil. Ministério da Saúde. Agência Nacional de Vigilância Sanitária. Portaria no 1.353 , de 13 de junho de 2011. Aprova o Regulamento Técnico de Procedimentos Hemoterápicos. Diário Oficial da União, Brasília, 14 de junho de 2011.

\section{José Edson Paz da Silva}

Endereço para correspondência - Av. Roraima n 1000, Prédio 26 - sala 1332

Campus - Universidade Federal de Santa Maria

Santa Maria - RS

CEP 97105-900

E-mail: jepazdasilva@gmail.com

Currículo lattes: http://lattes.cnpq.br/1177504021154172

Recebido em 10 de agosto de 2011.

Aprovado em 18 de novembro de 2011. 
Saúde (Santa Maria), v.37, n.2, p.49-56,

2011.

Estudo e Frequência do sistema RH e Kell nos doadores do hemocentro de Santa Maria - RS

56

ISSN 2236-5834 


\title{
Physico-chemical quality control and dosage of total polyphenols, flavonoids of Morus alba Leaves (MORACEAE)
}

\author{
Camila B. Pereira*, Aline Marin**, Tiago D. T. Maki*k, Raquel M. M. \\ Necchi***, Melânia Palermo Manfron ${ }^{* \star * *}$
}

\begin{abstract}
To establish parameters for quality control of Morus alba leaves were done tests of purity by determining the loss on drying, foreign matter, total ash, acid insoluble ash, swelling index, bitterness index, yield of crude extract, $\mathrm{pH}$ and organoleptic properties. The tests were done with samples collected on March, June, September and December according to Brazilian Pharmacopeia and World Health Organization. The percentage of loss on drying found are according to the established value of $14 \%$, the highest content was on September $12.89 \pm 0.1400 \%$. The indices of foreign matter found are agreement with the amount allowed by Brazilian Pharmacopeia, which establishes a maximum of $2 \%$ for most of the herbal drugs. The colletc on March showed the highest content of total ash and acid insoluble ash, respectively, $20.48 \pm 0.3517 \%$ and $5.68 \pm 0.1057 \%$. The swelling index showed higher values in samples collected on September $7.95 \pm 0.2186 \mathrm{~mL}$ and on December $7.1 \pm 0.8544 \mathrm{~mL}$. The bitterness index was higher in the first two collections, 1.037 units $/ g$ in both. The yield produced was 18 $\%$ on March, $29.61 \%$ on June, $26.47 \%$ on September and $24.35 \%$ on December. The $\mathrm{pH}$ of aqueous extract was neutral $(\mathrm{pH} 7.0)$ on March and slightly acid ( $\mathrm{pH} \mathrm{6.0)}$ in other months. The four collect showed small variations in relation the organoleptic properties. It was done dosage of total polyphenols and flavonoids with $70 \%$ ethanol extracts of $M$. alba leaves. The content found of polyphenols were $6.467 \pm 0,012 ; 5.503 \pm 0.007 ; 6.016 \pm 0.020 ; 6.943 \pm 0.046$ milligrams of gallic acid per gram of dried plant on March, June, September and December, respectively. The content of flavonoids found were $4.345 \pm 0.008 ; 3.782 \pm 0.016 ; 4.362 \pm 0.005 ; 4.893 \pm 0.013$ milligrams of rutin per gram of dried plant.
\end{abstract}

Descriptors: Morus alba; Moraceae; Quality Control; Leaves.

\section{Controle de qualidade físico-químico e dosagem de polifenóis totais e favonóides nas folhas de Morus alba (MORACEAE)}

RESUMO: Visando estabelecer parâmetros para o controle de qualidade das folhas de Morus alba foram realizados ensaios de pureza através das determinações de umidade, matéria estranha, cinzas totais, cinzas insolúveis em ácido, teor de mucilagem, índice de amargor, rendimento do extrato bruto, propriedades organolépticas e $\mathrm{pH}$. Os ensaios foram realizados com amostras coletadas em março, junho, setembro e dezembro, de acordo com a Farmacopéia Brasileira e a Organização Mundial de Saúde. A perda por dessecação apresentou teor de umidade de acordo com o valor estabelecido de 14 $\%$, o valor mais elevado foi em setembro $12.89 \pm 0,1400 \%$. Os índices de matéria estranha encontrados estão de acordo com a quantidade permitida pela Farmacopéia Brasileira, que estabelece um máximo de $2 \%$ para a maioria das drogas vegetais. A coleta de março apresentou o maior teor de

\footnotetext{
*Mestranda em Ciência e Tecnologia Farmacêuticas pela Universidade Federal de Santa Maria (UFSM), RS, Brasil.

**Aluno de graduação em Farmácia pela Universidade Federal de Santa Maria (UFSM), RS, Brasil.

*** Mestre em Ciência e Tecnologia Farmacêuticas pela Universidade Federal de Santa Maria (UFSM), RS, Brasil

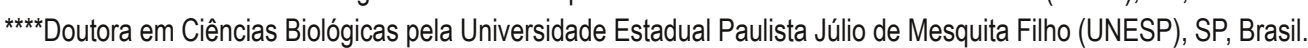


cinzas totais e cinzas insolúveis em ácido, respectivamente, $20,48 \pm 0,3517 \%$ e 5,68 $\pm 0,1057 \%$. 0 índice de intumescência mostrou valores mais elevados nas amostras coletadas em setembro $7.95 \pm$ $0,2186 \mathrm{~mL}$ e dezembro $7.1 \pm 0,8544 \mathrm{~mL}$. 0 índice de amargura foi mais elevado nas duas primeiras coletas 1,037 unidades/g em ambas. O rendimento produzido foi $18 \%$ em março, 29,61 \% em junho, $26,47 \%$ em setembro e $24,35 \%$ em dezembro. $\mathrm{O} \mathrm{pH}$ do extrato aquoso foi neutro $(\mathrm{pH} 7,0)$ em março e levemente ácido $(\mathrm{pH} \mathrm{6,0)}$ nos outros meses. As quatro coletas apresentaram pequenas variações em relação as propriedades organolépticas. Foi realizada dosagem de polifenóis e flavonóides com 0 extrato etanólico $70 \%$ das folhas de $M$. alba. $O$ valor de polifenóis encontrado em março, junho, setembro e dezembro foi $6.467 \pm 0,012 ; 5.503 \pm 0.007 ; 6.016 \pm 0.020 ; 6.943 \pm 0.046$ miligramas de ácido gálico por grama de planta seca, respectivamente. 0 valor de flavonóides encontrado foi $4.345 \pm$ $0.008 ; 3.782 \pm 0.016 ; 4.362 \pm 0.005 ; 4.893 \pm 0.013$ miligramas de rutina por grama de planta seca.

Descritores: Morus alba; Moraceae; Controle de qualidade; Folhas.

\section{Introduction}

The use of medicinal plants in therapy requires quality of herbal drugs, which begins on the correct identification of species, planting, harvesting, preparation of plant extracts and medicines. Therefore, it is necessary to obtain parameters of quality for pharmaceutical purposes, which are set out in Pharmacopeias and Officers Codes.

Family Moraceae occurs in tropical and subtropical regions and subdivided into approximately 60 genera, which comprise about 1400 species. ${ }^{1}$ The genus Morus is distinguished by its inflorescence spike amentacea type. Inflorescence is formed during months of July and August, with small flowers, often single-sex. They have corolla and a cup formed by four free sepals. ${ }^{2}$ Due to diversity of species of fruits, they are known as whitemulberry ( $M$. alba), blackberry ( $M$. nigra), cranberry-red ( $M$. rubra) and bramble-rose ( $M$. rosea). The main cultivated are white-blackberry and blackberry because they don't have thorns. They are adapted to different soil types, except those with trend water logging. ${ }^{3-6}$ The Moraceae family leaves are rich in protein, fiber, minerals and vitamin $C$, they also show a type of glycoprotein, called moran A, which is atributted an antidiabetic effect. ${ }^{7}$ The genus Morus has a variety of phenolic compounds including isoprenyl flavonoids, coumarins, chromones and xanthones. Many of these compounds exhibit biological properties such as antiinflammatory, diuretic and hypotensive effects. ${ }^{1}$ The leaves, bark and branch of $M$. alba (Fig. 1), are used in traditional medicine as antihyperglycemic, to treat fever, to protect the liver, to improve eyesight and to strengthen joints. ${ }^{8-9}$ Due to lack $M$. alba in monographs, this work aims to establish standards of quality and purity of plant drug by physico-chemical analysis and evaluation of total polyphenols and flavonoids in four collections during the year. The physico-chemical analysis carried out were: determination of loss on drying, foreign matter, yield of ethanol extrac, total ash, sulphated ash, swelling index, bitterness index, $\mathrm{pH}$ and organoleptic properties.

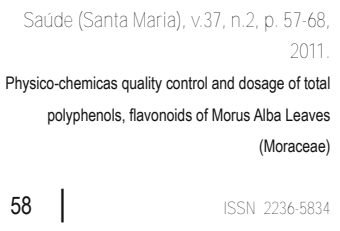




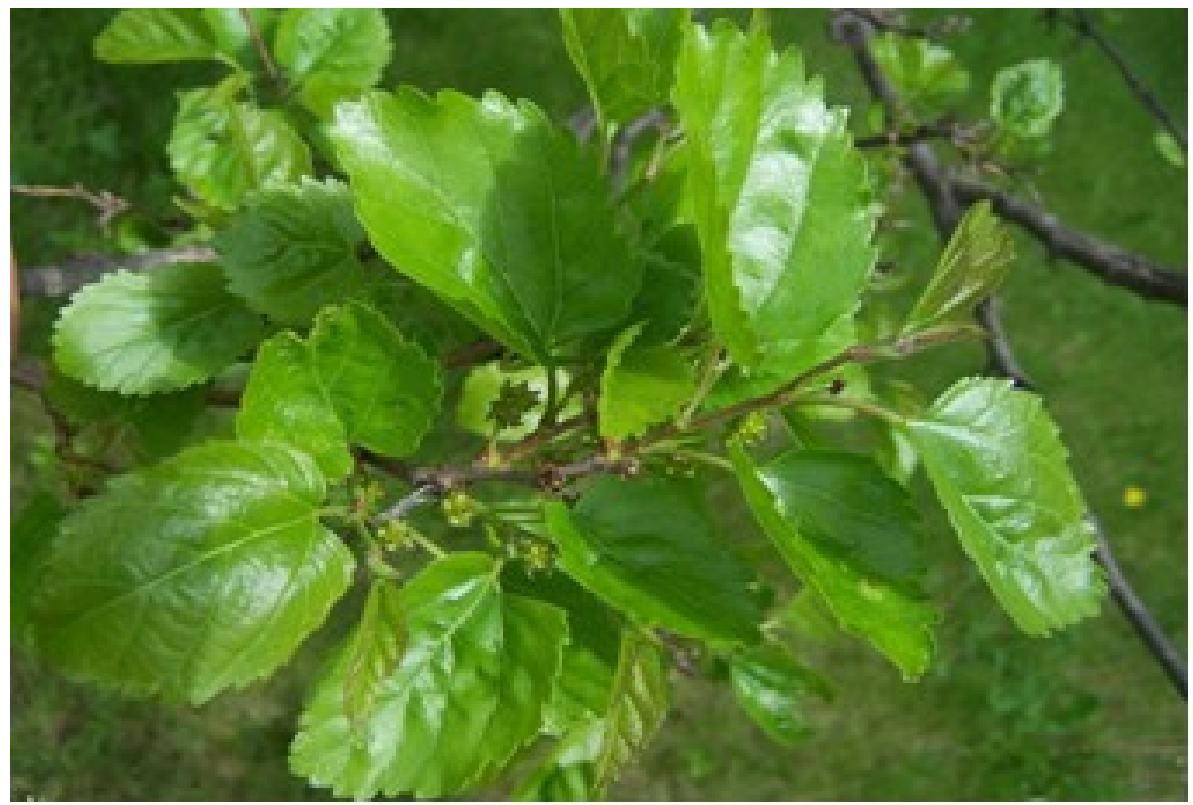

Material and methods

\section{Plant material}

The Morus alba leaves were collected in March, June, September and December 2010, in Santa Maria city, Rio Grande do Sul State, Brazil. A sample of plant material was identified by $\mathrm{Dr}^{\mathrm{a}}$ Jumaida Maria Rosito and voucher specimens were deposited in the Herbarium of Biology Department of the Federal University of Santa Maria (UFSM) as voucher specimen SMDB 13079. The plant material was dried at $40{ }^{\circ} \mathrm{C}$ with air circulation and grounded in a knife mill.

\section{Preparation of ethanol extract}

The extracts were obtained by cold maceration of powdered plant drug ( $80 \mathrm{~g})$ with drug solvent ratio $20 \%$ (w/v) in $70 \%$ hydroetanolic solvent during 30 days, after this, they were concentrated, lyophilizated and calculated yield.

\section{Physical-chemistry quality control}

\section{Loss on drying}

The water determination was performed according to Brazilian Pharmacopeia. ${ }^{10}$ It was weighed exactly $1 \mathrm{~g}$ of powdered plant drug and it underwent heating in an oven at $105^{\circ} \mathrm{C}$ during 5 hours. The loss of drying weight was calculated considering the air-dried sample. The analysis was performed in triplicate.

Saúde (Santa Maria), v.37, n.2, p. 57-68, 2011. Pereira, C.D., et al. 


\section{Foreign matter}

Macro e microscopy examination was conveniently employed to determine the presence of foreign matter in powdered plant drug according to Brazilian Pharmacopeia. ${ }^{10}$ In the macroscopy examination, $25 \mathrm{~g}$ of plant drug was spread on a thin layer from which the foreign matter was selected by inspection through the magnifying less. The content of foreign matter was calculated considering the air-dried sample. The analysis was performed in triplicate.

\section{Total ash}

The analysis of total ash was conducted according to Brazilian Pharmacopeia.10 The powdered plant drug $(3 \mathrm{~g})$ was accurately weighed into a crucible that has been previously ignited, cooled and weighed. Then the sample was ignited by gradual heating to $450{ }^{\circ} \mathrm{C}$, cooled in a desiccator and weighed. For obtaining carbon-free ash, the residue was moistened whit $2 \mathrm{~mL}$ of water after cooling the crucible. The remaining material was dried on a water-bath and then placed on a hot-plate, being ignited again until constant weight. The residue was cooled in a desiccator for 30 minutes and weighed. Total ash content was calculated considering the dry material. The analysis was performed in triplicate.

\section{Acid insoluble ash}

The analysis of acid insoluble ash was conducted according to Brazilian Pharmacopeia. ${ }^{10}$ In the crucible containing the total ash, it was added $25 \mathrm{~mL}$ of hydrochloric acid $(70 \mathrm{~g} / \mathrm{L})$, covered with a watch-glass and boiled gently for 5 minutes. The watch-glass was rinsed with 5 $\mathrm{mL}$ of hot water and then this liquid was added to the crucible. The insoluble matter was collected on an ashless filter-paper and washed with hot water until the filtrate was neutral. Thereafter, the filter-paper containing the insoluble matter was transferred to the original crucible, which was dried on a hot-plate and ignited to constant weight. After cooling the residue in a desiccator, the crucible was weighted and the content of acid-insoluble ash calculated considering the dry material. The analysis was performed in triplicate.

\section{Swelling index}

The analysis of swelling index was conducted according to Brazilian Pharmacopeia. ${ }^{10}$ One gram of powdered plant drug was introduced into a $25 \mathrm{~mL}$ glass-stoppered measuring cylinder for the verification of the volume occupied by the sample. Next, $25 \mathrm{~mL}$ of water was added and the mixture was shaken thoroughly every 10 minutes for about 1 hour. After that, the mixture was stood for 3 hours at room temperature, and finally the volume in ml occupied by the plant material was remeasured. The test was performed in triplicate.

Saúde (Santa Maria), v.37, n.2, p. 57-68,

Physico-chemicas quality control and dosage of totat polyphenols, flavonoids of Morus Alba Leaves 60

\section{Bitterness index}

The determination of the index of bitterness was performed according to Brazilian Pharmacopeia. ${ }^{10}$ The bitter properties of plant material were determined by comparing the threshold bitter concentration of the extract from the material with the concentration from a 
dilute solution of quinine hydrochloride. Drinking-water was the vehicle to the extraction of plant materials and for the mouth-wash after each tasting. It's was prepared a stock solution (St) of $M$. alba at $1 \%(\mathrm{w} / \mathrm{v})$. St was transferred to 10 tubes with volumes from 1 to $10 \mathrm{~mL}$. The standard solution of quinine hydrochloride $\mathrm{R}$ was distributed in nine tubes from 0.042 to 0.058 $\mathrm{mg} / 10 \mathrm{~mL}$. The birtteness value was expressed in units equivalent to the bitterness of a solution containing $1 \mathrm{~g}$ of quinine hydrochloride in $2000 \mathrm{~mL}$.

\section{Yield}

The analysis of yield was conducted according to Costa. ${ }^{11}$ The yield was determined using the equation: Yield $(\%)=\mathrm{Mf} / \mathrm{Mi} X 100$, where Mi is the initial mass of sample $(\mathrm{g})$ and $\mathrm{Mf}$ is the final mass of the dry extract $(\mathrm{g})$. Crude extracts were obtained by cold maceration of powdered plant drug $(80 \mathrm{~g})$ with drug solvent ratio $20 \%$ (w/v) in $70 \%$ hydroetanolic solvent during 30 days and the yield determined. Botanical studies of yield must be performed as an indicative of correct amount of material to be collected for production of extracts and fractions used in pharmacological tests.

\section{Organoleptic properties and $\mathrm{pH}$}

The organoleptic features analyzed were odour, flavor and color. The odour was checked by pressing of a small portion of leaves on the palm of the hand, inhaling slowly and repeatedly. The color of the leaves was analyzed with fresh plant under diffuse daylight. The flavor was tasted through the instillation of few drops on tongue of an aqueous solution $1 \%$ (w/v) of the powdered plant drug heated on an eletric-plate and brought to be boiling for 5 minutes..$^{12} \mathrm{pH}$ was verified by potentiometry with the above solution, according to Brazilian Pharmacopeia. ${ }^{13}$

\section{Dosage of total polyphenols}

The dosage of polyphenols was performed through the Folin-Ciocalteau, with some modifications. ${ }^{14-15}$ Based on the solution of $0.04 \%$ of the ethanol extract of $M$. alba, solutions was prepared in volumetric flasks at concentrations of 5,10,20,30 $\mu \mathrm{g} / \mathrm{mL}$. To this end, we used the required amount of solution of $0.04 \%$ with addition of $1 \mathrm{~mL}$ of Folin-Ciocalteau for 5 minutes, $2 \mathrm{~mL}$ of sodium carbonate $\left(\mathrm{Na}_{2} \mathrm{CO}_{3}\right) 20 \%$ for 10 minutes. The solutions were homogenized, capped and protected from light and kept at room temperature. The absorbance was measured at $730 \mathrm{~nm}$ using water as a blank. The test was performed in triplicate. The standard curve was obtained using standard solutions of gallic acid at the same concentration of the sample. The content of total polyphenols was expressed as milligram of gallic acid equivalent per gram of dried plant. 


\section{Dosage of flavonoids}

The dosage of flavonoids was performed according to a modified methodology from Rio ${ }^{16}$. Based on the solution of $0.04 \%$ of the ethanol extract of $M$. alba, solutions was prepared in volumetric flasks at concentrations of $10,20,50,100,150 \mu \mathrm{g} / \mathrm{mL}$. To this end, we used the required amount of solution of $0.04 \%$ with addition of $75 \quad$ I of $5 \%$ methanol $(\mathrm{MeOH})$ solution of $\mathrm{AlCl}_{3}, 3.9 \mathrm{~mL}$ of methanol $70 \%$ for 30 minutes. The solutions were homogenized, capped and protected from light and kept at room temperature. The absorbance was measured at $425 \mathrm{~nm}$ using $\mathrm{MeOH} 70 \%$ as a blank. The test was performed in triplicate. The standard curve was obtained using standard solutions of rutin at the same concentration of the sample. The flavonoids content was expressed as milligram of rutin equivalent per gram of dried plant.

\section{Statistical analysis}

Results were expressed as mean \pm standard error of mean (SEM). Statistical analysis was performed using One-way ANOVA followed by Tukey test using Graph Prism 5.0 software (Graph Pad Software, San Diego, CA, USA) and the results were considered significant when $p<0.05$.

\section{Results and discussion}

\section{Physico-Chemical Quality Control}

The loss on drying of $M$. alba leaves showed a moisture content according to the established value of $14 \%$, which is the maximum limit recommended of moisture for plant drugs. ${ }^{12 ; 13 ; 17}$ According to Simões ${ }^{18}$ the water founded in the plant drug is directly related to its storage and microbial contamination or enzymatic degradation by action of the chemical constituents. The excess of water in the raw material enables the development of fungi and bacteria. ${ }^{19}$ Therefore, preliminary operations employed in the leaves were effective in standardizing of moisture content to established values. Through statistical analysis were checked significant differences in the loss on drying in the four collections (table 1).

\begin{tabular}{ccc}
\multicolumn{2}{c}{ Table 1- Loss on drying, mean \pm standard error of mean (SEM) of Morus alba leav } \\
\hline Month & Mean (\%) & SEM \\
\hline March & 9.73 & \pm 0.1253 \\
June & 11.15 & \pm 0.2118 \\
September & 12.89 & \pm 0.1400 \\
December & 8.56 & \pm 0.0808 \\
\hline
\end{tabular}

Indices of foreign matter found in $M$. alba on March and June are agreement with the amount allowed by Brazilian Pharmacopeia, ${ }^{10}$ which establishes a maximum of $2 \%$ for most of 
foreign matter. There weren't significant differences in the indices of foreign matter in the four collections. The amount of foreign matter may be related to the fact of leaves have been preselected and milled. ${ }^{20}$ Analysis for determination of foreign matter has the purpose to identify portions or products not specified in the definition and description of the drug, besides impurities from mineral or organic nature, don't related to the drug. ${ }^{13}$

Table 2 - Foreign matter, mean \pm standard error of mean (SEM) of Morus alba leaves

\begin{tabular}{ccc}
\hline Month & Mean (\%) & SEM \\
\hline March & 0.0200 & \pm 0.0121 \\
June & 0.0126 & \pm 0.0063 \\
\hline
\end{tabular}

The determination of contenting total ash is important for quality control, since its aim is to check the presence of non-volatile inorganic impurities that may contaminate the plant drug. 10;21 The colletc that had the highest content of total ash was done on March (table 3). This can be explained by the higher amount of inorganic salts present in the first collection. ${ }^{17}$

In the analysis of acid insoluble ash was possible to observe a large discrepancy in values. In the gathering done on March and December, the content found was $5.68 \%$ and $3.50 \%$, respectively. Through statistical analysis were checked significant differences in the content of total ash and acid insoluble ash in the four collections. Determination of ash insoluble in acid chloridric is intended to detect constituents of silica and siliceous constituients, wich above of the established for the plant drug indicates contamination by excess soil or sand..$^{13}$ There is not maximum value for total ash and acid insoluble ash officially established for the species in study.

Table 3 - Determination of total ash, acid insoluble ash, mean \pm standard error of mean (SEM) of Morus alba leaves.

\begin{tabular}{ccc}
\hline Month & Total ash (\%) & Acid insoluble ash (\%) \\
\hline March & $20.48 \pm 0.3517$ & $5.68 \pm 0.1057$ \\
June & $9.57 \pm 0.4908$ & $0.75 \pm 0.0333$ \\
September & $11.88 \pm 0.2408$ & $1.67 \pm 0.0738$ \\
December & $17.86 \pm 0.4020$ & $3.508 \pm 0.0601$ \\
\hline
\end{tabular}

Analyzing the swelling index, $M$. alba leaves showed the highest values in samples collected on September and December (Table 4). The significant differences were checked only in results obtained on September versus March and September versus June. Banderó 22 found a quantity of swelling index of $2.03 \mathrm{~mL}$ to Glechon spathulata. This test serves to measure the volume $(\mathrm{mL})$ occupied by plant matter plus mucilage or other material attached. ${ }^{12,13,17}$ 
Table $4-$ Swelling index, mean \pm standard error of mean (SEM) of Morus alba leaves.

\begin{tabular}{ccc}
\hline Month & Mean $(\mathrm{mL})$ & SEM \\
\hline March & 5.83 & \pm 0.1202 \\
June & 5.73 & \pm 0.0882 \\
September & 7.95 & \pm 0.2186 \\
December & 7.1 & \pm 0.8544 \\
\hline
\end{tabular}

Pharmacopeias and specialist books on herbal drugs include certain types of sensation like flavour. Analysis of the bitterness index is determined by comparing the threshold concentration of bitterness of an extract and the dilute solution of quinine chloride. Thus, there are astringent, oily, mucilaginous, bitter and pungent tastes. The bitterness index was higher in the first two collections (table 5), it shows that the drug contains bitter substances, especially considering the dilution used in the test. To Wasicky et al., ${ }^{23}$ bitterness index has solid bases theoretical and experimental, which competes with the best biological methods. However, Mello et al., ${ }^{24}$ affirmed that this test may introduce errors due to individual variability, since it doesn't statistically reproducing real information. Thus, to perform this test it is necessary a previous training of experimenter, which combined with statistical analysis, allow that the biological variability be minimized, becoming a reliable method.

There were differences in about $11 \%$ in yield's assessment of $70 \%$ ethanol extracts. The highest yields were on June and September. The $\mathrm{pH}$ of the aqueous extract was neutral $(\mathrm{pH}$ 7.0) on March and slightly acid ( $\mathrm{pH} \mathrm{6.0)} \mathrm{in} \mathrm{other} \mathrm{months,} \mathrm{this} \mathrm{suggests} \mathrm{presence} \mathrm{of} \mathrm{neutral} \mathrm{and}$ acid substances, respectively, in $M$. alba leaves.

Table 5 - Bitterness index, yield, $\mathrm{pH}$ of Morus alba leaves.

\begin{tabular}{cccc}
\hline Month & Bitterness index (units/g) & Yield (\%) & pH \\
\hline March & 1.037 & 18.0 & 7 \\
June & 1.037 & 29.61 & 6 \\
September & 0.84 & 26.47 & 6 \\
December & 0.84 & 24.35 & 6 \\
\hline
\end{tabular}

In relation the organoleptic properties, the four collect showed small variations, they were odorless and the aquous extract showed a slight bitter flavor. The fresh leaves showed a light green color in the collection of March, mid-green on June and September and dark green on December. Total polyphenols content found in ethanol extracts of $M$. alba on March, June, September and December were $6.467 \pm 0,012 ; 5.503 \pm 0.007 ; 6.016 \pm 0.020 ; 6.943 \pm 0.046$ milligrams of gallic acid per gram of dried plant (figure 2). The regression curve obtained was $Y$ $=0.2879 x-0.0685(R=0.9912)$. The highest content of polyphenols was found in collection on December $(6.943 \pm 0.046 \mathrm{mg} / \mathrm{g})$. The content of flavonoids found was $4.345 \pm 0.008 ; 3.782$ $\pm 0.016 ; 4.362 \pm 0.005 ; 4.893 \pm 0.013$ milligrams of rutin per gram of dried plant. The regression curve obtained was $Y=0.1821 x-0.1545(R=0.9935)$. 
Figure 2 - Contents of polyphenols and flavonoids in ethanol extracts produced in four seasons.

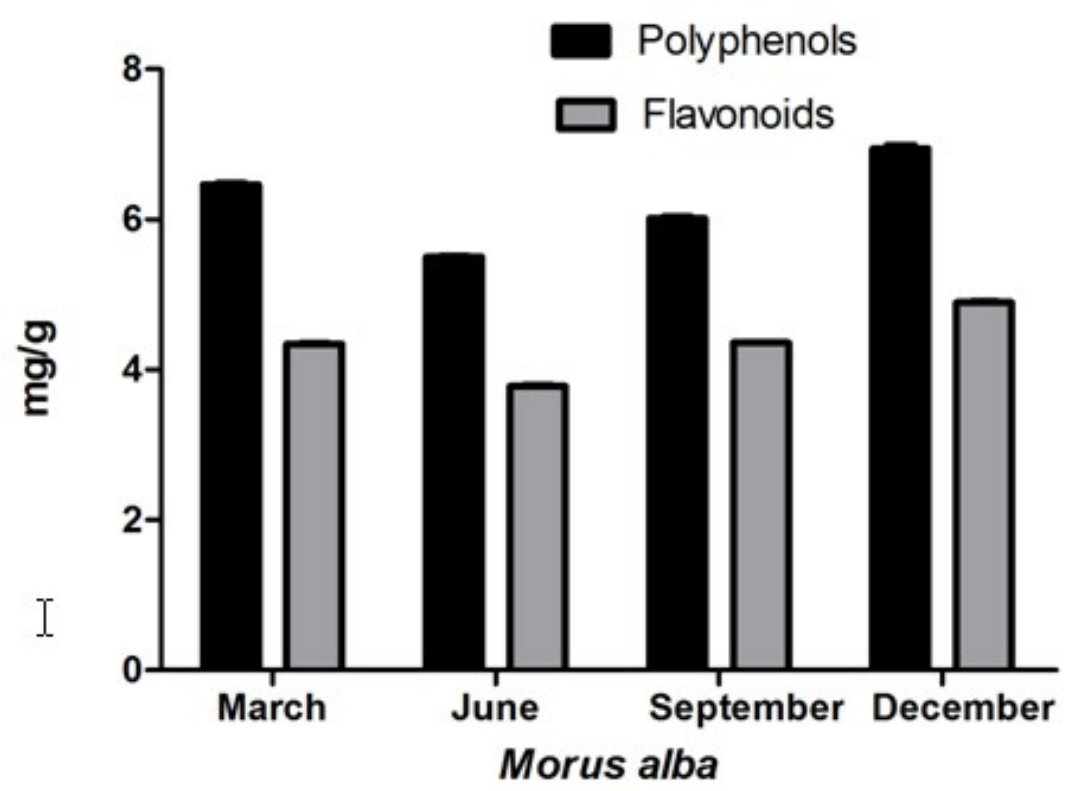

Plants can accumulate phenolic compounds in their metabolism under various stress conditions. ${ }^{25,26}$ Second Paliyath et al., ${ }^{27}$, most plants suffer physiological and biochemical damage by exposure to different temperatures. Sývacý et.al., ${ }^{28}$ found significant differences in polyphenol content of $M$. nigra and $M$. alba stem in the four seasons.

Through statistical analysis used in this study, was checked significant differences in the polyphenol and flavonoids content in four collections, only on March versus September there were not significant differences in flavonoids content. This fact can be explained by changes in climate, collection time, soil formation, plant age, temperature and total rainfall. The information obtained in this study has been relevant to characterization and physico chemical quality control of $M$. alba leaves.

\section{Conclusion}

Due to widespread use of $M$. alba leaves in traditional medicine, it is necessary to obtain quality standard for the use of this plant. The methods employed were adequate to assess the quality control of vegetable drugs in study, since it hasn't description in Pharmacopoeias. The dosages of polyphenols and flavonoids in the four colletions showed higher content in summer.

\section{References}

1. Nomura T, Hano T. Isoprenoid-substituted phenolic compounds of moraceus plants. Nat. Prod. Rep. 1994; 11: 205-18.

2. Corradello, EFA. Bicho-da-seda e amoreira: da folha ao fio, a trama de um segredo milenar. São Paulo: Ícone. 1987; p. 101.

3. Donadio LC, Nachtigal, JC, CK, Sacramento. Frutas exóticas. Jaboticabal:FUNEP. 1998; p. 279.

2011.

Pereira, C.D., et al.

ISSN 2236-5843

65

4. Silva S. Frutas no Brasil. São Paulo: Nobel. 2001; p. 236. 
5. Donadio LC. Dicionário das frutas. Jaboticabal. 2007; p. 300.

6. Gomes P. Fruticultura brasileira 13ª ed. São Paulo: Nobel. 2007; p. 446.

7. Andallu B, Vardacharyulun CH. Effect of mulberry leaves on diabetes. Int. J. Diab. Dev. Countries. 2001; 21: $147-51$.

8. Zhishen J, Mengcheng T, Jianming W. The determination of flavonoid contents in mulberry and their scavenging effects in superoxide radicals. Food Chemistry. 1999; 64: 555-59.

9. Kim SU, Kim LHS, Kim I, MY, Kim, KS Ahn. Determination of 1deoxynojirimycin in Morus alba L. leaves through derivatization with 9-fluorenylmethyl chloroformate followed by reversed-phase high performance liquid chromatography. Journal of Chromatography. 2003; 1002:93-9.

10. Farmacopéia Brasileira. 4. ed. São Paulo: Atheneu. 2000

11. Costa AF. Farmacognosia. Lisboa: Fundação Calouste Gulbenkian. 4 ed.; 1994; v.2, p. 1117.

12. World Health Organization. Quality Control Methods for Medicinal Plant Materials. Geneva, 1998, p.122.

13. Farmacopéia Brasileira. 4. ed. São Paulo: Atheneu. 1988.

14. Simonovska B, Vovk I, Andrensek S, Valentova K, Ulrichova J. Investigation of phenolic acids in yacon (Smallanthus sonchifolius) leaves and tubers. Journal of Chromatography. 2003; 1016(1), 89-98.

15. Kumazawa S, Hamasaka T, Nakayama T. Antioxidant activity of propolis of various geographic origins. Food Chem. 2004; 84:329-39.

16. Rio RGW. Métodos de controle químico de amostras de própolis. Dissertação de mestrado. Universidade de São Paulo, São Paulo. 1996

17. Hänsel R, Sticher O, Steinegge RE. Pharmakognosie - Phytopharmazie.Berlin: Springer. 1999

18. Simões CMO, Mentz LA, Schenkel EP, Irgang BE, Stehmann JR. Plantas da medicina popular no Rio Grande do Sul. 5. ed. Porto Alegre: Ed. Universidade/UFRGS. 1998, p. 173.

19. Farias, MR. Avaliação da qualidade de matérias-primas vegetais In: Simões, C.M.O. et al (Org.). "Farmacognosia: da planta ao medicamento". 5. ed. Porto Alegre/Florianópolis: Ed. Universidade - UFRGS/ Ed. da UFSC. 2003

20. Frasson, APZ, Bittencourt CF, Heinzmann BM. Caracterização físico química e biológica do caule de Caesalpinia ferrea Mart. Rev. Bras. Farmacog. 2003; 13: 35-9.

21. Sonaglio D, Ortega $G G$, Petrovick $P R$, Bassani VL. Desenvolvimento tecnológico e produção e fitoterápicos. In: Simões C.M.O, E.P. Schenkel, M.J.C.P. Gosmann, L.A. Mentz., P.R. Petrovick. Farmacognosia: da planta ao medicamento. 5.ed. Porto Alegre/Florianópolis: Editora da UFRGS/ Editora da UFSC. 2003

22. Banderó VC. Physico-chemical characterization for qualiy control of Glechon spathulata. Dissertação de Mestrado, Progama de Pós-graduação em Ciências Farmacêuticas, Universidade Federal de Santa Maria. 2009

23. Wasicky R, Barbieri E, Weber H. Contribuição para o método de dosagem de princípios ativos em drogas e preparações pelo amargor. Anais da Faculdade de Farmácia e Odontologia da Universidade de São Paulo. 1943; 3: 113-19.

24. Mello JCP, Petrovick PR. Quality control of Baccahris trimera (Less) DC (Asteraceae) hydroalcoholic

Saúde (Santa Maria), v.37, n.2, p. 57-68,

2011.

polyphenols, flavonoids of Morus Alba Leaves (Moraceae) extracts. Acta Farm Bonaerense. 2000; 19: 211-15.

25. Pasqualini V., Robles C., Garzino S., Greff S., Bousquet MA, Bonin G.. Phenolic compounds content in Pinus halepensis Mill needles: a bioindicator of air pollution. Chemosphere. 2003; 52:239-48.

26. Christie PJ, Alfenito MR, Walbot V. Impact of low-temperature stress on general phenilpropanoid and anthocyanin pathways: enhancement of transcript abundance and anthocyanin pigmentation in maize 
seedlings. Planta. 1994; 194: 541-49.

27. Paliyath G., Pinhero RG, Rao MV, Murr DP. Fletcher RA. Changes in activities of antioxidant enzymes and their relationship to the genetic and paclobutrazol-induced chilling tolerance in maize seddlings. Plant Physiol. 1997; 114:695-704.

28. Sývacý A., Sökmen M. Seasonal changes in antioxidant activity, total phenolic and anthocyanin constituent of the stems of two Morus species (Morus alba L. and Morus nigra L.) Plant Growth Regulation. 2004; 44: 3251-256.

\section{Camila Bugnotto Pereira}

Endereço para correspondência - Programa de Pós-Graduação em Ciências Farmacêuticas, Universidade

Federal de Santa Maria, Prédio 26, Santa Maria, RS, Brasil.

CEP: $97105-900$

E-mail: camilabugno@hotmail.com

Currículo lattes: http://lattes.cnpq.br/5954851418582018

Recebido em 01 de junho de 2011.

Aprovado em 30 de agosto de 2011. 
Saúde (Santa Maria), v.37, n.2, p. 57-68,

$$
2011 .
$$

Physico-chemicas quality control and dosage of total polyphenols, flavonoids of Morus Alba Leaves (Moraceae) 68 | ISSN 2236-5834 


\title{
Anticorpos de reação cruzada durante infecção aguda por T. gondii
}

\author{
Alison Menna Fontoura*, Sandra Trevisan Beck*
}

RESUMO: No presente estudo, foi descrito a presença de testes sorológicos falso-reagentes para pesquisa de anticorpos IgM anti- citomegalovirus e anti-HIV, em um indivíduo apresentando fase aguda da infecção por Toxoplasma gondii com anticorpos IgM anti T. gondii verdadeiramente reagentes. Esclarecer os aspectos sorológicos torna-se importante uma vez que agentes como T. gondii, Citomegalovírus (CMV) e vírus da imunodeficiência humana (HIV) podem causar a Síndrome da Mononucleose Infecciosa, apresentando inicialmente aspectos clínicos muito semelhantes. Reações sorológicas com anticorpos lgM presentes para mais de um agente etiológico devem ser interpretadas com cautela pois nem sempre a sua presença traduz uma infecção aguda, podendo ser decorrente de uma reação cruzada de anticorpos IgM contra estes patógenos.

Descritores: Reação cruzada; Sorologia; Toxoplasmose.

\section{Cross-Reactivity of antibodies during primary T. gondii infection}

ABSTRACT: This study described the presence of false-reactive serological tests for antibodies $\operatorname{lgM}$ anti-cytomegalovirus and anti-HIV. Actuality the individual had an acute Toxoplasma gondii infection, with IgM antibodies to $T$. gondii truly reagents. To clarify these serological aspects is relevant, once agents like $T$. gondii, cytomegalovirus (CMV) and human immunodeficiency virus (HIV) may cause an infectious mononucleosis like syndrome, with clinical presentation very similar. Serological results, with IgM antibodies present for more than one etiologic agent must be interpreted with caution. In this situation their presence does not always characterize an acute infection but can be caused by across-reactivity of lgM antibodies against these pathogens.

Descriptors: Cross-reactivity; Serology; Toxoplasmosis.

\footnotetext{
*Graduando no Curso de Farmácia e no Curso de Medicina pela Universidade Federal de Santa Maria (UFSM), Santa Maria, RS, Brasil.

${ }^{* *}$ Doutoura em Farmácia pela Universidade Federal de São Paulo (USP), São Paulo, SP, Brasil. Professora adjunta na Universidade Federal de Santa Maria (UFSM), Santa Maria, RS, Brasil.
} 


\section{Introdução}

A presença de anticorpos na infecção pelo Toxoplasma gondii (T. gondii) é importante na opsonização dos parasitas permitindo a fusão dos lisossomos aos vacúolos parasitóforos onde estão contidos, reduzindo sua inacessibilidade dentro dos macrófagos infectados. ${ }^{(1)}$ Diferentes clones celulares (linfócitos $\mathrm{T} \mathrm{CD} 4^{+}$e $\mathrm{T} \mathrm{CD} 8^{+}$, macrófagos, células "natural killer" NK, etc.) têm importante papel na resposta celular contra a infecção toxoplásmica em suas fases aguda e crônica. (2)

A proteção humoral eficaz contra um agente infeccioso deve ser o resultado de um equilíbrio entre uma resposta rápida, de menor afinidade contra um antígeno multivalente, e uma resposta mais lenta de alta avidez para antígenos mono e divalentes. É sabido que a resposta inicial a um processo infeccioso pode ser feita predominantemente por anticorpos naturais polivalentes, sendo menos específica, proveniente de células T-independentes ( $\mathrm{TI}$ ) isotipo lgM. A resposta tardia é feita por células $T$ dependente (TD) isotipo lgG, que geralmente surge na sequência da resposta $\mathrm{TI}$ e resulta em uma resposta de memória . A resposta de $\operatorname{lgM~TI}$, iniciada logo após a infecção, sendo esta adaptável, pode apresentar algum grau de reatividade cruzada como resultado de sua (ainda) atividade multivalente. ${ }^{(3)}$

Clinicamente, infecções por agentes tais como $T$. gondii, citomegalovírus, adenovírus, vírus da rubéola, vírus da hepatite e da imunodeficiência humana (HIV) podem apresentar um quadro clínico com alterações laboratoriais comuns a Mononucleose Infecciosa (MI) que é provocada pelo vírus Epstein-Bar (EBV). Este conjunto de sinais e sintomas é conhecido como a Síndrome da Mononucleose Infecciosa (SMI). A SMI é caracterizada por febre, linfadenopatia, faringite, mal-estar, que são sinais e sintomas comuns a diversas patologias, 0 que dificulta o diagnóstico pelo clínico, sendo necessários exames laboratoriais específicos para definir o agente causador da infecção. ${ }^{(4)}$

0 presente caso descreve as características clínicas e laboratoriais de um paciente apresentando resultado reagente para anticorpos $\lg M$ e $\lg G$ nos testes sorológicos realizados para pesquisa de infecção por $T$ gondii, Citomegalovírus e HIV, bem como a evolução dos testes laboratoriais que, junto com a clínica, auxiliaram a definir a patologia que acometeu 0 paciente.

\section{Metodologia}

\section{Relato de caso}

O presente trabalho foi aprovado pelo Comitê de Ética em Pesquisa da UFSM sob o protocolo de número 0254.0.243.000-10 em 19/10/2010.

Paciente do sexo masculino, 23 anos, realizou sua primeira consulta após aparecimento de sintomas em abril de 2010 . Relatava febre prolongada, acima de $38^{\circ} \mathrm{C}$, aproximadamente há cinco dias, acompanhada de cefaléia e mal-estar. Apresentava discreta adenopatia generalizada, mais proeminente na região cervical.

As dosagens de glicose, uréia, creatinina, ácido úrico, sódio, potássio, cálcio, fósforo, magnésio e fosfatase alcalina, resultaram dentro dos valores de referência considerados normais. Foram evidenciadas alterações na dosagem de Desidrogenase Lática (DHL), Transaminases (AST E ALT) e Leucograma, descritos na tabela 1. 
Os testes sorológicos, devido a reatividade dos anticorpos lgM, sugeriam um caso improvável, onde o paciente poderia estar apresentando fase aguda de doença causada por mais de um agente infeccioso. Após uma semana, foi solicitada a repetição dos testes sorológicos reagentes, juntamente com dosagens bioquímicas e hematológicas demonstrados na tabela 1.

Tabela 1-Evolução dos Marcadores bioquímicos, hematológicos e imunológicos avaliados para auxilio diagnóstico

\begin{tabular}{|c|c|c|c|c|}
\hline & Metodologia & $\begin{array}{l}\text { Resultados } \\
(27 / 04 / 2010)\end{array}$ & $\begin{array}{l}\text { Resultados } \\
(04 / 05 / 2010)\end{array}$ & $\mathrm{VR}^{*}$ \\
\hline $\mathrm{DHL}^{1}$ & EFA & 774 UI/L & 371 UI/L & 100 a 190 UI/L \\
\hline $\mathrm{AST}^{2}$ & EFA & $423 \mathrm{UI} / \mathrm{L}$ & $82 \mathrm{UI} / \mathrm{L}$ & 15 a $37 \mathrm{UI/I}$ \\
\hline $\mathrm{ALT}^{3}$ & EFA & $385 \mathrm{UI} / \mathrm{L}$ & $169 \mathrm{UI} / \mathrm{L}$ & 30 a $65 \mathrm{UI} / \mathrm{L}$ \\
\hline HEMOGRAMA & - & & & \\
\hline Eritrograma & & Normal & Normal & \\
\hline \multicolumn{5}{|l|}{ Leucograma } \\
\hline Leucócitos Totais & & $10.100 / \mathrm{mm}^{3}$ & $6.800 / \mathrm{mm}^{3}$ & 4 a $10.000 / \mathrm{mm} 3$ \\
\hline Segmentados & & $35,6 \%$ & $42,3 \%$ & 45 a $75 \%$ \\
\hline Linfócitos & & $51,5 \%$ & $38,9 \%$ & 22 a $40 \%$ \\
\hline Eosinófilos & & $4,3 \%$ & $7,3 \%$ & 1 a $5 \%$ \\
\hline Basófilos & & $1,3 \%$ & $0,8 \%$ & 0 a $2 \%$ \\
\hline Monócitos & & $7,3 \%$ & $10,7 \%$ & 4 a $8 \%$ \\
\hline PLAQUETAS & & $168.000 / \mathrm{mm}^{3}$ & $228.000 / \mathrm{mm}^{3}$ & $150.000-350.000 / \mathrm{mm} 3$ \\
\hline Citomegalovírus IgG & QML & R: 8.09 & NT & R: índex > ou = a 1,1 \\
\hline Citomegalovírus IgM & QML & $\mathrm{R}: 1,10$ & NT & R: índex > ou = a 1,1 \\
\hline Citomegalovírus IgM & ELFA & NT & NR: 0,43 & R: index $>=$ a 0,70 \\
\hline T. gondii IgG & QML & $R: 534,50$ & NT & R: índex > ou = a 10 \\
\hline T. gondii IgM & QML & $\mathrm{R}: 38,7$ & & $R:$ index $=$ ou $>1,0$ \\
\hline T. gondii IgM & ELFA & NT & $R:>40,00$ & $\mathrm{R}:$ index $=$ ou $>0.65$ \\
\hline Monoteste & Aglutinação & NR & NR & Ausência de aglutinação \\
\hline HIV 1 e 2 & QML & $\mathrm{R}: 1,44$ & $\mathrm{R}: 1,15$ & $\mathrm{R}$ : índex = ou > a 1,0 \\
\hline HIV 1 e 2 & ELFA & NT & NR: 0,02 & $\mathrm{R}$ : índex $>$ ou = a 1,0 \\
\hline
\end{tabular}

\section{Resultados e discussão}

A presença de linfocitose e transaminases elevadas, com reatividade múltipla para IgM, ${ }_{2011}^{\text {saud }}$ no presente caso, levou inicialmente a suspeita clínica de Ml. 
Há relatos de resultados sorológicos falso-positivos após infecção por EBV. Este vírus é um potente estimulador de células $B$ podendo induzir a produção de anticorpos da classe lgM contra outros agentes infecciosos que o paciente possa ter entrado em contato no passado, incluindo-se o CMV. Da mesma forma, os anticorpos IgM formados podem reagir de forma cruzada entre estes dois vírus, uma vez que apresentam epítopos semelhantes por ambos pertencem a família dos Herpes vírus. ${ }^{(5)}$ Estudo realizado por Miendje e colaboradores ${ }^{(5)}$, assim como um relato de caso descrito por Jee e colaboradores ${ }^{(6)}$, relataram falsa-reatividade IgM para CMV em indivíduos com infecção aguda por EBV, devido a ativação policlonal de linfócitos B induzida pelo EBV.

Porém, no caso relatado, a pesquisa de anticorpos heterófilos, pelo teste de aglutinação em placa (Monoteste- Wiener ${ }^{\circledR}$ ) resultou não reagente. Com exceção das crianças pequenas em que a pesquisa de anticorpos heterófilos muitas vezes é negativa, na maioria dos casos, a ausencia destes anticorpos diminuem a probablilidade de MI devido ao EBV. ${ }^{(7)}$ O número de leucócitos inicialmente elevado, também diminuiu a probabilidade de $\mathrm{Ml}$, uma vez que estudo anterior relata que entre os casos de MI com pesquisa de anticorpos heterófilos negativa, apenas $3 \%$ dos indivíduos apresentavam leucocitose. ${ }^{(8)}$

Uma vez que o paciente estudado tinha 23 anos, sendo excluída a probabilidade de infecção por EBV, CMV seria a causa mais comum da síndrome da MI com anticorpos heterófilos negativos. A não reatividade para anticorpos IgM para CMV na segunda amostra de soro testada descartou a possibilidade de infecção por este agente.

Após nova sorologia para HIV 1-2, também foi descartada a hipótese da presença deste agente infeccioso. A reatividade fraca para anticorpos HIV1-2 apresentada na primeira amostra manteve-se sem alteração após repetição pelo mesmo método, apresentando resultado negativo quando utilizado um método laboratorial com princípio diferente do primeiro teste (Enzyme Linked Fluorescent Assay -ELFA). Frente à infecção ativa, era esperado que houvesse um aumento na reatividade de anticorpos no momento da soroconversão. Além disto, o método ELFA, realizado na segunda semana, é mais sensível para o diagnóstico de HIV, por detectar tanto imunoglobulinas totais anti-HIV-1 (grupo M e 0) e anti-HIV-2 quanto 0 antígeno p24 do HIV-1, o que permitiria um diagnóstico mais precoce desta infecção, se ela estivesse presente. ${ }^{(9)}$

Os anticorpos lgM anti - T. gondii mantiveram-se altos, também no método de captura (ELFA), que possui especificidade de $94 \%$, conforme informação do fabricante. Este fato, fez com que não fosse necessário repetir a pesquisa de anticorpos $\mathrm{lgG}$, nem a pesquisa de avidez de lgG para as outras patologias relacionadas, onde 0 resultado de anticorpos lgG específicos de alta avidez, seriam indicativos de infecção com mais de 4 meses. ${ }^{(10)}$

Referente à reatividade sorológica a múltiplos agentes etiológicos evidenciados neste relato de caso, a justificativa pode ser encontrada na possibilidade de ocorrência de reação cruzada.

O aumento do número de linfócitos encontrado inicialmente no presente estudo pode estar relacionado com a resposta mediada pelas células $T$, que é extremamente efetiva no mecanismo de defesa contra agentes intracelulares, o que é o caso dos protozoários, existindo uma associação entre as contagens aumentadas de linfócitos $T \mathrm{CD} 8^{+}$e a ocorrência dos sintomas clínicos no curso da infecção toxoplásmica adquirida. (11) Segundo Debenedictis e colaboradores "as células T podem exercer sua função através da citotoxicidade mediada por células CD8+ [...]" (11:5) ou através da secreção de citocinas restringindo a disseminação da parasitemia por T. gondii. ${ }^{(12)}$ 
Em relação às alterações encontradas nas determinações de DHL e transaminases, novas dosagens realizadas após uma semana apresentaram resultados com valores próximos aos níveis de normalidade. Estes resultados podem ser esperados uma vez que na fase aguda da toxoplasmose, a rápida multiplicação dos taquizoítos produz destruição das células hospedeiras em diferentes órgãos, incluindo o fígado, até que ocorra o controle da infecção pela resposta imune do hospedeiro. ${ }^{(13)}$ As enzimas $\mathrm{DHL}$, aspartato aminotransferase (AST) e alanina aminotransferase (ALT) são encontradas em pequenas quantidades no soro e a elevação sérica dessas enzimas pode ocorrer mediante a degeneração ou destruição hepatocelular pelo parasita ${ }^{(13)}$, o que justifica a significativa elevação dessas enzimas em um primeiro momento da infecção seguida de declínio, demonstrando uma possível resposta do organismo contra o agente infeccioso.

\section{Conclusão}

Provavelmente pela infecção por T.gondii se desenvolver na maioria das vezes de forma assintomática, poucas são as descrições de reações sorológicas cruzadas na fase aguda desta patologia, como aqui relatado. 0 mais comum são relatos referentes à infecção por CMV e EBV. Portando é relevante chamar a atenção para resultados sorológicos, onde os anticorpos lgM são reportados como reagentes contra mais de um agente etiológico .

\section{Referências bibliográficas}

1. Sharma SD. Immunology of toxoplasmosis. In: David JW, Modern parasite biology: cellular, immunological and molecular aspects. New York: WH Freeman. 1990; 184-99.

2. Derouin F, Rabian-Herzog C, Sulahan A. Longitudinal study of the specific humoral and cellular response to Toxoplasma gondii in a patient with acquired toxoplasmosis. J Clin Lab Immunol. 1989 30: 97-102.

3. Hodgkin PD, et al. Role of cross-reactivity in the development of antibody responses. Immunologist. 1998; 6:223-6.

4. Sumaya CV. Epstein-Barr virus. In: Feigin RD, Cherry JD, editors. Textbook of pediatric infectious diseases.1999; (4):1755-64

5. Miendje YD, Goubau P, Bodéus M. False-Positive IgM Antibody Tests for Cytomegalovirus in Patients with Acute Epstein-Barr Virus Infection. Eur J Clin Microbiol Infect Dis. 2000; (19):557-60.

6. Jee MP, et al. False Positive Immunoglobulin M Antibody to Cytomegalovirus in Child with Infectious Mononucleosis Caused by Epstein-Barr Virus Infection. Yonsei Med J. 2009; 50(5):713-6.

7. Gerber MA, et al. Evaluations of enzyme-linked immunosorbent assay procedure for determining specific Epstein-Barr virus serology and of rapid test kits for diagnosis of infectious mononucleosis. J Clin Microbiol. 1996; 34(12):3240-1.

8. Ventura KC, Hudnall SD. Hematologic Differences in Heterophile-Positive and Heterophile-Negative Infectious Mononucleosis. Am J Hematol. 2004; 76:315-8.

9. Saville RD, et al. Fourth-generation enzyme-linked immunosorbent assay for the simultaneous etection of human immunodeficiency virus antigen and antibody. J Clin Microbiol. 2001; 39(7): 2518-24.

Saúde (Santa Maria), v.37, n.2, p. 69-74 2011. Fontoura, A. M.; Beck, S. T.

10. Montoya, JG, Liesenfeld, O. Toxoplasmosis. Lancet, 2004; 363:1965-76. 
11. Brown C, Mcleod R. Class I MHC genes and CD8 ${ }^{+} \mathrm{T}$ cells determine cyst number in Toxoplasma gondii infection. J Immunol. 1990; 145: 3438-41.

12. Gazzinelli RT, et al. Parasite-induced IL12 stimulates early IFN- synthesis and resistence during acute infection with Toxoplasma gondii. J Immunol. 1994; 153:2533-43.

13. Dubey JP, Beattie CP. Toxoplasmosis of animals and man. Boca Raton, FC: CRC Press. 1998; 1-220.

\section{Sandra Trevisan Beck}

Endereço para correspondência - Campus universitário - Camobi. Departamento de Análises Clínicas e Toxicológicas - Prédio 26, 20. andar, sala 1205. CEP 97105-900

E-mail: sbeck@ig.com.br

Currículo lattes: http://lattes.cnpq.br/4435727183593265

Recebido em 12 de junho de 2011.

Aprovado em 21 de setembro de 2011. 


\title{
Parasitos gastrointestinais e sanguíneos em cães. Risco para a adoção?
}

\author{
Mario Luiz de la Rue*, Ariéli de Andrade ${ }^{\star *}$, Lilian Varini Ceolin ${ }^{\star *}$, \\ Carina de Castro Gabriel**, Lis Schons Garrot ${ }^{\star *}$, Vanessa Correa da

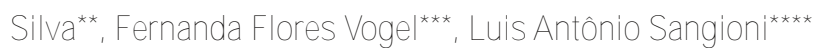

Resumo: Este estudo teve 0 objetivo de verificar a prevalência de parasitos intestinais e teciduais e estabelecer relação com zoonoses parasitárias por ocasião da adoção de cães errantes. Assim, coletou-se amostras de fezes e soro de 20 cães errantes sem prévio tratamento anti-parasitário, provenientes de cidades da região da Campanha do Rio Grande do Sul entre novembro a dezembro de 2007. Nas fezes foram encontrados ovos de Ancylostoma em todas as amostras (20/20) e Trichuris em $15 \%$ (3/20) das amostras. Coproantígenos de Echinococcus granulosus foram observados em $25 \%$ (5/20) das fezes. A imunofluorescência revelou 55\% (11/20) de prevalência para Toxoplasma gondii e $30 \%(6 / 20)$ de Neospora caninum Os resultados permitiram verificar que que a ingestão de formas parasitárias transmitidas por meio de carnes mal-cozidas (E. granulosus, $T$. gondii e $N$. caninum) é comum e que ovos de nematódeos que poderiam causar danos a seres humanos também foram identificados. Baseado nisto, pode se inferir que 0 ambiente endêmico permite a fácil contaminação com helmintos e protozoários. Sugere-se, assim que as pessoas encarregadas da adoção estabeleçam tratamentos eficazes contra todos os parasitos que possam infringir danos a saúde humana

Descritores: Cães Errantes; Adoção; Parasitos Gastrointestinais; Sanguíneos.

\section{Gastrointestinal and blood parasites in dogs. Risk for adoption?}

Abstract: This study aimed to determine the prevalence of tissue and intestinal parasites and establish a relationship with parasitic zoonoses at the time of stray dogs adoption. Thus, stool and serum collected samples from 20 stray dogs without prior anti-parasitic treatment, from towns in the Campaign region of Rio Grande do Sul State between November-December 2007. Ancylostoma eggs were found in all samples (20/20) and Trichuris in 15\% (3/20) of the samples. Coproantigens of Echinococcus granulosus were observed in 25\% (5/20) from the fecal samples. Immunofluorescence revealed $55 \%$ (11/20) prevalence of Toxoplasma gondii and 30\% (6 / 20) of Neospora caninum. Results showed that the ingestion of parasitic forms transmitted through poorly cooked meat (E. granulosus, T. gondii and N. caninum) is common and that eggs of nematodes that could cause harm to humans were also identified. Based on these aspects it could be inferred that the environment allows easy endemic infection with helminths and protozoa. It is suggested to the persons, responsible for adoption, to establish effective treatments against all parasites that may infringe human health damage.

Descriptors: Stray dogs; Adoption; Blood; Intestinal Parasites.

*Pós-Doutor em Helmintologia Animal pela Universidade Hohenheim, Alemanha. Professor titular da Universidade Federal de Santa Maria (UFSM), Santa Maria, RS, Brasil.

**Graduanda no curso de Medicina Veterinária pela Universidade Federal de Santa Maria (UFSM), Santa Maria, RS, Brasil.

***Doutora em Medicina Veterinária pela Universidade Federal de Santa Maria (UFSM), Santa Maria, RS, Brasil. Professor adjunto pela Universidade Federal de Santa Maria (UFSM), Santa Maria, RS, Brasil.

****Doutor em Epidemiologia Experimental Aplicada Às Zoonoses pela Universidade de São Paulo (USP), São Paulo, SP, Brasil. Professor Adjunto pela Universidade Federal de Santa Maria (UFSM), Santa Maria, RS, Brasil. 


\section{Introdução}

O estímulo a adoção de cães urbanos errantes tem sido intensificada por Organizações Não-Governamentais (ONG) que procuram conscientizar a população sobre seus benefícios, contrapondo a prática da eutanásia. Entretanto, a proximidade dos cães com os humanos representa um maior risco de ocorrência de doenças de caráter zoonótico ${ }^{1}$. Crianças em particular são altamente suscetíveis pelo íntimo contato com animais domésticos. Os ovos dos parasitos do gênero Trichuris² , de Ascarídeos e de Taenia são extremamente resistentes, representando assim um risco constante de re-infecção. Giardia, Cryptosporidium, Toxoplasma gondii e Neospora caninum também são considerados agentes infecciosos importantes ${ }^{3}$ assim como Toxocara canis causando larva migrans visceral e o Ancylostoma, responsável pela síndrome de larva migrans cutânea ${ }^{1}$.

A infecção de canídeos pelo gênero Echinococcus, causa nos hospedeiros intermediários ou acidentais, na forma larvar, a denominada equinococose cística e é uma zoonose de grande significado4,5. No Estado do Rio Grande do Sul o parasito tem como principais hospedeiros intermediários os bovinos e os ovinos, que asseguram a transmissão do helminto aos canídeos quando ingerem vísceras desses contaminadas com cisto hidático ${ }^{6}$. A infecção por T. gondii tem demonstrado prevalências variáveis, entre 20 e $91 \%$ entretanto, a toxoplasmose clínica em cães é rara, mas pode ocasionalmente ser encontrada em filhotes afetados por infeç̧ões congênitas, em cães com sistema imune deprimido ou associado a infecções concomitantes como 0 vírus da cinomose canina ${ }^{7}$. A neosporose clínica é muitas vezes vista em cães jovens afetados pela transmissão vertical. Os sinais clínicos são caracterizados por desordens neuromusculares devido a disseminação do parasita pelo sistema nervoso central e tecidos musculares ${ }^{7,8}$. Os cães são hospedeiros definitivos de Neospora caninum e a neosporose clínica é muitas vezes vista em cães jovens afetados pela transmissão vertical. Os sinais clínicos são caracterizados por desordens neuromusculares devido a disseminação do parasita pelo sistema nervoso central e tecidos musculares ${ }^{9,10}$.

Este trabalho teve como objetivo verificar a prevalência de parasitos gastrointestinais, Neospora caninum e Toxoplasma gondii em cães errantes provenientes da Campanha Gaúcha e alocados no Biotério Central da Universidade Federal de Santa Maria, Brasil. Além de avaliar as taxas de prevalência, procurou-se vincular sua importância com o risco que estas parasitoses poderiam oferecer aos humanos, principalmente por ocasião das adoções caninas.

\section{Material e métodos}

Foram analisadas amostras fecais e amostras de soro de 20 cães urbanos errantes provenientes de Dom Pedrito e Santiago, cidades da Campanha Gaúcha, de ambos os sexos e independente da idade, alocados no Biotério Central da Universidade Federal de Santa Maria entre novembro e dezembro de 2007. Estes animais continuaram neste local a disposição das necessidades didáticas da Universidade. As amostras fecais foram coletadas diretamente da ampola retal e acondicionadas em frascos individuais e armazenadas sobre refrigeração até o processamento laboratorial. As amostras de soro foram obtidas por punção da veia cefálica e alocadas em tubos sem anticoagulante. Imediatamente as amostras foram 
centrifugadas, sendo que o sobrenadante foi coletado e armazenado a $-20^{\circ} \mathrm{C}$ até a realização dos testes sorológicos.

As amostras foram processadas nos Laboratórios de Parasitologia Humana e de Doenças Parasitárias da mesma instituição. Nas fezes foi realizada a técnica de centrífugoflutuação para visualização de ovos de endoparasitos ${ }^{11}$ e ensaio de imunoadsorção enzimática (ELISA), conforme instruções do fabricante do "kit" (Chekit®), Bommeli Diagnostics, Suiça) para deteç̧ão de coproantígenos de Echinococcus granulosus. A leitura foi realizada em espectofotômetro para microplacas, obtendo-se os valores absolutos de absorbância em densidade óptica, e análise segundo as normas prescritas pelo fabricante. Já nas amostras de soro realizou-se o teste de imunofluorescência indireta (IFI) para detecção de anticorpos IgG para T. gondii e N. caninum empregando-se conjugado fluorescente anti-lgG canina (Sigma, EUA) ${ }^{12,13}$. O projeto foi analisado no Comitê de Ética em Experimentação Animal da Universidade Federal de S. Maria sob nº 15/2007.

\section{Resultados e discussão}

Neste estudo, a percentagem de cães parasitados com ancilostomideos foi de $100 \%$ (20/20) (Tabela 1) o que pode ser justificada pela ausência de tratamento antiparasitário aos cães errantes e pela alta exposição aos parasitos a que são submetidos pelo fato de viver nas ruas. A presença de ancilostomideos em cães errantes já está bem descrita, apresentando variáveis taxas de prevalência como $17,1 \%^{14}, 34,8 \%^{15}$ e $22 \%{ }^{16}$. Os dados encontrados no presente trabalho foram superiores aos encontrados na literatura, mas esta variabilidade pode ser devida a condições ambientais (temperatura, umidade) além de fatores intrínsecos do hospedeiro como imunidade e condições alimentares ${ }^{17}$.

Em um estudo anterior houve uma prevalência de 9,7 \% (23/273) de Trichuris em amostras fecais de cães errantes da área central do Balneário Cassino, no Rio Grande do Sul, Brasil, sendo que a principal associação foi com o Ancylostoma $(16,9 \%)^{18}$. Dados semelhantes foram encontrados no presente trabalho (3/20), o que demonstra sintonia nas condições ambientais e fatores epidemiológicos. Apesar da presença de Giardia em cães ser comumente descrita na literatura, nenhum caso foi encontrado no presente estudo. Podem ter pesado para este aspecto a resistência adquirida pelos cães devido a sucessivas exposições e, também, ao baixo número de amostras examinadas ${ }^{19}$.

No único trabalho que relata a presença de coproantígenos de $E$. granulosus em cães urbanos errantes no Rio Grande do Sul ${ }^{6}$ foi relatada a prevalência de 10,8\% (7/65) de animais positivos. A alta prevalência, no presente trabalho, deste parasito $(5 / 20)$, poderia ser explicada, pela procedência dos cães, já que a região da Campanha Gaúcha, fronteiriça com o Uruguai e Argentina, constitui a área endêmica no Rio Grande do Sul20. Além disto, a amostra analisada neste trabalho (20 cães) poderia ter sido insuficiente para exata interpretação dos resultados, mas, evidencia que os animais ingeriram carne crua de hospedeiros intermediários. 
Tabela 1 - Prevalência de parasitos encontrados em 20 cães provenientes da região da Campanha no Rio Grande do Sul

\begin{tabular}{ccc}
\hline PARASITO & No de casos $^{\circ}$ & Porcentagem (\%) \\
\hline Ancylostoma & 20 & 100 \\
\hline Trichuris & 3 & 15 \\
\hline E. granulosus & 5 & 20 \\
\hline T. gondii & 11 & 55 \\
\hline N. caninum & 6 & 30 \\
\hline
\end{tabular}

Há muitos testes sorológicos que podem detectar anticorpos contra Neospora caninum sendo um deles a imunofluorescência indireta que é frequentemente usada. Estes testes sorológicos demonstraram que o parasito é encontrado em todo o mundo, com prevalências entre 0 e 31\%7,8,9, valores semelhantes ao do presente trabalho (30\%). Como o cão é considerado o hospedeiro definitivo, este propagaria os oocistos do parasito para 0 ambiente e seria uma fonte de infecção importante para os bovinos onde é um dos principais agentes de aborto. Até a presente data, não tem sido relatada a presença em seres humanos. ${ }^{21}$

Cães urbanos errantes tem anticorpos contra $T$. gondii, o que já foi evidenciado por vários trabalhos, ${ }^{22,23,24}$ com frequências variáveis (52, 46 e 50\%, respectivamente). No presente estudo foi encontrada uma frequência de $55 \%$ das amostras que apresentavam anticorpos anti $T$. gondii, utilizando a técnica de imunofluorescência indireta. Como se pode observar há uma considerável variação entre as freqüências de anticorpos anti T. gondii em cães, 0 que pode ser explicada pelo limiar positivo fixado para cada teste e conseqüentemente sua sensibilidade. Além disto, o tipo de alimentação disponível aos cães pode influenciar as taxas, já que, no presente caso, carne crua pode ser um dos componentes alimentares. Esta mesma fonte de alimentação poderia ser a fonte de infecção de N. caninum e $E$. granulosus o que justificaria as elevadas prevalências encontradas nestes animais.

Pela análise dos resultados pode-se concluir que existe uma gama grande de parasitos que infectavam os cães analisados. Estes podem ter sido encontrados devido a falta de tratamento antiparasitário e, também, pela alta exposição a patógenos tanto do solo como em carnes consumidas "in natura" Com isto ocorre uma fácil disposição desses animais à infecção parasitária. Mesmo que alguns dos patógenos encontrados não possam ser diretamente transmitidos a humanos, pode ser evidenciada a grande acessibilidade a infectarse e, provavelmente, a facilidade em se contaminar. Além disto, a partir dos dados encontrados na região analisada, a adoção de cães de procedência desconhecida deverá sempre ser precedida de um tratamento anti-parasitário amplo, que destrua não somente nematódeos intestinais, bem como outras formas passíveis de tratamento, como cestódeos e protozoários.

\section{Referências Bibliográficas}

Saúde (Santa Maria), v.37, n.2, p. 75-80,

2011. Riscos para adoaço? ISSN 2236-5834
1. SANTOS FAG, YAMAMURA MH, VIDOTTO O, CAMARGO PL. Ocorrência de parasitos gastrintestinais em cães (Canis familiaris) com diarréia aguda oriundos da região metropolitana de Londrina, Estado do Paraná, Brasil. Ciências Agrárias 2007; 28(2): 257-268. 
2. KENNEY M, YERMAKOV V. Infection of man with Trichuris vulpis, the whipworm of dogs. Am. J. Trop. Med Hyg. 1980; 29(6): 1205-1208.

3. NEVES DP. Parasitologia Dinâmica. 3 ed. São Paulo: Atheneu, 2009.

4. DEPLAZES P, ECKERT J. Diagnosis of the Echinococcus multilocularis infection in final hosts. Applied Parasit. 1996; 37(4): 245-252.

5. NONAKA N, IIDA M, YAGI K., ITO T, OOI HK, OKU Y, KAMIYA M. Time course of coproantigen excretion in Echinococcus multilocularis infections in foxes and an alternative definitive host, golden hamsters. Int. J. Parasit:; 26(11): 1271-1278.

6. HOFFMANN NA, MALGOR R, DE LA RUE, ML. Prevalência de Echinococcus granulosus (BATSCH, 1768) em cães urbanos errantes do município de Dom Pedrito (RS), Brasil. Ciência Rural, S. Maria 2001; 31(5):843-847.

7. MINEO TWP, SILVA DOA, NÃSHUND K, BJÕRKMAN A, UGGLAA, MINEO, JR. Toxoplasma gondii and Neospora caninum serological status of different canine populations from Uberlândia, Minas Gerais. Arq. Bras. Med. Vet. Zoot. 2004; 56(3): 414-417.

8. MCALLISTER MM, DUBEY JP, LINDSAY DS, JOLLEY WR, WILLS RA, MCGUIRE AM. Dogs are definitive hosts of Neospora caninum. Int. J. Parasit. 1998; 28(9):1473-1479.

9. DUBEY JP. Review of Neospora caninum and neosporosis in animals. Korean J. Parasit. 2003; 41 (1): 116.

10. DUBEY JP, KNICKMAN E, GREENE CE. Neonatal Neospora caninum infections in dogs. Acta Parasit. 2005; 50(2): 176-179.

11. URQUHART GM, ARMOUR J, DUNCAN JL, DUNN AM, JENNINGS FW. Parasitologia Veterinária. 2 ed. Rio de Janeiro: Guanabara \& Koogan; 1996.

12. BERTSCHINGER B. Técnicas de Imunofluorescência e Análise Interpretativa dos Resultados. Porto Alegre: Ed. Autor, 1980

13. SCHARES G, PETERS M, WURM R, BÄRWALD A, CONRATHS FJ. The efficiency of vertical transmission of Neospora caninum in dairy cattle analyzed by serological techniques, Vet. Parasit. 1998; 80:87-98.

14. ALVES OF, GOMES AG, SILVA AC. Ocorrência de enteroparasitos em cães do municipio de Goiânia, Goiás: Comparação de técnicas de diagnóstico. Ciência Animal Brasileira 2005; 6(2): 127-133.

15. OLIVEIRA-SEQUEIRA TCG, AMARANTE AFT, FERRARI TB, NUNES LC. Prevalence of intestinal parasites in dogs from São Paulo State, Brazil. Vet. Parasit. 2002; 3:19-27.

16. VASCONCELLOS MC, BARROS JSL, OLIVEIRA CS. Parasitas gastrointestinais em cães institucionalizados no Rio de Janeiro, RJ. Rev. Saude Pub. 2006; 40(2): 321-323.

17. TAN JS. Human zoonotic infections transmitted by dogs and cats. Arch. Internal Med. 1997;157: 1933-43.

18. SCAINI CJ, DE TOLEDO RN, LOVATEL R, DIONELLO MA, GATTI FA, SUSIN L, SIGNORI VLM. Contaminação ambiental por ovos e larvas de helmintos em fezes de cães na área central do Balneário Cassino, Rio Grande do Sul. Rev. Soc. Bras. Med. Trop.2003; 6(5): 617-619.

19. BOWMAN DD, LUCIO-FORSTER A. Cryptosporidiosis and giardiasis in dogs and cats: Veterinary and public health importance. Exp. Parasit. 2010; 124(1): 121-7.

20. DE LA RUE ML. Cystic echinococcosis in southern Brazil. Rev. Inst. Med. Trop S. Paulo 2008; 50: 53-56.

21. MENEZES RCAA. Coccídeos. In: MONTEIRO S.G. Parasitologia na Medicina Veterinária, Roca, S. Saúde (Santa Maria), v.37, n.2, p. 75-80, Paulo, 2011. p.141-157.

De La Rue, M. L., et al.

22. CABRAL DD, SILVA DAO, MINEO JR, FERREIRA FA, DURAN FP. Frequency of anti-Toxoplasma gondii 
antibodies in apparently healthy dogs of the city of Uberlândia - MG. Rev. Bras. Parasit. Vet. 1998; 7: 87-90.

23. DOMINGUES LM, MACHADO RZ, COSTA MT, CARVALHO CS, COSTAAJ, MALHEIROS EB. Canine toxoplasmosis: a comparative evaluation of the detection anti Toxoplasma gondii antibodies by the indirect immunoenzymatic assay (ELISA) and the indirect immnufluorescence reaction (IFI). Rev. Bras. Parasit. Vet. 1998; 7:79-85.

24. MEIRELES LR, GALISTEO JR, POMPEU E, ANDRADE JR. Toxoplasma gondii spreading in an urban area evaluated by seroprevalence in free-living cats and dogs. Trop. Med. Int. Health; 2004; 9(8) 876 - 881.

\section{Mario Luiz de La Rue}

Endereço para correspondência - Depto. de Microbiologia e Parasitologia, Prédio 20 Campus, Av. Roraima, 1000. Santa Maria, RS, Brasil.

CEP: $9715-900$

Email: mldelarue@hotmail.com

Currículo lattes: http://lattes.cnpq.br/5733736449142334

Recebido em 30 de junho de 2011.

Aceito em 26 de outubro de 2011. 


\title{
Prevalência de Candida e Cryptococcus em hemoculturas oriundas de pacientes do Hospital Universitário de Santa Maria, RS (HUSM) no ano de
}

\author{
Danieli Urach Monteiro*, Thiele Faccim de Brum*, Charlise Bolson \\ Noal***, Roselene Alves Righi****, Edileusa Rosa dos Santos*, \\ Loiva Therezinha Ottonelli de Oliveira ${ }^{\star \star * *}$, Mário Luiz de La Rue**
}

RESUMO: As candidiases constituem um sério problema médico, pela sua elevada taxa de morbidade e mortalidade. Com o aumento de casos de Síndrome de Imunodeficiência Adquirida os casos de criptococose aumentaram acentuadamente. Devido a isto, o diagnóstico das fungemias é indispensável, tendo a hemocultura como o melhor procedimento deste diagnóstico laboratorial. Neste estudo foi avaliada a prevalência de casos de Candida spp. e Cryptococcus spp. em hemocultivos de pacientes no Hospital Universitário de Santa Maria, no ano de 2006, bem como sexo, idade e doença predisponente; 37 de 4336 amostras coletadas para análise de hemocultura no HUSM (0,85\%) foram positivas, dentre estas 70,2\% para Candida spp. prevalecendo o sexo feminino e 29,8\% para Cryptococcus spp. prevalecendo o sexo masculino. Estas fungemias acometeram pacientes na faixa etária de 0 a 84 anos de idade. Concluiu-se que o exame, por meio de hemocultura, é a melhor forma de diagnóstico em fungemias.

Descritores: Candida spp; Cryptococcus spp; Hemocultura; Infecções nosocomiais.

\section{Prevalence of Candida and Cryptococcus in blood cultures derived from patients from University Hospital of Santa Maria, RS (HUSM) in 2006}

ABSTRACT: The candidiasis is a serious medical problem, for its high rate of morbidity and mortality. With the increase of cases of Acquired Immunodeficiency Syndrome cases of cryptococcosis have increased sharply. Because of this, the diagnosis of fungemia is indispensable, and the blood culture as the best procedure in this laboratory diagnosis. This study assessed the prevalence of cases of Candida spp. and Cryptococcus spp. in blood cultures of patients at University Hospital of Santa Maria, in 2006, as well as gender, age and predisposing disease, 37 of 4336 samples collected for analysis of blood culture in HUSM $(0.85 \%)$ were positive, among them $70.2 \%$ for Candida spp. whichever is female and $29.8 \%$ for Cryptococcus spp. prevalent among males. These fungemia affected patients aged 0 to 84 years of age. It was concluded that the examination through blood culture is the best form of diagnosis in fungemia.

Descriptors: Candida spp; Cryptococcus spp; Blood culture; Nosocomial infections.

*Acadêmica do Curso de Pós-Graduação em Ciências Farmacêuticas da Universidade Federal de Santa Maria (UFSM), Santa Maria, RS, Brasil.

**Professor Adjunto da Universidade Federal de Santa Maria (UFSM). Santa Maria, RS, Brasil.

***Farmacêutica, especialista em Análises Clinicas e Toxicológicas,.

****Farmacêutica no Laboratório de Análises Clínicas do Hospital Universitário de Santa Maria (HUSM), Santa Maria, RS, Brasil. 


\section{Introdução}

O desenvolvimento das pesquisas no campo da micologia demonstra um alarmante aumento na freqüência de infecções fúngicas oportunistas, particularmente aquelas causadas por Candida spp. e Cryptococcus spp..$^{1}$ A elevada incidência de infecções fúngicas ocasionadas por estas duas leveduras tem representado grande desafio aos clínicos de diferentes especialidades devido às dificuldades de diagnóstico e tratamento destas infecções. ${ }^{2}$

Candida spp. é um fungo presente na microbiota da pele e mucosa do homem desde o nascimento, sendo que a interação levedura - hospedeiro ocorre durante toda a vida. A simples presença de cepas de Candida spp. na microbiota humana não induz nenhum transtorno determinante de patologias, todavia alterações nas defesas do hospedeiro que alterem o equilíbrio do binômio parasito/ hospedeiro, favorecem a invasão desta levedura através de vários mecanismos incluindo a translocação de Candida spp. até os capilares mesentérios. ${ }^{2,3}$ Alterações nas mucosas e pele, ocasionadas por estas leveduras, como hidratação, pH e nutrientes podem alterar a microbiota normal e causar infecções causadas por este fungo. Em relação as espécies, Candida albicans é a principal espécie implicada nas candidemias sendo responsável por mais de $50 \%$ dos casos seguida por C. glabrata, C. parapsilosis, $C$. tropicalis e $C$. krusei que mostraram alternância de frequência. ${ }^{4}$

É importante observar que além da alta incidência de candidemia nos hospitais terciários, esta complicação infecciosa apresenta índice de mortalidade geral de $60 \%$ e mortalidade atribuída de $40 \%$ com falhas terapêuticas frequentes e exacerbadas pela possibilidade da emergência de resistência aos antifúngicos poliênicos e azólicos. ${ }^{2,5,6}$

A criptococose é uma infecção fúngica causada por leveduras do gênero Cryptococcus spp. ${ }^{7}$ Baseado em características biológicas, ecológicas, epidemiológicas e genéticas, verificou-se que o gênero Cryptoccoccus, apresenta 37 espécies onde as mais relacionadas a criptotocose são: C. neoformans (sorotipo A e D) e C. gatti (sorotipo B e C). O C. neoformans, divide-se em duas variedades: $C$. neoformans variedade grubii (sorotipo $A$ ) e $C$. neoformans var. neoformans (sorotipo D). ${ }^{8}$ Embora Cryptococcus neoformans var grubii esteja presente em excretas de várias espécies de aves, geralmente esta variedade não causa doenças nas aves, pois a elevada temperatura interna $\left(42^{\circ} \mathrm{C}\right)$ destas inibe a expressão da virulência do fungo. A elevada concentração de amônia nas excretas frescas é outro fator que inibe 0 crescimento do fungo ${ }^{8,9}$ Já no homem, C. neoformans é um patógeno intracelular facultativo com alguns fatores de virulência definidos, que incluem a capacidade de crescer a $37^{\circ}$, a produção de cápsula polissacarídica, melanina e algumas enzimas. ${ }^{8} \mathrm{~A}$ maioria dos fatores de virulência permite a sobrevivência do fungo tanto no meio ambiente, como no organismo humano. A infecção pelo vírus da imunodeficiência adquirida (SIDA) é um fator predisponente em aproximadamente 80 a 90\% das infecções criptocócicas; cerca de 6 a 13\% destes pacientes são acometidos pelo $C$. neoformans var. grubii causando principalmente meningites. ${ }^{9}$

A via de transmissão mais importante é através da inalação de partículas infectadas e mais raramente por inoculação direta do agente na pele. Uma vez instalada a infecção em imunocomprometidos, o agente dissemina-se pelo sangue acometendo outros órgãos como Sistema Nervoso Central, pele, linfonodos, ossos, articulações, olhos, coração, fígado, baço, rins, tireóide e supra-renais. A próstata pode ser considerada como reservatório para a recidiva da doença. ${ }^{7,10}$ 
Neste contexto, registra-se que a incidência de infecções por Candida spp. e Cryptococcus spp. vem crescendo acentuadamente nos últimos anos, sendo de grande importância o conhecimento por parte dos profissionais de saúde das medidas necessárias para o diagnóstico, controle e tratamento de infecções invasivas por esses patógenos. Devido a isto, o diagnóstico das fungemias é indispensável, tendo a hemocultura significativo valor preditivo de infecção e o melhor procedimento deste diagnóstico laboratorial. ${ }^{5,11}$

Este trabalho objetivou fazer um levantamento do número de casos de hemoculturas positivas, para Candida spp. e Cryptococcus spp. em pacientes internados no Hospital Universitário de Santa Maria (HUSM) no ano de 2006, comparando a prevalência destes casos com sexo, idade e doença predisponente.

\section{Materiais e métodos}

\section{Amostragem}

Foi realizado um estudo retrospectivo de 4336 registros internos dos pacientes hospitalizados e submetidos a exames de hemocultura no ano de 2006 no Laboratório de Análises Clinicas do Hospital Universitário de Santa Maria (LAC/ HUSM) em Santa Maria I RS. Foram obtidos dos registros, informações sobre idade, sexo, diagnóstico micológico nomeando-se as espécies envolvidas, como doença predisponente.

\section{Procedimento laboratorial}

Para o hemocultivo, o sangue foi obtido de acordo com os procedimentos de rotina do LAC atendendo a solicitação médica. Os hemocultivos foram realizados em caldo $\mathrm{BH}$ distribuído em frascos do sistema Bactec (Becton-Dickinson, Califórnia, USA), utilizando um volume de 8 a $10 \mathrm{ml}$ para adultos e 1 a $3 \mathrm{ml}$ para crianças. A incubação e o monitoramento teve período máximo de 7 dias seguindo a técnica descrita pelo fabricante. As hemoculturas foram identificadas como positiva para fungos através do sistema Bactec. Em seguida, foram semeadas alíquotas do material biológico em tubos contendo ágar sabouraud dextrose seguido de incubação a $30^{\circ} \mathrm{C}$ durante $72 \mathrm{~h}$. As colônias eram avaliadas quanto à presença de cápsula no exame a fresco com tinta da china para identificação de Cryptococcus spp. A identificação dos gêneros Candida spp. requereu o emprego de técnicas micológicas como: produção de tubo germinativo, produção de clamidoconídios, microcultivo em ágar fubá, hidrólise da uréia, auxanograma e pigmentação no ágar níger.

Este projeto de pesquisa obteve aprovação do Conselho de Ética do Hospital Universitário da Santa Maria (DEPE) sob o número de registro 106.

\section{Resultados}

Das 4336 amostras de hemoculturas analisadas no ano de 2006, um total de $37(0,85 \%)$ evidenciaram crescimento fúngico. Dentre estas, $26(70,2 \%)$ permitiram 0 isolamento de

2011. Monteiro, D. U., et al. 
Candida spp. e $11(29,8 \%)$ corresponderam a Cryptococcus spp. Estas fungemias acometeram indivíduos de 0 a 84 anos de idade. As infecções por Candida spp. foram mais prevalentes no sexo feminino enquanto que as fungemias causadas por Cryptococcus spp. foram mais prevalentes no sexo masculino, conforme descritos nas tabelas 1 e 2 a seguir.

Tabela 1-Distribuição dos casos de candidemia diagnosticadas de acordo com o sexo, faixa etária e principais patologias associadas em indivíduos internados no HUSM (2006).

\begin{tabular}{|c|c|c|}
\hline \multicolumn{3}{|c|}{ Candida spp. } \\
\hline Patologias associadas $\quad \mathrm{N}^{\circ}$ de casos & $\mathrm{N}^{\circ}$ de pacientes & $N^{\circ}$ de pacientes \\
\hline Diabetes mellitus .................. 1 caso & Recém nascidos................... 9 & Masculino................... 7 \\
\hline Pneumonia ...................... 2 casos & De 0 a 1 ano ..................... 5 & Feminino................... 10 \\
\hline SIDA ............................ 1 caso & De 2 a 10 anos .................... 5 & Sexo não informado ${ }^{\dagger} \ldots . . . .9$ \\
\hline Câncer ............................ 3 casos & Maiores de 50 anos............... 7 & \\
\hline Septicemia ........................ 2 casos & & \\
\hline Outros $^{*} \ldots \ldots \ldots \ldots \ldots \ldots \ldots \ldots . .17$ casos & & \\
\hline Total ............................. 26 casos & & \\
\hline
\end{tabular}

Tabela 2 - Distribuição dos casos de criptococosemia diagnosticadas de acordo com o sexo, faixa etária e principais patologias associadas em indivíduos internados no HUSM (2006).

\begin{tabular}{|c|c|c|}
\hline \multicolumn{3}{|c|}{ Criptococcus spp. } \\
\hline Patologias associadas $\quad \mathrm{N}^{\circ}$ de casos & Idade $\quad \mathrm{N}^{\circ}$ de pacientes & $N^{\circ}$ de pacientes \\
\hline SIDA $\ldots \ldots \ldots \ldots \ldots \ldots \ldots \ldots \ldots$ casos & De 20 a 30 anos ............. 3 & Masculino .................. 9 \\
\hline 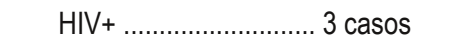 & De 31 a 40 anos .............. 6 & Feminino ................... 2 \\
\hline Outros $^{*}$...................... 3 casos & De 41 a 50 anos ............. 2 & \\
\hline Total ............................. 11 casos & & \\
\hline
\end{tabular}

*Outros: requisições sem identificação de fatores predisponentes.

†Sexo não informado: dado significativo apenas para controle total de candidemia.

\section{Discussão}

Fungos do gênero Candida representam os principais agentes envolvidos nas infecções nosocomiais, manifestando elevadas taxas de mortalidade, sobretudo nos países subdesenvolvidos. ${ }^{2}{ }^{3}$ Durante o período deste estudo pode-se observar a alta incidência de candidemias, sendo que, $72,2 \%$ das hemoculturas positivas foram atribuídas a Candida spp. Segundo Meneghetti, 2004, a incidência de Candida spp. em hemoculturas no Hospital

Saúde (Santa Maria), v.37, n.2, p. 81-88,

Prevalência de candida e criptocryptococcus en hemoculturas oriundas de pacientes do Hospital Universitário de Santa Maria, RS (HUSM) no ano de ISSN 2236-5834 Universitário de Santa Maria, é relevante, sendo que, das amostras analisadas pode-se observar uma positividade para fungos em $4,88 \%$ do total de infecções de corrente sanguínea. ${ }^{6}$

Colombo e colaboradores, 2003, conduziram um estudo epidemiológico na cidade de São Paulo, onde $4,3 \%$ do total de infecções de corrente sanguínea atribuía-se a Candida 
spp..$^{12}$ Este panorama ressalta a importância na identificação desta levedura, pois é um risco eminente na rotina hospitalar.

A disseminação hematogênica por Candida spp. pelo organismo humano é rara em pacientes imunocompetentes, entretanto é bastante documentada em pacientes imunocomprometidos. ${ }^{4,14}$ Alterações na imunidade causadas por doenças como SIDA, câncer, pneumonia como se pode observar neste estudo, acarretam complicações sérias no organismo humano, pois junto com 0 imunocomprometimento, estes encontram-se no ambiente hospitalar local propicio a novas translocações especialmente a Candida spp. No geral 40 a $60 \%$ dos pacientes que desenvolvem a candidemia, não conseguem evoluir para cura, sendo a alta mortalidade decorrente do diagnóstico tardio e da gravidade das comorbidades. ${ }^{5}$

Casos de candidemia entre neonatos internados na Unidade de Tratamento Intensivo de Recém-Nascidos (UTI/RN) é bastante frequente, esta contaminação pode estar relacionada com a manipulação destes pacientes, que após o nascimento não tem completamente formada sua imunidade e ficam susceptíveis a vários patógenos, além de deglutição ou aspiração de secreção vaginal infectada no momento do parto e pelo contato daqueles que cuidarão da criança, podendo haver a contaminação cruzada de uma criança para outra. 4,10 Em estudo no ano de 2005, no HUSM, a prevalência de hemocultivos ocorreu em UTI/RN. ${ }^{6}$ Desta forma explica-se a maior incidência de neonatos acometidos por candidemia neste estudo, ficando evidente a susceptibilidade dos recém nascidos frente a cepas de Candida spp. de um ano para o outro.

A criptococose em indivíduos sadios é raramente encontrada, sendo que, a maior freqüência ocorre em indivíduos imunocomprometidos, geralmente quando se apresenta como uma doença grave e potencialmente fatal. 0 sítio inicial da infecção é geralmente 0 pulmão, onde a infecção pode permanecer de forma latente ou oligossintomática por um longo período. Em $10 \%$ dos casos evolui através da disseminação hematogênica, com predileção especial pelo sistema nervoso central em particular as meninges. ${ }^{15} \mathrm{~A}$ cryptococcocemia esteve presente em $29,8 \%$ das hemoculturas realizadas no HUSM no ano de 2006, estando estas estritamente relacionadas por fatores que alteram a imunidade, confirmando os dados encontrados na literatura.

Com o surgimento da SIDA na década de 1980, a utilização de drogas imunossupressoras, em maior escala e 0 aprimoramento das técnicas diagnósticas, justificase 0 aumento da freqüência de infecções por Cryptococcus spp. ${ }^{16}$ Nos prontuários analisados neste estudo, pode-se confirmar a prevalência de Cryptococcus spp. em pacientes acometidos por SIDA, geralmente causado pelo imunocomprometimento e susceptibilidade na aquisição do patôgeno. A faixa etária que acometeu os pacientes deste estudo está dentro do esperado, segundo Ramos et al, 2008 a infecção é mais evidente dos 30 aos 60 anos, sendo rara na infância. ${ }^{18}$

A criptococose tem se destacado entre outras micoses, por acometer a próstata, sendo esta, um potencial reservatório para a levedura, em virtude de sua persistência nessa glândula observa-se recorrências freqüentes dificultando a erradicação da doença, o que

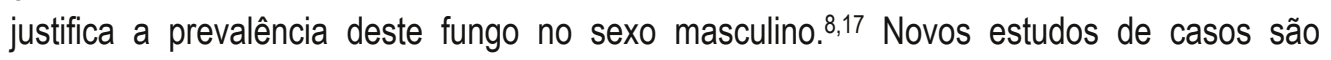
necessários, pois é desta forma que poderemos acompanhar e analisar os casos positivos, procurando a melhor forma de tratá-los, diminuindo cada vez mais a incidências destes patógenos no ambiente hospitalar.

Saúde (Santa Maria), v.37, n.2, p. 81-88, 2011.

Monteiro, D. U., et al. 


\section{Conclusão}

A freqüência do diagnóstico de hemoculturas positivas para Candida spp. e Cryptococcus spp. no HUSM fica evidenciada neste estudo. Isto requer maior atenção dos profissionais e atualização quanto às técnicas micológicas para o rápido e seguro diagnóstico. Os esforços deverão convergir para diminuir a incidência de infecções; acelerar o diagnóstico; ministrar o tratamento correto para garantir reais benefícios aos pacientes. Neste sentido, o uso de equipamentos automatizados como o sistema Bactec é de fundamental importância para a rápida detecção das fungemias abordadas neste estudo.

\section{Referências bibliográficas}

1. Boff E. Relação entre a suscetibilidade de Candida spp a anfotericina B, com óbitos ou sobrevivência dos pacientes em episódios de candidemia. Santa Maria, RS. 2007. 76f. Dissertação (Mestrado em Ciências Farmacêuticas) — Universidade Federal de Santa Maria, Santa Maria, 2007.

2. Colombo AL. Guimarães, T. Epidemiologia das infecções hematogênicas por Candida spp. Rev Soc Bras Med Trop 2003; 36(5): 599-607.

3. Ribeiro EL. Guimarães, R.I.; Inácio, M.C.C.; Ferreira, W.M.; Cardoso, C.G.; Dias, S.M.S.; et al. Aspectos das Leveduras de Candida vinculadas as Infecções Nosocomiais. New Lab 2004; 64: 106-226.

4. Sidrim JJC. Micologia Médica à luz de autores contemporâneos. 1ed. Rio de Janeiro. Guanabara Koogan S.A. p. $252-273,2004$.

5. Wenzel RP. Nosocomial candidemia: risk factors and attributable mortality. Cl Inf Dis. 1995; 20: 1531-1534.

6. Meneghetti BH, Salla A, Dal Forno NL, Oliveira LT, Righi R, Alves SH. Epidemiologia das infecções bacterianas e fúngicas diagnosticada através de hemocultivos, no Hospital Universitário de Santa Maria HUSM, RS. Santa Maria. Rev Bras An Clin 2004; 36(3): 173-175.

7. Bivanco FC, Machado CAS, Martins EL. Criptococose cutânea. Arq Med ABC 2006; 31(2): 102-109.

8. Franzot SP, Salkin IF, Casadevall A. Cryptococcus neoformans var grubii: separate varietal status for Cryptococcus neoformans serotype a Isolates. J Clin Microbiol 1999; 37: 838-840.

9. Amaro MCO. Caracterização de Isolados Clínicos de Cryptococcus neoformans e Cryptococcus Gattii Quanto à Suscetibilidade a Fluconazol. Santa Maria, RS. 2006. 80f. Dissertação (Mesttrado em Biologia Celular e Molecular) - Universidade Federal de Santa Maria, 2006.

10. Kumar P, Saran RK, Gondal R, Malhotra V. Smear Morphology of Cyptococcosis presenting as a subcutaneous swelling in healthy adults: a report of three cases. Crytopath 2005; 16: 143-146.

11. Lacaz CS. Microbiologia Médica. 8 ed. São Paulo. Livros Médicos Itda.172-179, 1991.

12.Colombo AL. Contribuições para o entendimento da epidemiologia das infecções hematogênicas por Candida spp. e para sua abordagem terapêutica. Tese para obtenção do título de livre docência apresentada a Universidade Federal de São Paulo, São Paulo, SP, 2003.

13. Dal Forno NLF, Campos AS, Rosa LC, Godoy LP, Noal AL, Horner R. Influência do volume de sangue no exame de hemocultura utilizando sistema automatizado em Hospital de Ensino de Santa Maria. Rev Bras Anal Clin 2005, 37(1): 7-9.

Saúde (Santa Maria), v.37, n.2, p. 81-88,

2011.

Prevalência de candida e criptocryptococcus em Universitário de Santa Maria, RS (HUSM) no ano de

2006.

14. Righi RA. Perfil da suscetibilidade de espécies de Candida, isoladas de hemocultivos, a agentes antifúngicos. Santa Maria, RS. 2004. 111f. Dissertação (Mestrado em Ciências e Tecnologia Farmacêutica) - Universidade Federal de Santa Maria, 2007.

15. Souza MB, Melo CSN, Silva CS, Santos RM, Malayoshi S. Criptococose palpebral: relato de caso. Arq IssN 2236.5834 Bras oftalmol 2006; 69(2). 
16. Darzé C, Lucena R, Gomes I, Melo A. Características clínicas laboratoriais de 104 casos de meningoencefalite criptocócica. Rev Soc Bras Med Trop 2000; 33(1): 21-26.

17. Lima MA, Santos JAM, Lazo L, Vergara MLS, Santos LAM, Santos VM. Infecção por Cryptococcus limitada à prostate em pacientes aidéticos com micobacteriose disseminada. Relato de necropsia. Rev Soc Bras Med Trop 1997; 30(6): 501-505.

18. Ramos LM, Rodriguez DF, Café MEM, Pinto JM, Sousa MLL. A Criptococose Cutânea Primária: Relato de um Caso em Imunossuprimido. An Bras Dermatol 1998; 73(5): 425-428.

\section{Danieli Urach Monteiro}

Endereço para correspondência: Silva Jardim, 1854, apt. 71 - Santa Maria, RS, Brasil.

E-mail: daniurach@yahoo.com.br

Currículo lattes: http://lattes.cnpq.br/8542724887878084

Recebido em 14 de julho de 2011.

Aprovado em 26 de outubro de 2011. 
Saúde (Santa Maria), v.37, n.2, p. 81-88,

2011.

Prevalência de candida e criptocryptococcus em hemoculturas oriundas de pacientes do Hospital Universitário de Santa Maria, RS (HUSM) no ano de

$$
2006 .
$$

88

ISSN 2236-5834 


\title{
As concepções dos enfermeiros/docentes frente à atuação da enfermagem na terapia com células tronco
}

\author{
Danusa Begnini*, Silvana Bastos Cogo Bisogno**, Tamires Patrícia
}

Souza*

RESUMO: Há vários anos, comunidades científicas internacionais analisam novas formas de tratamento de doenças, uma delas é a terapia com células tronco. Haja vista a necessidade dos profissionais enfermeiros estarem inseridos nessa temática, pretendeu-se realizar uma pesquisa com 0 objetivo analisar e descrever a concepção dos enfermeiros/docentes quanto à atuação e inserção da enfermagem na terapia com células tronco. Acerca da metodologia, trata-se de uma pesquisa qualitativa de caráter descritiva e exploratória. A coleta de dados ocorreu por meio de perguntas semiestruturadas aos dez enfermeiros/docentes de uma instituição de ensino superior do norte do RS. Como método de análise dos dados, utilizou-se a análise temática de Minayo (2007). Quanto às questões éticas, estas foram estritamente respeitadas, tendo em vista a aprovação pelo Comitê de Ética em Pesquisa da UFSM. Dessa forma, incide a necessidade do conhecimento em células tronco, por parte dos profissionais da enfermagem, para uma boa intervenção na condição de saúde de seu cliente.

Descritores: Bioética; Células tronco; Enfermagem; Ética.

\section{The conceptions of the nurses/teachers front to the performance of the nursing in the therapy with stem cell}

\begin{abstract}
It has some years international scientific communities analyze new forms of treatment of illnesses, one of them is the therapy with stem cell. It has seen the necessity of the professional nurses to be inserted in this thematic one was intended to carry through a research with the objective to analyze and to describe the conception of the nurses/teachers how much the performance and insertion of the nursing in the therapy with stem cell. Concerning the methodology one is about a qualitative research of descriptive and exploratory character. The collection of data occurred by means of questions half-structuralized to the ten nurses/teachers of an institution of superior education of the north of the RS. As method of analysis of the data it was used thematic analysis of Minayo (2007). How much to the ethical questions, these strict had been respected, in view of the approval for the Committee of Ethics in Research of the UFSM. Of this form, the necessity of the knowledge in stem cell on the part of the professionals of the nursing for a good intervention in the condition of health of its customer.
\end{abstract}

Descriptors: Bioethics; Ethics; Nursing; Stem Cells.

*Enfermeira, graduada em Enfermagem na Universidade Federal de Santa Maria (UFSM), pelo Centro de Educação Superior do Norte do RS (CESNORS), RS, BRASIL.

**Enfermeira, Mestre em enfermagem, Professora Assistente no Curso de Graduação em Enfermagem da Universidade Federal de Santa Maria (UFSM), pelo Centro de Educação Superior do Norte do RS (CESNORS), RS, Brasil. 


\section{Las concepciones de los enfermeros/maestros al frente de la actuación de enfermería en la terapia concélulas troncales}

RESUMEN: Hace varios años, las comunidades cientificas internacionales analizar nuevas formas de tratamiento de la enfermedad, una de ellas es la terapia de células madre. Teniendo en cuenta la necesidad de que las enfermeras se incluyen en este tema fue la intención de llevar a cabo una encuesta para analizar y describir el diseño de las enfermeras / maestros sobre el desempeño y la integración de la enfermería en la terapia de células madre. Acerca de la metodología es un carácter cualitativo descriptivo y exploratorio. La recolección de datos fue a través de preguntas semiestructuradas a los diez enfermeras / profesores de una institución de educación superior en el norte de RS. Como un método de análisis de datos se utilizó el análisis temático de Minayo (2007). Lo que respecta a las cuestiones éticas, estos se cumplan estrictamente, con miras a su aprobación por el Comité de Ética en Investigación de UFSM. Por lo tanto, se refiere a la necesidad de tener conocimientos sobre las células madre de los profesionales de la intervención de enfermería en un buen estado de salud de su cliente.

Descriptores: Bioética; Enfermería; Ética; Las células madre.

\section{Introdução}

Em geral, pesquisas com células tronco visam, principalmente, o tratamento de doenças, a compreensão do desenvolvimento humano da diferenciação e proliferação celular, bem como a geração de linhagens celulares para teste de drogas in vitro. Para tanto, há vários anos, comunidades científicas internacionais analisam a possibilidade, os riscos e aspectos éticos de estudos, envolvendo células tronco.

Sabendo da existência dos dois tipos de células tronco - as adultas e as embrionárias vemos a formação de vertentes, no que tange opiniões, conceitos éticos e científicos. Destarte, existem aqueles que defendem a necessidade da pesquisa com células tronco embrionárias, por se diferenciarem mais do que os outros tipos celulares, tendo assim, uma maior abrangência sobre os órgãos lesados. Por outro lado, há os que se opõem a esse vértice, a partir de aspectos relacionados à segurança dos procedimentos de regeneração tecidual por células tronco e questões éticas. No caso, como as células tronco embrionárias são muito indiferenciadas, sua introdução no organismo adulto pode, ao contrário do previsto, levar à formação de tumores benignos ou malignos, ao invés de regenerar o tecido. Deste modo, o uso de células tronco embrionárias, em seres humanos, ainda precisa de muitos estudos que garantam a segurança de que o indivíduo não desenvolva um câncer.

As questões éticas presentes em qualquer estudo de ordem humana, que se impõem imperativamente frente às inúmeras possibilidades de utilização das células tronco, são especialmente pertinentes ao se tratar das células tronco embrionárias, dentre outros motivos, por causar a morte do embrião ${ }^{1}$. Portanto, em qualquer discussão ética, deve-se ter sempre em mente o princípio da responsabilidade, ressaltando a responsabilidade individual, a qual deve ser assumida por todos os envolvidos em pesquisas com terapia celular.

Mesmo cientes de que a ciência faz a interação cientistas/pesquisadores, é visível que

Saúde (Santa Maria), v.37, n.2, p. 89-100,

2011.

atuação da enfermagem na terapia com células esse contexto pode acarretar lucros ou prejuízo aos interesses do paciente, devendo, acima de tudo, prestar contas de seus atos à sociedade. Dessa forma, a objetividade de qualquer tipo de estudo, envolvendo seres humanos, deve ser questionada perante sua real legitimidade, devendo, qualquer estudo, passar pelo tribunal incerto de fidedignidade 
científica. Afora isso, há de ser submetido a todas as outras instâncias julgadoras, as quais têm o dever de dizer se as mesmas são sustentáveis ou não.

Os preceitos morais e éticos, em pesquisa, exigem uma conduta voltada ao melhoramento social e de saúde humana. Em vista disso, a terapia celular está, cada vez mais, ganhando um espaço nos procedimentos técnicos e com resultados satisfatórios, cumprindo, eficientemente, a missão confiada aos pesquisadores de tratamento celular.

Dada a sua complexidade, a discussão do uso e não uso de células tronco embrionárias, principalmente nas diversas áreas da saúde, precisa ser aprofundada. Assim, frente às questões éticas suscitadas, surge a indagação: Qual a concepção dos enfermeiros/docentes sobre a inserção e a atuação da enfermagem nessa terapia? Qual a abrangência de seu conhecimento, quanto ao uso de células tronco embrionárias e adultas no uso da terapia regenerativa celular?

As presentes questões são de grande relevância, pois na graduação e na profissão da Enfermagem são priorizados ensinamentos que visam ao cuidado do indivíduo, de forma humanizada e ética, bem como a promoção da saúde. Enfim, normas básicas para a formação dos profissionais que devem ser seguidas durante sua vida profissional.

Essa visão está pautada nas Diretrizes Curriculares Nacionais do Curso de Graduação em Enfermagem ${ }^{2}$, através do Conselho Nacional de Educação, pela resolução CNE/CES $n^{0} 3$, de 7 de novembro de 2001, perante seu artigo VI, que trata das Ciências Biológicas e da Saúde, onde incluem-se os conteúdos, de base moleculares e celulares dos processos normais e alterados, da função e estrutura dos órgãos, tecidos, aparelhos e sistemas, aplicados às situações que surgem do processo saúde/doença no desenvolvimento da prática assistencial de Enfermagem.

Frente a esse fundamento, profissionais enfermeiros/docentes são incumbidos, principalmente, de desenvolver o cuidado, tendo em vista uma forma de tratamento plausível para dada patologia e, consequentemente, a reabilitação do indivíduo acometido por ela. Assim, deve-se estar atento à novas formas de tratamento e possível cura oferecida por novas tecnologias, aperfeiçoando seus conhecimentos.

Haja vista a necessidade dos profissionais enfermeiros estarem inseridos nessa temática pretendeu-se realizar uma pesquisa com o objetivo de analisar e descrever a concepção dos enfermeiros/docentes quanto à atuação e inserção da enfermagem na terapia com células tronco. Como resultado adjacente dessa pesquisa, buscou-se identificar, ainda, a visão do enfermeiro/docente acerca da inclusão social dos indivíduos na terapia celular.

\section{Materiais e métodos}

Este trabalho tratou-se de uma pesquisa qualitativa, de caráter descritivo exploratório. A pesquisa qualitativa, além de desvelar processos sociais ainda pouco conhecidos, referentes a grupos particulares, propicia a construção de novas abordagens, revisão e criação de novos conceitos e categorias durante a própria investigação ${ }^{3}$.

O local do estudo correspondeu a uma Instituição de Ensino Público de nível Superior, localizada na região Norte do Estado do Rio Grande do Sul. O Curso de Enfermagem, oferecido pela Instituição, forma profissionais com perfil generalista, habilitando e formando Saúde (Santa Maria), v.37, n.2, p. 89-100, 2011. para atuar na prevenção, promoção e reabilitação da saúde das pessoas, bem como no ensino e na pesquisa. 
Neste local, atuam dezesseis professores com graduação em enfermagem, pertencentes ao departamento de Enfermagem. Nesta pesquisa, foram entrevistados dez enfermeiros/docentes, considerando os que aceitaram participar da pesquisa e que possuíam atuação efetiva com os acadêmicos do curso de graduação em Enfermagem. Ressalta-se que foram excluídos, da participação, os docentes envolvidos diretamente a essa pesquisa.

Dessa forma, pretendia-se, interativamente, ter como produto uma descoberta de opiniões no meio docente. A escolha dos sujeitos para a presente investigação se deu com 0 intuito de, por meio dela, examinar o conhecimento dos profissionais e, desse modo, thes chamar à atenção para essa importante temática acerca das células tronco. No que se refere à Enfermagem, tem-se relevância especial por se tratar de uma possibilidade de tratamento para algumas doenças crônicas de alta relevância no meio social, as quais acometem o ser que será alvo de cuidado pela enfermagem.

Os sujeitos foram identificados no texto por uma letra seguida de um número (Ex: E1 equivalente ao entrevistado número um).

A coleta de dados foi realizada por meio de entrevistas, até que houvesse a saturação dos dados. Desta forma, por critério de saturação, se entende o conhecimento formado pelo pesquisador, no campo de que conseguiu compreender a lógica interna do grupo ou da coletividade em estudo 3 .

Os depoimentos foram gravados com gravador digital e posteriormente transcritos, respeitando a fidedignidade à compreensão do material. O registro fidedigno, e se possível "ao pé da letra", de entrevistas e outras modalidades de coleta de dados, cuja matéria prima é a fala, torna-se crucial para uma boa compressão da lógica interna do grupo ou coletividade estudada ${ }^{3}$.

A análise dos dados se deu de forma homogênea, utilizando, como método de análise, a temática de Minayo ${ }^{3}$.

Fundamentado no conceito celular, ético e metodológico advindo dessa pesquisa, após a análise das entrevistas, emergiram duas categorias: A enfermagem inserida na terapia com células tronco e a inclusão social nessa terapia.

O estudo foi iniciado após aprovação e autorização do Comitê de Ética em Pesquisa da Universidade Federal de Santa Maria no dia 09/08/2010, com número de protocolo 23081.009909/2010-56, conforme prevê a Resolução 196/96 e 251/97 do Conselho Nacional de Saúde - CNS, que visa fundamentalmente resguardar o respeito às pessoas.

A participação dos sujeitos na pesquisa não envolveu nenhuma forma de pagamento. Os pesquisadores estiveram e estarão à disposição para prestar esclarecimentos aos participantes, sempre que solicitado. Será preservado o anonimato dos participantes.

\section{Resultados e discussões}

\section{A enfermagem inserida nessa terapia}

Saúde (Santa Maria), v.37, n.2, p. 89-100, 2011. atuação da enfermagem na terapia com células
Exercer o cuidado, como profissão, conforme está pautado na profissão do enfermeiro, requer a busca de conhecimento. Sabe-se, hoje, que tanto no período de graduação quanto na vida profissional do enfermeiro são priorizados preceitos que visam à atenção ao indivíduo enfermo de forma humanizada e ética. Para tanto, é necessário atentar tanto aos velhos quanto aos novos tratamentos, por parte do profissional enfermeiro, para que ele possa, de 
certa forma, contribuir na propedêutica do indivíduo acometido por doenças, sejam elas crônicas ou não. A obscuridade no conceito dentro da enfermagem sobre o tema é evidenciado na fala a seguir:

[...] se tiver mais estudos, mais esclarecimento, vir algumas pessoas explicar pra nós como funciona, eu acredito que é importante, não só para a enfermagem, mas para todas as profissões, primeiro ter um conhecimento do que é para poder discutir sobre [...] (E8)

Dessa forma, sabe-se que a enfermagem tem atividades específicas, porém, cabe a todos os profissionais da saúde realizar a escuta, o acolhimento, 0 aconselhamento, 0 estímulo para a autonomia e principalmente a cidadania 4 . Por ter um contato de maior proximidade com o indivíduo, é de suma importância desempenhar o papel educador e elucidativo perante a essa nova terapia, como evidenciado abaixo:

A enfermagem trabalha diretamente com pacientes e na maioria das vezes portadores de doenças crônicas, então eu acho que o conhecimento nessa área trás uma nova opção terapêutica para esses pacientes, e eu acho que justifica a importância deles saberem dessa utilização e da existência desse procedimento, desse processo todo. (E10)

É necessário que o profissional enfermeiro exponha os rumos do tratamento com células tronco em todos os âmbitos, inclusive aqueles que podem gerar danos ao ser. Em alguns casos escassos, o tratamento com células tronco causa complicações, podendo levar a pessoa à morte ou mesmo alterar a sua qualidade de vida, tanto durante o procedimento, quanto no período pós-transplante. É neste contexto, que o paciente enfrenta as diferentes fases do tratamento, desde o surgimento da doença, o enfrentamento a ela, a perspectiva futura de cura, estabilidade do quadro clínico ou, ainda, a morte. Assim, no transcorrer do tratamento celular, o enfermeiro desempenha um papel significativo no cuidado ao transplantado e também à família. É imprescindível a presença do enfermeiro, gerando a assistência da saúde em todas as fases da doença do indivíduo, cuidando não somente do corpo, mas também da mente dos envolvidos ${ }^{5}$.

A falta de interesse em buscar informações sobre essa terapia, por parte do enfermeiro, pode estar associada à tão longínqua e distante realidade em que se inserem os profissionais participantes da pesquisa, de modo que, é uma possibilidade muito remota ter algum paciente, no cotidiano desses profissionais, que participou ou participe desse tipo de terapia gênica. Um dos fatores desse afastamento, em relação ao conhecimento, pode ser a própria distância quilométrica de grandes centros, onde essa terapia é disponibilizada, ou até mesmo a falta de inclusão social no tratamento com relação aos habitantes de certas loco regiões. A fala a seguir enaltece a inspiração por um futuro promissor para o tratamento celular:

[...] eu acho que é importante que saibamos sobre esse tema, até por que tenho a impressão que vai acabar sendo descentralizando de grandes centros urbanos. (E4)

De tal modo, o interesse em novas tecnologias, principalmente aquelas que somam na propedêutica do indivíduo, devem ser estudadas. Os profissionais da saúde têm o dever de fazer o que é benéfico do ponto de vista da saúde e o que é benéfico para os seres humanos em geral ${ }^{6}$.

Saúde (Santa Maria), v.37, n.2, p. 89-100, 2011.

Begnin, D.; Bisogno, S. B. C.; Souza, T. P. 
Outra possível causa para o afastamento do profissional enfermeiro, para com essa terapia, seria uma possível desilusão diante ao tratamento, quando é verificado que, apesar dos avanços nessa área, grande parte das promessas atuais da aplicação médica das células tronco somente serão alcançadas num período de médio a longo prazo.

A terapia celular regenerativa não é um produto colocado à venda e, muito menos, a promessa de sonhos inatingíveis. Entretanto, a realidade aponta para avanços notáveis na saúde e melhoria de vida. Este contato entre 0 agente vulnerável e 0 tratamento celular faz nascer o conceito de bioética, que não só defende a vida, como também defende a sua qualidade. 0 paciente passa a ser parte integrante e ativa, não no equacionamento do seu mal, mas sim, em saber quais são as opções clínicas e cirúrgicas para o seu tratamento. Já foi o tempo em que o profissional da saúde tratava o paciente, como um sujeito passivo de suas ações, 0 alvo de sua intervenção profissional ${ }^{7}$.

[...] dentro dos serviços de saúde tem uma imensidão de doentes crônicos... Aliar esse âmbito que trabalha bastante com o doente crônico com o âmbito das pesquisas, dessa tecnologia mais dura que seriam essas pesquisas cientificas dentro do laboratório [...] eu acredito que seria muito importante. Em relação à enfermagem mais ainda, por que a enfermagem tem um acompanhamento ao individuo ela não trata somente a doença crônica, mas também cuida durante todo o processo. Então ela pode acompanhar sinais e sintomas diferentes. Pode acompanhar a vivência dessa pessoa com sua doença crônica. Investir em estudos com células tronco que possam melhorar a qualidade de vida dos portadores de doenças crônicas eu acho que seria um bom caminho. (E7)

A fala acima tem importante sentido quanto colocada lado a lado com a análise de Mercês ${ }^{5}$, a qual menciona que 0 enfermeiro tem 0 dever de integrar a novidade, a idéia, modelar e compor, ou seja, conhecer o fato novo e torná-lo familiar; interpretar a realidade, na qual a idéia é naturalizada, o percebido pelo concebido, ou seja, traduzir o fato novo, ou interpretá-lo; orientar as condutas e as analogias sociais, ou seja, tomar decisões e agir. Esses aspectos perduram, ainda mais, quando se trata de terapia celular. É 0 dever de 0 enfermeiro instruir o indivíduo não somente para uma garantia de cura, mas para despertar de uma esperança na reabilitação desse indivíduo.

Debater sobre células tronco, na área de Enfermagem, não é tarefa fácil. Os procedimentos envolvidos nessa terapia envolvem questões do início e do final da vida, dos limites da individualidade e dos direitos individuais, em contraposição com o bem coletivo, despertando, de tal forma, um embate legal e ético.

$\mathrm{O}$ cuidado de enfermagem remete à visão abrangente e ampla do cuidado, enquanto conteúdo ou essência da vida dos seres ou processo dinâmico produtor e protetor da vida. Este sistema configura-se, ora por pequenos atos/momentos, ora como atividade básica do profissional enfermeiro, ora como um misto de atividades de saúde e ora como um encadeamento de medidas assistenciais, administrativas e legais dos diferentes sistemas sociais; ora situado no mundo concreto e nos limites de uma estrutura organizacional; ora transcendendo ao controle objetivo real, extrapolando até mesmo as políticas sociais e as

Saúde (Santa Maria), v.37, n.2, p. 89-100, 2011. vontades individuais, assim como cita Mercês ${ }^{5}$. conceppões dos enf atuaçăo da enfermagem na terapia com células 


\section{A inclusão social no tratamento com células tronco}

A inserção social da terapia celular, pela população, ainda é pequena se comparada aos benefícios expostos, porém há a necessidade de incorporar profissionais capacitados em ambos os lados: tanto envolvidos na terapia em si - gerando a assistência de qualidade durante o tratamento, atenção e cuidado ao indivíduo como um todo - como também, enfermeiros engajados em inserir novos indivíduos nessa terapia, atentando para as constantes mudanças, além de descobertas, atualizando cada vez mais seus conhecimentos. Desta forma, eles podem intervir, de maneira educativa, na condição de vida do seu paciente, gerando, de tal modo, uma possibilidade a mais para um bom prognóstico.

Quando falamos em equidade - universalidade e integralidade - retoma-se, na memória, princípios do Sistema Único de Saúde (SUS), os quais norteiam as ações destinadas ao indivíduo usuário desse Sistema, vigente em nosso país. A competência principal é a de diminuir o sofrimento humano, prevenindo ou tratando doenças e, por conseqüência, aumentando a expectativa de vida. Incentivos à pesquisa científica, para o tratamento, cura ou amenização de patologias e sua dor, deveriam ser baseados em políticas públicas de saúde específicas, contribuindo assim, para novas descobertas no ramo biológico e de tecnologia, cooperando na propedêutica do indivíduo.

Sabe-se que, atualmente, a maioria dos tratamentos com células tronco disponíveis no Brasil é realizado por meios de pesquisa, excluindo-se 0 transplante de medula óssea. Todavia, uma grande barreira é enfrentada, pois a maioria das pesquisas com células tronco no Brasil são financiadas por Institutos de Pesquisa e não pelo SUS. Quanto à coleta de células tronco adultas como, por exemplo, as do cordão umbilical - o qual necessita de um armazenamento desse cordão - requer um custo. Se optado for, pelo banco de armazenagem público, a própria instituição o custeia. Porém, se a escolha for um banco privado, o valor, em média, é de $\mathrm{R} \$ 4.000,00$ (quatro mil reais) para a coleta e mais os gastos anuais com 0 armazenamento desse cordão.

Em entrevista ao Diabetes Net em 2008, Voltarelli8 cita que "raras exceções são feitas através da Justiça, de modo que, uma liminar concedida pelo Juiz faz com que o SUS custeie essa coleta e posterior armazenagem".

É importante ressaltar, aqui, o transplante de medula óssea, o que é, de fato, conhecido por muitos, todavia, mesmo com o nome de transplante de células tronco, não o deixa de ser. Este, por sua vez, visa à retirada de células tronco da medula óssea ou até mesmo do cordão umbilical do doador e, posteriormente, a uma reimplantação das mesmas, no portador de leucemias, e outras doenças neoplásicas do sangue. Há, hoje, 50 (cinquenta) centros financiados pelo SUS em tratamento de leucemias, doenças medulares, hematológicas e genéticas no Brasil.

O primeiro transplante com células tronco, retiradas da medula óssea em pacientes com insuficiência cardíaca devido à doença de chagas, foi realizado pela equipe do Centro de Pesquisa Gonçalo Moniz, da Fiocruz, na Bahia, um acontecimento até então inédito no mundo. Os resultados foram obtidos muito rapidamente. Tal projeto contou com 0 financiamento do Ministério da Ciência e Tecnologia, Fiocruz, CNPq e também do Hospital Santa Izabel da Santa Misericórdia, que chegou a investir recursos próprios para a realização dos transplantes 9 .

Saúde (Santa Maria), v.37, n.2, p. 89-100, 
Sabemos que as pesquisas com células tronco, no Brasil, acontecem em um ritmo mais lento, se comparado ao avanço que outros países já fizeram nesse âmbito. Porém, a expectativa de que o Brasil se torne auto-suficiente nesse setor e que esse tratamento fique mais disponível e, consequentemente, profissionais da saúde, incluindo enfermeiros, possam participar desse mecanismo de inserção, é confirmada a fala a seguir:

[...] quem usufrui das células tronco hoje no Brasil? Sabemos que nos outros países as pesquisas estão mais avançadas, os tratamentos são mais efetivos, o Brasil ainda está engatinhando nesse sentido. Mas eu acredito que ainda fique disponível, fique com maior acesso às pessoas que não tem condições sócio-econômicas pra bancar esse tratamento. Eu não sei dizer hoje se o Sistema Único de Saúde com a verba desse sistema publico, se ele cobre esse tipo de transplante, mas pelo senso comum que vejo na televisão eu acredito que fique restrito a uma camada social. (E7)

O "ficar restrito a uma camada social", citado pelo entrevistado número 7 é um fato pertinente atualmente em nosso país, pois, de certa forma, o local de inserção/residência do indivíduo que participa dessa terapia, mais frequentemente, os residentes das metrópoles, ou até mesmo 0 ato de conhecer 0 tratamento definem o perfil das pessoas que usufruem dessa terapia, as quais se detêm em sua maioria a essas características.

No que se refere à ajuda profissional a indivíduos acometidos por doenças relacionando-as à possibilidade de novos tratamentos, incluindo aí a terapia celular - é necessário compreender a trajetória do indivíduo como um todo, ou seja, a influência de sua cultura, suas crenças e valores, além do conhecimento sobre saúde e, finalmente, sobre sua doença. Esta afirmativa pode ser observada através da seguinte fala:

[...] às vezes, as pessoas não querem aceitar esse tipo de tratamento $e$ nem aceitam que alguns familiares se submetam a isso, mas não porque elas não acreditam, por que elas têm medo, às vezes, algumas religiões que não querem receber sangue, por exemplo, porque a religiosidade não permite que ela receba a transfusão de sangue, eu vejo como a mesma questão das células tronco, as pessoas desconhecem o assunto, a religião é uma coisa muito presente, forte na comunidade de uma forma em geral, e que se a ciência não fizer amizade, se a ciência não tiver um andar junto com a religiosidade ela trava. (E8)

A oportunidade de ser sujeito de um protocolo de pesquisa, isto é, "participar da pesquisa" ou de "fazer a experiência", deixar que experimentassem no seu corpo novos tratamentos, às vezes é vista como chance a aproveitar ${ }^{10}$. Essas negociações de sentido confirmam a diferença entre a disciplina oficial eclesiástica e a adesão voluntária dos fiéis. A esperança do bem maior, por vezes, direciona a uma aspiração, tanto religiosa, como referente aos objetivos da biomedicina.

Atualmente, existe 51 centros transplantadores de células tronco hematopoiéticas no Brasil, com aproximadamente 280 leitos. A maioria (85\%) destes centros é pública. A necessidade anual de transplantes de células tronco hematopoiéticas é de aproximadamente

Saúde (Santa Maria), v.37, n.2, p. 89-100, As concepç̃es dos atuação da enfermagem na terapia com células 5.100 transplantes, embora o número de pacientes com doador aparentado seja da ordem de $30 \%$. Esse cenário tem favorecido a expansão de fontes alternativas de células tronco hematopoiéticas no país, representadas pela criação de novos bancos de sangue de cordão umbilical. ${ }^{11}$ 
Porém, nos é oportuno lembrar que essa é uma particularidade do transplante com células tronco adultas, retiradas da medula óssea, por vezes do próprio receptor de células tronco. Para tanto, sabemos que o cenário que impera sobre as pesquisas com células embrionárias e, até mesmo, outros tipos de transplantes com células adultas é outro. Este, por sua vez, encontra dificuldades em suas pesquisas e experimentos quando 0 assunto é tratado a nível nacional. Esta afirmativa pode ser exemplificada pela fala do sujeito E10, quando diz:

\begin{abstract}
Eu acho que ainda há pouca inclusão social, mas existem muitos estudos que vem sendo feitos em relação a isso, e cada vez mais vão ser incentivados, eu acho que a oferta ainda é pouca até pela aprovação e conceitos éticos em relação ao assunto, mas acredito que cada vez mais a disponibilidade dessa opção vai ajudar na fonte da população em geral.
\end{abstract}

Segundo Souza e Elias ${ }^{12}$, a prática de experimentos com células tronco em humanos enfrenta, evidentemente, várias barreiras, uma vez que envolve comitês de ética em pesquisa, o que, de certa forma, justifica a pouca oferta para esse tratamento. A medicina veterinária, que é menos vulnerável às considerações legais, éticas e religiosas, já obteve progressos enormes no emprego terapêutico das células tronco.

Embora com muita dificuldade, as pesquisas avançam, todavia, é necessário não queimar etapas. É primordial a segurança e 0 respeito ao indivíduo em qualquer procedimento. Para tanto, vários testes devem ser feitos a fim de obter, gradualmente, garantia da efetividade no tratamento com células tronco. É necessário entender que a aplicabilidade da pesquisa, nos seres humanos, é o último passo a ser conquistado. Essa somente é realizada através do progresso que a ciência comete pesquisa após pesquisa.

\title{
Considerações finais
}

Os avanços, envolvendo a biotecnologia, causaram enormes benefícios, uma vez que praticamente permitem o controle da vida, habilitando profissionais a criar e modificar os fundamentos vitais.

No que se refere a estudos de terapias com células tronco, vários debates ocorreram quanto à tramitação de um projeto de lei no Congresso Nacional que se refere à utilização de embriões humanos em pesquisas científicas. A Lei n. ${ }^{0} 11.105 / 05$, ou Lei da Biossegurança ${ }^{13}$ não possibilita que se utilizem todos e quaisquer embriões que se originem de fecundação in vitro.

Para tanto, o tratamento com células tronco possui uma grande massa de informações sobre sua utilização terapêutica e as descobertas, acerca desse tema, têm surpreendido a comunidade científica. Além do mais, as pesquisas celulares sustentam a esperança humana de encontrar no tratamento a amenização dos sintomas ou talvez a cura para doenças, as quais teriam possibilidade de regressão patológica desconhecida até pouco tempo atrás.

Assim sendo, com base nos depoimentos colhidos, nota-se que a terapia celular ainda não foi devidamente explorada pela enfermagem brasileira, demonstrando a pouca inserção do profissional enfermeiro nos escassos serviços que dispõem esse tipo de tratamento, elucidando também a não divulgação do conhecimento produzido no seu cotidiano.

Saúde (Santa Maria), v.37, n.2, p. 89-100, 2011. Begnin, D.; Bisogno, S. B. C.; Souza, T. P. 
Sob este ponto de vista, outros vários fatores podem ser elencados. Estes, contribuem para esse afastamento em relação à terapia celular, por vezes, no meio acadêmico e/ou profissional como: falta de domínio da metodologia científica, pouco incentivo e estímulo à pesquisa e publicação, ingresso reduzido de enfermeiros dos serviços de terapia celular em mestrados e doutorados, além de outros fatores. A carência principal ainda se evidencia quanto a estudos que focalizam o cuidado de enfermagem a esses pacientes.

Quanto à visão do enfermeiro, perante a inclusão social de indivíduos na terapia celular com células tronco, fica claro que dentre os entrevistados todos conhecem a situação do país com relação à escassez de instituições que dispõem desse serviço. Afora isso, analisam que a questão ética, a qual engloba as pesquisas, impera, diante dessa realidade.

Questões éticas permeiam esse processo de lapidar um conhecimento. À medida que se conhece as células tronco, as origens e quais os procedimentos para a obtenção dessas células, avaliam-se também seus riscos e benefícios. De tal forma, alguns pronunciamentos demonstram certa imprecisão quanto a esse conhecimento, evidenciado, por vezes, pelo ato de não tomar partido de alguns participantes da pesquisa.

Ao final desse trabalho, nota-se que muitos são os fatores que se somam, levando-nos a acreditar no potencial terapêutico das células tronco. Nota-se, ainda, que esse potencial, até agora, não foi descoberto por inteiro e, a partir dessa afirmação, advêm a necessidade de mais estudos. É possível visualizar que os escassos serviços, disponíveis em terapia celular, hoje, são um dos motivos que gera a baixa inserção e interesse da enfermagem sobre essa temática. Em relação à enfermagem, ainda não há um interesse sólido, estabelecido por esse tipo de terapia celular, sendo que os próprios profissionais evidenciam o saber, de que ainda há muito a ser aprofundado.

O processo de adoecer cronicamente traz consigo uma fragilidade do indivíduo, tanto espiritual, emocional e não esquecendo 0 abatimento, em se tratando da própria saúde. A possibilidade de estar junto a esse indivíduo e sua terapêutica, inclinando-se diante dele e de sua dor permite entrar em contato com suas emoções em prol de compreendê-las. Esse é o trabalho dignificado por muitos na Enfermagem.

É pertinente lançar um olhar cuidadoso, bem como atencioso ao indivíduo na Enfermagem. Do mesmo modo, esse zelo deve ser praticado a um paciente transplantado com células tronco. Saber da importância do profissional em distinguir e reconhecer sinais e sintomas, orientar quanto à nova condição de vida e os riscos que podem envolver esse procedimento, são fundamentais.

O profissional Enfermeiro, nesse momento transitório, participa da vida dessa pessoa, mas o viver é dela, com seus significados, enfrentamentos. É com essa manifestação de cuidados que a essência da importância de cada ser humano é despertada. Passa-se, então, a dedicar atenção àquele indivíduo enfermo, dispondo-se a participar em seu destino, suas buscas, seus sofrimentos e sucessos; consequentemente, participa de todo o seu prognóstico.

Não tão distante, é associado a esse pensar, que profissionais enfermeiros inseridos

Saúde (Santa Maria), v.37, n.2, p. 89-100, As concepcōes dos enfermeiros/docentes frente à atuação da enfermagem na terapia com células numa realidade talvez distante da dos transplantes com células tronco, podem intervir também na realidade daqueles doentes crônicos, que ainda não conhecem essa terapia ou não a reconhecem com vistas a seu potencial. A possibilidade de correlacionar sua patologia com a possibilidade de cura deve ser elucidada pelo profissional enfermeiro, ressaltando, assim, a possibilidade de melhor prognóstico da doença ou até mesmo a sua cura. Oferecer 
essa possibilidade ao indivíduo pode trazer-Ihe uma nova condição de vida e de saúde.

Alimentar a esperança nos sujeitos, por parte da enfermagem, não se trata apenas em alegar uma nova conduta terapêutica, mas sim, aliar a esperança como parte integrante do cuidado. É a busca da consolação para o sofrimento humano. Em outra esfera, sabendo que as células tronco são uma esperança de cura no indivíduo e que, por vezes, a confiança depositada nessa terapia supera seu potencial, a enfermagem deve adentrar nessa realidade preparando o indivíduo para um possível mau prognóstico e intervindo de forma efetiva e ética frente à situação. De tal forma, é imprescindível que o paciente esteja ciente de todos seus riscos e benefícios ao se inserir nesse tipo de terapia.

Por fim, incide a necessidade do conhecimento por parte da enfermagem sobre células tronco para uma boa intervenção na condição do paciente. É necessária ainda, maior inclusão social desses indivíduos em sistemas que dispunham desse serviço. $O$ enfermeiro tem de estar ciente sobre o que deve saber, conhecendo direta e indiretamente os fatores associados a essa terapia.

\section{Referências bibliográficas}

1. Nardi, NB; Teixeira, LAK.; Silva, EFA. Terapia gênica: Ciência e Saúde Coletiva. Porto Alegre-RS: 2002

2. CONSELHO NACIONAL DE EDUCAÇÃO. Câmara de Educação Superior. Resolução CNE/CES 3/2001. Diário Oficial da União, Brasília, 9 de Novembro de 2001. Seção 1, p. 37.

3. Minayo, MCS. O desafio do conhecimento: pesquisa qualitativa em saúde. 10. Ed. - São Paulo: Hucitec, 2007.

4. Reis, AC. dos. Papel da enfermagem na equipe multidisciplinar. Coordenadora de Enfermagem CRT/DST/AIDS. São Paulo -2009.

5. Mercês, NNA da. Representações sociais sobre o transplante de células tronco hematopoiéticas e do cuidado de enfermagem. Tese de doutorado. Florianópolis (SC): UFSC/PEN, 2009.

6. Koerich, MS.; Machado, R.R.; Costa, E. Ética e bioética: para dar início à reflexão. Texto e Contexto Enferm. SC- 2004.

7. Junior, EQO. A ética médica, a bioética e os procedimentos com células tronco hematopoéticas. Rev. Bras. Hematol. Hemoter. vol.31 supl.1 São Paulo, 2009.

8. Entrevista: Júlio César Voltarelli, imunologista do Centro de Terapia Celular. 16/8/2008. Gazeta Online. Disponivel em: <http://www.diabetenet.com.br/conteudocompleto.asp?idconteudo=3879> . Acesso em: 29 out.

9. Telles, M. Terapia com aumenta a sobrevida de pacientes cardíacos. Saúde. Inovação em pauta. [s.n.]

10. Luna, N. Religiosidade no contexto das terapias com células tronco: uma investigação comparativa entre pesquisadores "iniciantes e iniciados" e seus pacientes. Religião e Sociedade, Rio de Janeiro, 28(2): 156$178,2008$.

11. Junior, FCS.; Odongo, FCA.; Dulley, FL. Células-tronco hematopoéticas: utilidades e perspectivas. Rev. Bras. Hematol. Hemoter Faculdade de Medicina da Universidade de São Paulo - São Paulo-SP. 2009.

12. Souza, MHL; Elias, DO. As células tronco e seu potencial de reparação de órgãos e tecidos. Centro de estudos Alfa Rio - Programa de educação continuada. Manual de Instrução Programada: Princípios de Hematologia e Hemoterapia - Segunda Edição 2005.

13. BRASIL. Audiência Pública no Supremo Tribunal Federal (STF). Ação Direta de Inconstitucionalidade

Saúde (Santa Maria), v.37, n.2, p. 89-100, 2011.

Begnin, D.; Bisogno, S. B. C.; Souza, T. P.

ISSN 2236-5843 
(ADI) 3510 que contesta o uso de células tronco em pesquisas científicas, com base na Lei de Biossegurança (Lei no 11.105/05). Relator: Min. Ellen Gracie. Acórdão de 20 de abr. de 2007. Disponível em: < http://www.stf. gov.br/noticias/ imprensa/ ultimas/> Acesso em: 10 mai. de 2010.

\section{Danusa Begnini}

Endereço para correspondência - Rua Valentin Stefanelo, 274, Centro. Jaboticaba - RS.

E-mail: danusabegnini@hotmail.com

Currículo lattes: http://lattes.cnpq.br/0435509110105107

Recebido em 23 de julho de 2011.

Aprovado em 26 de outubro de 2011. 


\title{
Análise fitoquímica preliminar das folhas de Vitex Megapotamica (Sprengel) Moldenke
}

\author{
Thiele Faccim de Brum*, Marina Zadra**, Amanda Luana Forbrig \\ Froeder*, Aline Augusti Boligon*, Janaína Kieling Frohlich*, \\ Margareth Linde Athayde***
}

RESUMO: A espécie Vitex megapotamica (Sprengel) Moldenke, usualmente conhecida como tarumã, pertence à família Verbenaceae a qual compreende cerca de 100 gêneros distribuídos nas regiões tropicais de todo o mundo. Esta espécie tem sido usada na medicina tradicional principalmente para hemorróidas, depurativa do sangue, hipertensão arterial, anti-inflamatória, dentre outras. 0 presente trabalho teve por objetivo a realização da triagem farmacognóstica de extratos das folhas de Vitex megapotamica. Os resultados da análise fitoquímica indicaram a presença de heterosídeos antociânicos, fenóis e taninos, catequinas, flavonóis, flavanonas, flavanonóis e xantonas, esteroides e triterpenoides (esteroides livres), heterosídeos cardioativos, fenóis com posição orto e meta livres, fenóis com a posição para livre, cumarinas, ácidos orgânicos e fenóis.

Descritores: Vitex megapotamica; Tarumã; Folhas; Estudo fitoquímico.

\section{Phytochemical preliminary analysis leaves of Vitex Megapotamica (Sprengel) Moldenke}

ABSTRACT: The species Vitex megapotamica (Sprengel) Moldenke, usually known as tarumã, belongs to the Verbenaceae family which comprises about 100 genera distributed in tropical regions around the world. This species has been mainly used in traditional medicine for hemorrhoids, purifying the blood, hypertension, anti-inflammatory, and others. The aim of this study was to carry out a pharmacognostic screening of extracts of $V$. megapotamica leaves. The results of phytochemical analysis indicated the presence of anthocyanins, phenols and tannins, catechins, flavonols, flavanones, and flavanonóis xanthones, triterpenoids and steroids (steroid free), cardioactive glycosides, phenols with ortho and meta position free phenol with the position free, coumarins, organic acids and phenols.

Descriptors: Vitex megapotamica; Tarumã; Leaves; Phytochemical study.

\footnotetext{
* Mestranda em Ciências Farmacêuticas pela Universidade Federal de Santa Maria, Santa Maria, RS, Brasil.

** Graduanda no Curso de Graduação em Farmácia, Universidade Federal de Santa Maria, Santa Maria, RS, Brazil.

*** Professora e coordenadora do PPGCF.
} 


\section{Introdução}

Nos últimos anos, tem-se verificado um grande avanço científico, envolvendo os estudos químicos e farmacológicos de plantas medicinais que visam obter novos compostos com propriedades terapêuticas. $^{1}$

Estes produtos naturais podem ser tão eficientes quanto os produzidos pela síntese química, contudo a transformação de uma matéria-prima vegetal em um medicamento deve visar à preservação da integridade química e farmacológica do vegetal, garantindo a constância de sua ação biológica e a sua segurança de utilização, além de valorizar seu potencial terapêutico. Para garantir esses objetivos, a produção de fitoterápicos requer, necessariamente, estudos prévios relativos a aspectos botânicos, agronômicos, fitoquímicos, farmacológicos, toxicológicos, de desenvolvimento de metodologias analíticas e tecnológicas. ${ }^{2}$

Entre as inúmeras espécies vegetais de interesse medicinal, encontra-se a Vitex megapotamica (Sprengel) Moldenke, usualmente conhecida como tarumã, pertence à família Verbenaceae a qual compreende cerca de 100 gêneros distribuídos nas regiões tropicais de todo o mundo. ${ }^{3} \mathrm{~V}$. megapotamica distribui-se no nordeste da Argentina, no leste do Paraguai, no Uruguai e comumente encontrada no sul do Brasil. Na medicina popular, a infusão das folhas desta planta é utilizada no tratamento das hemorróidas, depurativa do sangue (hipocolesterolêmica), diuréticas, afecções cutâneas, expectorante, hipertensão arterial, antiinflamatória, dentre outras propriedades terapêuticas. ${ }^{4-7}$ Para a espécie em estudo foi relatado 0 isolamento de esteróides e iridóides. ${ }^{8,9} \mathrm{Em} \mathrm{2007,} \mathrm{foi} \mathrm{relatada} \mathrm{a} \mathrm{atividade} \mathrm{hipoglicemiante} \mathrm{das}$ folhas de $V$. megapotamica. ${ }^{10}$ e em 2009, foi demonstrado a ação do extrato bruto hidroalcóolico e decocção das cascas sobre efeito hipolipidêmico e redução dos níveis séricos de colesterol e triacilglicerol. ${ }^{11}$ Estes mesmos autores realizaram um estudo fitoquímico preliminar do extrato bruto das folhas de $V$. megapotamica que revela a presença de taninos, glicosídeos flavonônicos, polifenóis, alcalóides, óleos essências e saponinas. Sendo assim, devido à escassez de estudos que comprovem tais efeitos, este estudo teve como objetivo realizar uma análise farmacognóstica dos extratos de V. megapotamica em diferentes solventes. Além disso, complementar outros estudos através de uma pesquisa preliminar das substâncias presentes nos extratos a fim de verificar a possivel presença de grupos químicos oriundos do metabolismo secundário desta espécie.

\section{Materiais e métodos}

\section{Material botânico}

As folhas e os galhos de V. megapotamica foram coletados em dezembro de 2010, no município de Santa Maria, no estado do Rio Grande do Sul. O material testemunho está depositado no herbário do Departamento de Biologia da UFSM catalogado sob o número de registro SMBD 13.071.

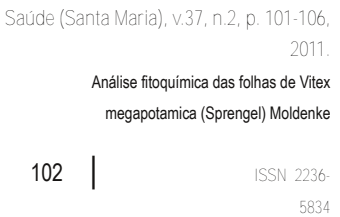




\section{Preparação dos extratos}

As folhas foram secas à temperatura ambiente e posteriormente trituradas em moinho de facas. A seguir, o material (1272,68 $\mathrm{g}$ de pó das folhas) foi submetido à maceração com etanol (70\%) a temperatura ambiente por sete dias com agitação diária. Uma parte do extrato etanólico foi reservada e a outra parte foi filtrada e evaporada para remoção do etanol obtendo-se 0 extrato aquoso remanescente.

\section{Análise fitoquímica}

O extrato aquoso e o extrato etanólico foram submetidos a uma série de reações de caracterização, para o extrato aquoso realizou-se as seguintes reações: heterosídeos antociânicos (cores diferentes pela variação do pH), heterosídeos cianogênicos (reação de ácido sulfúrico e papel picro-sódico), amino-grupos (nebulização com ninhidrina) e ácidos voláteis (variação do pH após fervura); para o extrato hidroalcóolico foram: fenóis e taninos (reação com cloreto férrico), antonianinas, antocianidinas e flavonoides (presença de coloração em pH 3, 8, 5 e 11), leucoantocianidinas, catequinas e flavonas (coloração da amostra alcalinizada e acidificada após aquecimento), flavonóis, flavanonas, flavanonóis e xantonas (reação com magnésio granulado com ácido clorídrico), esteroides e triterpenoides (extração com clorofórmio, anidrido acético e ácido sulfúrico), catequinas (reação com ácido clorídrico e aquecimento), resinas (formação de precipitado através da extração de resíduo sólido com etanol), heterosídeos cardioativos (teste de Kedde e Liebermann-Buchard), fenóis com posição orto e meta livres (reativo de Liebermann), fenóis com a posição para livre (reativo de Millon), cumarinas (extração com éter e câmara de luz ultravioleta), ácidos orgânicos (extração com éter e determinação do pH) e fenóis (reação de precipitação com cloreto férrico), segundo metodologias descritas em publicações especializadas. ${ }^{12,13}$

\section{Resultados e discussão}

A realização da prospecção fitoquímica das folhas de $V$. megapotamica (Tarumã) revelou resultados positivos para a presença de heterosídeos antociânicos, fenóis e taninos, catequinas, flavonóis, flavanonas, flavanonóis e xantonas, esteroides e triterpenoides (esteróides livres), heterosídeos cardioativos, fenóis com posição orto e meta livres, fenóis com a posição para livre, cumarinas, ácidos orgânicos e fenóis. Foram observados testes negativos para heterosídeos cianogênicos, amino-grupos, ácidos voláteis, antonianinas, antocianidinas e flavonoides, leucoantocianidinas e flavonas e resinas (Tabela 1). Os resultados negativos não implicam necessariamente na sua ausência, sendo possível que a quantidade dos mesmos esteja pequena para ser detectada. 
Tabela 1 - Prospecção fitoquímica das folhas de V. megapotamica em dois solventes (aquoso e etanólico); Forte: +++, Médio: ++, Fraco: +, Ausente: O, Não feito: -

\begin{tabular}{|c|c|c|}
\hline Testes & Aquoso & Hidroalcóolico \\
\hline Heterosídeos antociânicos & +++ & - \\
\hline Heterosídeos cianogênicos & 0 & - \\
\hline Amino-grupos & 0 & - \\
\hline Ácidos voláteis & 0 & - \\
\hline Fenóis e taninos & - & +++ \\
\hline $\begin{array}{c}\text { Antonianinas, antocianidinas e } \\
\text { flavonoides }\end{array}$ & - & 0 \\
\hline $\begin{array}{l}\text { Leucoantocianidinas, catequinas e } \\
\text { flavonas }\end{array}$ & - & $\begin{array}{c}\text { ++ para } \\
\text { catequinas }\end{array}$ \\
\hline $\begin{array}{l}\text { Flavonóis, flavanonas, flavanonóis e } \\
\text { xantonas }\end{array}$ & - & ++ \\
\hline Esteroides e triterpenóides & - & $\begin{array}{l}++ \text { esteróides } \\
\text { livres }\end{array}$ \\
\hline Catequinas & - & ++ \\
\hline Resinas & - & 0 \\
\hline Heterosídeos cardioativos & - & ++ \\
\hline Fenóis com posição orto e meta livres & - & ++ \\
\hline Fenóis com a posição para livre & - & +++ \\
\hline Cumarinas & - & +++ \\
\hline Ácidos orgânicos & - & ++ \\
\hline
\end{tabular}

Fenóis

$+++$

Saúde (Santa Maria), v.37, n.2, p. 101-106, Analise fitoquímica das folhas de Vitex megapotamica (Sprengel) Moldenke 104 ISSN 2236-

Os resultados indicam a presença de metabólitos secundários que podem estar relacionados à sua ação no tratamento de diversas patologias. Tendo em vista o resgate da biodiversidade brasileira e identificação das potencialidades das plantas e sua possivel ação medicinal, alguns metabólitos secundários são apontados neste estudo como ponto de partida para este enfoque. Conforme a relação dos metabólitos secundários com suas possíveis atividades biológicas descritas por Simões e colaboradores (2010), compostos fenólicos atuam na inibição da peroxidação lipídica e a lipoxigenase, a presença destes pode estar relacionados ao uso do tarumã como antiinflamatório e hipolipidêmico, taninos são 
empregados na medicina tradicional no tratamento de hipertensão arterial, reumatismo, feridas, antioxidante, anti-hemorrágico, cicatrizante, antiulcerogênico e anti-inflamatório em geral. Os heterosídeos cardioativos podem estar relacionados ao uso do tarumã como hipotensor citado na medicina popular. Triterpenos e esteroides atuam como antiinflamatórios e hormonais, as cumarinas como anticoagulante, relaxante vascular, hipolipidêmica e hipotensora. Leucoantocianidinas, flavonas, flavanonas, antocianos, flavonóis conferem propriedades anti-inflamatórias, antivirais, antimicrobiana, antioxidante entre outras. ${ }^{14} \mathrm{~A}$ presença de esteroides e compostos fenólicos encontrados justificam a ação hipolipidêmica já citada para esta espécie. ${ }^{11}$

\section{Conclusão}

A prospecção fitoquímica permitiu a detecção das principais classes de metabólitos secundários desta espécie, possibilitando correlacionar as suas possíveis atividades, com as descritas na literatura. Dessa forma, os farmacógenos encontrados neste estudo acenam para várias possibilidades terapêuticas o que servirá de apoio para direcionar os estudos a fim de se aprofundar ainda mais o conhecimento sobre essa espécie, uma vez que os dados sobre a planta ainda são escassos.

\section{Agradecimentos}

À Bióloga Profa. Dra ${ }^{a}$. Thais Scotti do Canto-Dorow, Departamento de Botânica da Universidade Federal de Santa Maria, por proporcionar a identificação de Vitex megapotamica (SPRENGEL) MOLDENKE.

\section{Referências bibliográficas}

1. Cechinel Filho V, Yunes RA. Estratégias para a obtenção de compostos farmacologicamente ativos a partir de plantas medicinais: conceitos sobre modificação estrutural para otimização da atividade. Quím. Nova 1998; 21(1): p. 99-105.

2. Miguel MD, Miguel GO. Desenvolvimento de fitoterápicos. São Paulo: Robe, 1999.

3. Joly AB. Introdução à taxonomia vegetal. 13ª ed. São Paulo: Companhia Editora Nacional, 2002; p. 579589 .

4. Longhi RA. Árvores e arvoretas do Sul. Porto Alegre: Ed. L\&PM, 1995; p. 151-152.

5. Alice CB, Mentz L, Siqueira NCS, Silva GAAB, Jose KF. Plantas medicinais de uso popular: atlas farmacognóstico. $1^{\text {a }}$ ed. Canoas: Ed. da Ulbra, 1995; p. 185-187.

6. Correa MP. Dicionário das plantas úteis do Brasil e das exóticas cultivadas. Rio de Janeiro: IBDF, 1984.

7. Franco IJ, Fontana VL. Ervas e plantas: a medicina dos simples. Erechim: Imprimax, 1997, p. 177.

Saúde (Santa Maria), v.37, n.2, p. 101-106, 2011.

8. Rimpler H. Pterosteron, polypodin B and neues ecdysonartiges steroids (viticosteron E) aus Vitex 
megapotamica. Tetrahedron Letters, 1969; 5 (10): p. 329-333.

9. Rimpler H. Phytoecdysones and iridoids from Vitex megapotamica. Archiv der Pharmazie 1972; 10 (305): p. 746-751.

10. Zanatta L, Sousa E, Cazarolli LH, Junior AC, Pizzolatti MG, Szpoganicz B, Silva FRMB. Effect of crude extract and fractions from Vitex megapotamica leaves on hyperglycemia in alloxan-diabetic rats. Journal of Ethnopharmacology, 2007, n. 109, p. 151-155.

11. Brandt AP, Oliveira LFS, Fernandes FB, Alba J. Avaliação in vivo do efeito hipocolesterolêmico e toxicológico preliminar do extrato bruto hidroalcoólico e decocção da Vitex megapotamica (Spreng) Moldenke (V. montevidensis Cham.). Rev. Bras. Farmacogn. 2009; 19(2A): p. 388-393.

12. Moreira EA. Contribuição para o estudo fitoquímico de Lobelia hassleri A. ZAHLB e Lobelia stellfeldii $R$. Braga. Companulaceae. Tribuna Farmacêutica 1979; 47 (1): 13-39.

13. Matos FJA. Introdução à fitoquímica experimental. $3^{\mathrm{a}}$ ed. Fortaleza: Editora da UFC; 2009.

14. Simões CMO, Schenkel EP, Gosmann G, Mello JCP, Mentz LA,Petrovick PR. Farmacognosia: da planta ao medicamento. $6^{\text {a }}$ ed. Porto Alegre/Florianópolis: Editora da UFRGS / Editora UFSC; 2010.

\section{Thiele Faccim de Brum}

Endereço para correspondência: Rua Silva Jardim, 1854, apto 82. - CEP: 97010-490, Santa Maria, RS, Brasil.

E-mail: thi_chaim@yahoo.com.br

Recebido em 30 de maio de 2011.

Aprovado em 13 de setembro de 2011.

Saúde (Santa Maria), v.37, n.2, p. 101-106, 